\title{
RELAÇÃO DO PESO ASSINTÓTICO E DA TAXA DE MATURAÇÃO COM IDADE E INTERVALO DOS QUATRO PRIMEIROS PARTOS DE VACAS GUZERÁ
}

\author{
ANTONIO FRANCISCO MARTIN ROLIM \\ Engenheiro Agrônomo
}

Orientador: Prof. Dr. Irineu Umberto Packer

\begin{abstract}
Dissertação apresentada à Escola Superior de Agricultura "Luiz de Queiroz", da Universidade de São Paulo, para obtenção do título de Mestre em Agronomia, Área de Concentração: Ciência Animal e Pastagens.
\end{abstract}

\section{PIRACICABA}

Estado de São Paulo - Brasil

Junho, 1995 
Dados Internacionais de Catalogação na Publicação (CIP)

DIVISÃO DE BIBLIOTECA E DOCUMENTAÇÃO - Campus "Luiz de Queiroz"/USP

Martin Rolim, Antonio Francisco

Relação do peso assintótico e da taxa de maturação com idade e intervalo dos quatro primeiros partos de vacas Guzerá. Piracicaba, 1995.

$64 p$. ilus.

Diss. (Mestre) - ESALQ

Bibliografia

1. Bovino misto - Crescimento - Modelo matemático 2. Bovino misto Manejo - Modelo matemático 3. Gado guzerá I. Escola Superior de Agricultura Luiz de Queiroz, Piracicaba 


\section{RELAÇ̃̃O DO PESO ASSINTÓTICO E DA TAXA DE MATURAÇÃO COM IDADE E INTERVALO DOS QUATRO PRIMEIROS PARTOS DE VACAS GUZERÁ}

\section{ANTONIO FRANCISCO MARTIN ROLIM}

Aprovada em 21.09.95

Comissão julgadora:

Prof. Dr. IRINEU UMBERTO PACKER (orientador)

ESALQ/USP

Prof. Dr. DÉCIO BARBIN

ESALQ/USP

Prof. Dr. JOSÉ EURICO POSSEBON CYRINO

ESALQ/USP

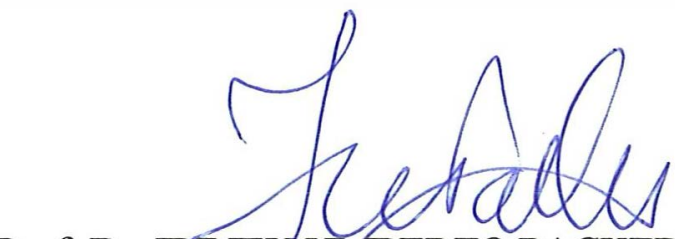

Prof. Dr. IRANEU UAMBERTO PACKER orientador 
Aos meus avôs Antonio Rolim Netto e Francisco Martin, de quem herdei o nome e tive exemplos de simplicidade, tranquilidade, força, e integridade;

e

ao meu querido irmão Luis Antonio, veterinário, com quem compartilhei as lições amor e respeito aos animais dadas pelo nosso avô, "Pai Tonico";

três presenças constantes, apesar da ausência fisica,

DEDICO.

Ao теи pai Juan Antonio, que me ensinou o valor do conhecimento e o prazer do raciocínio lógico;

$e$

às minhas queridas, Circe e Olímpia, mãe e esposa, pelo amor, carinho e dedicação constantes, 


\section{AGRADECIMENTOS}

Ao Prof. Dr. Irineu Umberto Packer, pela preciosa orientação, amizade e apoio concedidos durante toda a realização deste trabalho;

Ao professores do curso de pós-graduação, pelos ensinamentos transmitidos durante o programa de mestrado;

Ao Departamento de Zootecnia da ESALQ, na pessoa do Prof. Dr. Valdomiro Shigueru Miyada, pela oportunidade e apoio;

Aos membros da banca examinadora, pelas sugestões e ensinamentos;

Ao engenheiro agrônomo Antonio Ernesto de Salvo, pela cessão dos dados preciosamente coletados, pela presteza e confiança;

Ao pessoal da Bibioteca da ESALQ, pela competência, boa vontade e atenção constantes;

À CAPES - Coordenadoria de Aperfeiçoamento de Pessoal de Nível Superior, pela bolsa e ajuda financeira condedidas;

Aos dirigentes e colegas do CEETEPS - Centro Estadual de Educação Tecnológica "Paula Souza", pelo apoio;

Aos colegas do curso de pós-graduação, especialmente Monica Sutton e Soraya Abreu de Moraes, pela amizade, companhia e apoio;

Aos amigos e familiares que, de formas diversas, estimularam e contribuiram para a obtenção deste título;

O autor agradece imensamente. 
Relação do peso assintótico e da taxa de maturação com idade e intervalo dos quatro primeiros Partos de Vacas Guzerá

\author{
Autor : Antonio Francisco Martin Rolim \\ Orientador : $\quad$ Prof. Dr. Irineu Umberto Packer
}

\title{
RESUMO
}

O modelo de Brody foi utilizado para estimar o peso assintótico (PA) e a taxa de maturação (TM) de vacas Guzerá criadas em regime de pasto no Brasil Central. Foram realizadas estimativas independentes para os quatro primeiros partos, sendo que foram considerados somente as pesagens das vacas até o parto em questão $(377,373,315 \mathrm{e}$ 267 vacas respectivamente no $1^{\circ}, 2^{\circ}, 3^{\circ}$ e $4^{\circ}$ partos). Foram testados os efeitos ambientais sobre esses parâmetros, e os efeitos dos parâmetros e ambiente sobre a idade ao parto (ID) e o intervalo entre partos (IN).

A ID foi significativa fonte de variação para a TM nos 4 primeiros partos $(\mathrm{P}<0,001 ; \mathrm{P}<0,05 ; \mathrm{P}<0,001 ; \mathrm{P}<0,001)$. Seu efeito foi identificado também nas estimativas do PA no $1^{\circ}$ e $2^{\circ}$ partos $(\mathrm{P}<0,01 ; \mathrm{P}<0,001)$.

$\mathrm{O}$ ano de nascimento foi altamente significativo para $\mathbf{T M}$ nos quatro partos $(\mathrm{P}<0,001)$, sendo que as médias ajustadas, em todos os partos indicam o aumento das taxas com o avanço dos anos, nos períodos de 28, 27, 26 e 25 anos, respectivamente, do primeiro ao quarto parto. Para o PA o ano de nascimento foi causa significativa somente no $2^{\circ}$ parto $(\mathrm{P}<0,05)$, com tendência de estabilidade dos pesos corrigidos para ano com o avanço dos anos.

O efeito da estação do ano de nascimento não foi significativo para a TM em nenhum dos partos e para o PA apresentou significância somente no $1^{\circ}$ parto $(\mathrm{P}<0,05)$. A estação do ano de parto foi significativa $(\mathrm{P}<0,001)$ para PA e TM no $1^{\circ}$ e $2^{\circ}$ parto e 
para TM $(\mathrm{P}<0,001)$ também no $2^{\circ}$ parto, indicando que os efeitos sazonais próximos aos partos interferem nas estimativas da curva de crescimento, quando realizadas até o $2^{\circ}$ parto.

O ano de parto foi importante fonte de variação para a ID nos quatro partos $(\mathrm{P}<0,001)$, com tendência de redução da ID com o avanço dos anos. O IN não sofreu efeitos desta variável. Tampouco a estação do ano de nascimento teve qualquer influência significativa sobre as duas características reprodutivas.

Já a estação do ano do parto foi significativa somente para ID no $1^{\circ}$ parto e $1^{\circ}$ IN para as duas características $(\mathrm{P}<0,05$ e $\mathrm{p}<0,01)$ respectivamente, indicando que as maiores exigências das vacas primíparas são afetadas pelas disponibilidade de alimentos nos períodos próximos ao parto. $\mathrm{O} 3^{\circ} \mathbf{I N}$ também sofreu efeito da estação do ano do parto $(\mathrm{P}<0,05)$.

O touro foi importante fonte de variação para a ID $(\mathrm{P}<0,001 ; \mathrm{P}<0,001$; $\mathrm{P}<0,01 ; \mathrm{P}<0,01)$, para os quatro partos em sequência, e para o $1^{\circ} \mathbf{I N}(\mathrm{P}<0,01)$, indicando que os touros transmitem potenciais distintos para estas características, sugerindo a possibilidade de seleção genética.

O PA é significativa fonte de variação para ID no $3^{\circ}$ parto $(\mathrm{P}<0,001)$. Entretanto, os três últimos partos apresentaram coeficiente de regressão linear negativo para o PA sobre a ID, enquanto que no $1^{\circ}$ parto o coeficiente foi positivo, apesar de não significativo. Já o efeito do PA sobre o IN somente ficou evidenciado no $1^{\circ} \mathbf{I N}(\mathrm{P}<0,05)$, com coeficiente de regressão parcial negativo.

A TM é significativa $(\mathrm{P}<0,001)$ fonte de variação para a ID nos quatro partos, apresentando coeficiente de regressão parcial negativo (-312,565; -164,367; 243,296 e $-371,233$ ) do $1^{\circ}$ ao $4^{\circ}$ partos, o que indica que vacas que crescem com maior velocidade para o PA, apresentam partos mais precocemente. A TM foi significativa no $1^{\circ}(\mathrm{P}<0,05)$ e $3^{\circ}(\mathrm{P}<0,01) \mathbf{I N}$. 


\title{
Relations of assymptoptic weight and rate of maturing with
} age and interval of the four first calving of Guzera cows

\author{
Author: Antonio Francisco Martin Rolim \\ Advisor: Prof.Dr. Irineu Umberto Packer
}

\section{SUMMARY}

Brody's function was used to estimate the asymptotic weight (AW) and rate of maturing (RM) of Guzerá beef cows in Minas Gerais, Brazil. Four independ estimatives were done from the $1^{\text {st }}$ to the $4^{\text {th }}$ calving, considering only the weights of cow until the calving. Were analysed data from 337, 373, 315 and 267 cows respectively in the $1^{\text {st }}, 2^{\text {nd }}, 3^{\text {rd }}$ and $4^{\text {th }}$ calving. It was tested the environment effects on thouse parameters, and also the parameter's and environment's effects over age at calving (AC) and over the interval between calving $(\mathbf{C I})$.

The AC was significative for $\mathbf{R M}$ in all calving $(\mathrm{P}<0,001 ; \mathrm{P}<0,05$; $\mathbf{P}<0,001 ; \mathbf{P}<0,001)$ respectively. $\mathbf{A C}$ 's effect was identified also in the estimatives of $\mathbf{A W}$ in the $1^{\text {st }}$ and $2^{\text {nd }}$ calving $(\mathrm{P}<0,01 ; \mathrm{P}<0,001)$.

The year of birth was very significative to the $\mathbf{R M}$ in the four calving ( $P<0,001)$, least squares means in all calving show the $\mathbf{R M}$ increasing along the time, in 28, 27,26 and 25 years interval from the $1^{\text {st }}$ to $4^{\text {th }}$ calving. To $\mathbf{A W}$, the year of birth was significative only at the $2^{\text {nd }}$ calving $(\mathrm{P}<0,05)$, tending the adjusted weight, to be stabilized from year to year.

The effect of the season of birth was not significant to $\mathbf{R M}$ in all of the calvings and to $\mathbf{A W}$ it shows significance only in the $1^{\text {st }}$ calving $(\mathrm{P}<0,05)$. The season of calving was significant $(\mathrm{P}<0,001)$ to $\mathbf{A W}$ and $\mathbf{R M}$ in the $1^{\text {st }}$ and $2^{\text {nd }}$ calving and for $\mathbf{R M}$ also in the $2^{\text {nd }}$ calving $(P<0,001)$, showing that seasonal effects near calving influence $(\mathrm{P}<0,001)$ the growth curve when estimated until the $2^{\text {nd }}$ calving. 
The year of calving was important to $\mathbf{A C}$ for all groups $(\mathrm{P}<0,001)$ with a tendency to reduction. The $\mathbf{C I}$ does not suffer the effects of this factor. Not even the season of birth had any influence over this reprodutive characteristic.

However, the season of calving was significative only in the $1^{\text {st }} \mathbf{A C}$ and $1^{\text {st }}$ CI to both characteristics $(\mathrm{P}<0,05$ and $\mathrm{P}<0,01$, respectively), showing that in the first calving the cows were more susceptible. The $3^{\text {rd }} \mathbf{C I}$ also suffer the effects of the season of birth $(\mathrm{P}<0,05)$.

The bull was important factor to $\mathbf{A C}(\mathrm{P}<0,001 ; \mathrm{P}<0,001 ; \mathrm{P}<0,01 ; \mathrm{P}<0,01$ respectively) in all calves and for the $1^{\text {st }} \mathbf{C I}(\mathrm{P}<0,01)$, suggesting the possibility of genetic selection.

The $\mathbf{A W}$ is significative to $\mathbf{A C}$ in the $3^{\text {rd }}$ calving $(\mathrm{P}<0,001)$. However, the last three calving showed negative linear partial regression coefficient to $\mathbf{A W}$ over IP and in the $1^{\text {st }}$ calving it was positive but not significative. The coefficient of $\mathbf{A W}$ over $\mathbf{C I}$ was observed only in the $1^{\text {st }} \mathbf{C I}(\mathrm{P}<0,05)$, and it was negative.

The $\mathbf{R M}$ is significant $(\mathrm{P}<0,001)$ for $\mathbf{A C}$ in all calving, showing a negative linear partial regression coefficient $(-312,565 ;-164,367 ;-243,296$ and $-371,233)$ from $1^{\text {st }}$ to $4^{\text {th }}$ calving, what suggest that cows which grow up quicker do calving firstly. The RM was significant in the $1^{\text {st }}(\mathrm{P}<0,05)$ and $3^{\text {rd }}(\mathrm{P}<0,01)$ CI. 


\section{SUMÁRIO}

Ítem

Página

1. INTRODUÇÃO. 1

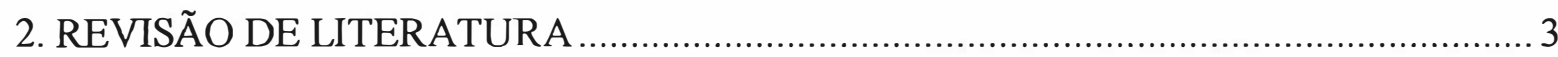

2.1. Uso de curvas de crescimento em bovinos .......................................................... 3

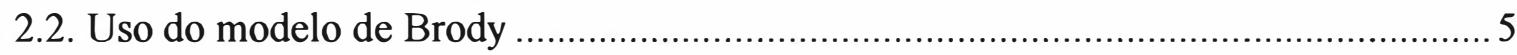

2.3. Pesos médios de fềmeas da raça Guzerá no Brasil ................................................ 9

2.4. Fatores que interferem no peso em diferentes idades de fêmeas da raça Guzerá

2.5. Médias de idade ao parto e intervalo entre partos de vacas da raça Guzerá no Brasil .....

2.6. Fatores que interferem na idade ao parto e no intervalo entre partos de animais criados a campo

2.7. Correlações entre pesos e reprodução de vacas........................................................ 17

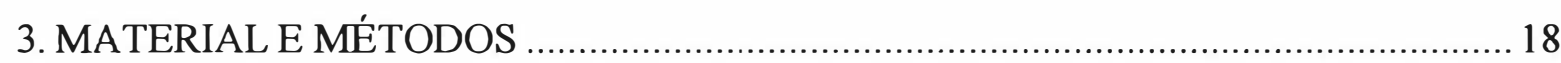

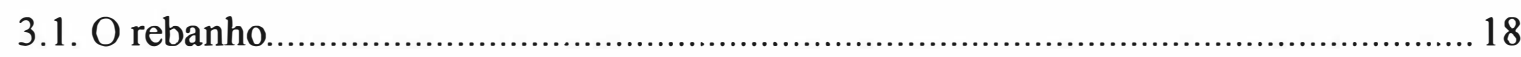

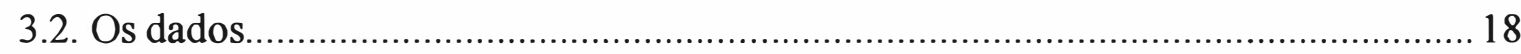

3.3. A metodologia para obtenção dos parâmetros da equação de Brody ......................... 19

3.4. Análise das estimativas dos parâmetros da equação de Brody ..................................22

3.5. Análise das variáveis idade ao parto e intervalo entre partos................................... 21

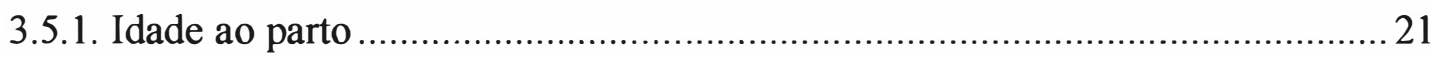

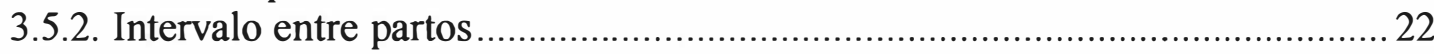

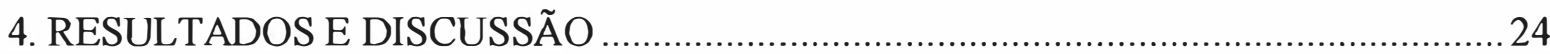

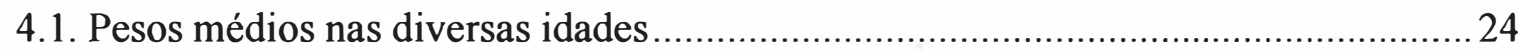

4.2. Estimativa dos parâmetros da equação de Brody .....................................................2 25 
4.3. Fatores que interferem no peso assintótico e na taxa de maturação. 30

4.3.1. Efeito da idade ao parto sobre o peso assintótico e taxa de maturação 31

4.3.2. Efeito do ano de nascimento sobre o peso assintótico e a taxa de maturação.

4.3.3. Efeitos das estações de nascimento e de parto sobre o peso assintótico e a taxa de maturação

4.3.4. Efeitos do touro sobre o peso assintótico e a taxa de maturação

4.4. Fatores que interferem na idade ao parto 37

4.4.1. Efeitos do ano de parto sobre a idade ao parto 38

4.4.2. Efeitos das estações do ano de nascimento e de parto sobre a idade ao parto... 39

4.4.3. Efeitos do touro sobre a idade ao parto. 40

4.4.4. Efeitos do intervalo entre partos sobre a idade ao parto 41

4.4.5. Efeitos do peso assintótico sobre a idade ao parto. 43

4.4.6. Efeitos da taxa de maturação sobre a idade ao parto. 44

4.5. Fatores que interferem no intervalo entre partos.

4.5.1. Efeitos do ano de parto e estações de nascimento e de parto sobre o intervalo entre parto.

4.5.2. Efeitos do touro sobre o intervalo entre partos

4.5.3. Efeitos da idade ao parto sobre o intervalo entre partos

4.5.4. Efeitos do peso assintótico sobre o intervalo entre partos 48

4.5.5. Efeitos da taxa de maturação sobre o intervalo entre partos

5. CONCLUSÕES.

REFERÊNCIAS BIBLIOGRÁFICAS. 


\section{QUADROS}

Página

QUADRO I:

QUADRO I:

QUADRO II:

QUADRO III:

QUADRO IV:

QUADRO V:

QUADRO VI:

\section{QUADRO VII:}

QUADRO VIII:

QUADRO IX:

QUADRO X:

QUADRO XI:

QUADRO XII:

QUADRO XIII:
Trabalhos com curvas de crescimento em gado de corte, conforme o tipo de equação utilizada

(continuação) Trabalhos com curvas de crescimento em gado de corte, conforme o tipo de equação utilizada

Estimativas dos parâmetros do modelo de Brody para fêmeas zebuínas ou suas cruzadas.

Estimativas das correlações fenotípica, genética e ambiental entre peso assintótico e taxa de maturação na equação de Brody.

Pesos médios (em kg) e desvios padrão (D.P.) no Brasil, de fêmeas Guzerá até 36 meses de idade

Pesos médios $(\mathrm{kg})$ no Brasil de fềmeas Guzerá após 36 meses de idade

Número de estimativas (NE), e médias \pm desvio padrão (média) para idade ao primeiro parto e intervalo entre partos de zebuínos e cruzamentos criados em condições tropicais.

Correlações fenotípicas e genéticas médias entre idade ao parto, intervalo entre partos e pesos em diversas idades

Informações sobre os arquivos de grupos de partos.

Número de pesos, pesos médios não ajustados e desvio padrão por idade, por parto

Média dos parâmetros das curvas individuais e curva global, por parto

Correlação fenotípica entre peso assintótico e a taxa de maturação, por parto.

Análises de variância do peso assintótico, por parto.

Análises de variância da taxa de maturação, por parto. 
QUADRO XIV: $\quad$ Coeficientes de regressão linear da idade ao parto sobre o peso assintótico e a taxa de maturação, por parto.

QUADRO XV: Pesos assintóticos e taxas de maturação médios ajustados aos anos de nascimento, por parto.

QUADRO XVI: Distribuição de touros conforme as médias ajustadas dos pesos assintóticos de suas filhas no $2^{\circ}, 3^{\circ}$ e $4^{\circ}$ partos.

QUADRO XVII: Distribuição de touros conforme as médias ajustadas das taxas de maturação de suas filhas no $2^{\circ}$ parto.

QUADRO XVIII: Análises de variância da idade ao parto, por parto. 38

QUADRO XIX: Idades ao parto médias, em meses, ajustadas para os anos de parto, por parto.

QUADRO XX: Média ajustada da idade ao primeiro parto, conforme a estação do ano de parto

QUADRO XXI: Distribuição de touros conforme as médias ajustadas das idades ao parto de suas filhas, no $1^{\circ}$ parto.

QUADRO XXII: Distribuição de touros conforme as médias ajustadas das idades ao parto de suas filhas, no $2^{\circ}$ parto.

QUADRO XXIII: Distribuição de touros conforme as médias ajustadas das idades ao parto de suas filhas, no $3^{\circ}$ parto.

QUADRO XXIV: Distribuição de touros conforme as médias ajustadas das idades ao parto de suas filhas, no $4^{\circ}$ parto.

QUADROXXV: Coeficientes de regressão linear entre o intervalo entre partos e a idade ao parto, por parto

QUADRO XXVI: Coeficientes de regressão linear entre a idade ao parto o peso assintóico, por parto.

QUADRO XXVII: Coeficientes de regressão linear da taxa de maturação e a idade ao parto, por parto.

QUADRO XXVIII: Análise de variância do intervalo entre partos em meses, por parto.

QUADRO XXIX: Médias ajustadas do intervalo entre partos, conforme a estação do ano, por parto 
QUADRO XXX: Distribuição de touros conforme as médias ajustadas dos intervalos entre partos de suas filhas, no $1^{\circ}$ intervalo (entre $\mathrm{o} 1^{\circ}$ e $2^{\circ}$ partos).

QUADRO XXXI: Coeficientes de regressão linear entre a idade ao parto e o intervalo entre partos, por parto.

QUADRO IA: $\quad$ Número de pesos, pesos médios e desvio padrão por grupo de parto.

QUADRO IA: (Continuação) Número de pesos, pesos médios e desvio padrão por grupo de parto.

QUADRO IA: (Continuação) Número de pesos, pesos médios e desvio padrão por grupo de parto.

QUADRO IIA: Análises de variância da idade do parto em meses sem intervalo entre partos como covariável no $2^{\circ}, 3^{\circ}$ e $4^{\circ}$ partos. 


\section{FIGURAS}

Página

FIGURA 1: Curvas das médias das estimativas dos parâmetros individuais, por parto. 26

FIGURA 2: Curvas globais, por parto. 26

FIGURA 3: Taxa de maturação em função do peso assintótico, por parto. 27

FIGURA 4: Pesos médios e curvas global e média no $1^{\circ}$ parto. 29

FIGURA 5: Pesos médios e curvas global e média no $2^{\circ}$ parto. 29

FIGURA 6: Pesos médios e curvas global e média no $3^{\circ}$ parto. 30

FIGURA 7: Pesos médios e curvas global e média no $4^{\circ}$ parto. 30

FIGURA 8: Pesos assintóticos médios ajustados ao ano de nascimento, por parto.

FIGURA 9: Taxas de maturação médias ajustadas ao ano de nascimento, por parto.

FIGURA 10: Idade ao parto em função do intervalo entre partos, por parto.

FIGURA 11: Idade ao parto em função do peso assintótico, por parto. 44

FIGURA 12: Idade ao parto em função da taxa de maturação, por parto. 45

FIGURA 13: Intervalo entre partos em função do peso assintótico, por parto. 48

FIGURA 14: Intervalos entre partos em função da taxa de maturação, por parto. 49 


\section{INTRODUÇÃO}

Contrariamente ao que acontece nos países tradicionalmente produtores de carne bovina, o Brasil fundamenta sua produção na criação extensiva de gado de sangue predominantemente zebuíno. Não só o rebanho de cria, como também o de engorda, são mantidos predominantemente a pasto. Uma pequena parte $(3,86 \%)$ dos 24.600 .000 abates estimados em 1994, provém de confinamento (ANUALPEC, 1995).

Entretanto, tecnologias como a engorda em confinamento, inseminação artificial, transplante de embriões, cruzamento industrial, rotação de pastagens, conservação de forragens, e outras, têm sido empregadas cada vez em maior escala. Da mesma forma, atenção crescente tem sido dada a técnicas de manejo que levem ao aumento da produtividade dos rebanhos.

O sucesso do processo produtivo depende também da eficiência com que o animal transforma o alimento ingerido em carne. $O$ entendimento do processo de crescimento bovino torna-se então fundamental. Desde o nascimento, o animal passa por várias transformações fisiológicas e morfológicas, que caracterizam o desenvolvimento até o alcance da maturidade física e reprodutiva, quando as transformações ainda acontecem, mas em escala reduzida.

O acompanhamento desse desenvolvimento tem sido feito mais usualmente através do controle das variações do peso, desde o nascimento até a fase adulta. Hoje, pode-se dizer que é grande o volume de informações a esse respeito, entretanto, o entendimento de todas as variáveis envolvidas torna-se extremamente complexo.

SANDLAND (1983) cita que, em 1935, Quetelet foi um dos primeiros a utilizar funções matemáticas para representar o crescimento de organismos. As curvas de crescimento obtidas da evolução dessas funções ganham importância pois sintetizam, em um pequeno número de parâmetros, as mudanças por que passa o organismo animal durante o seu desenvolvimento, simplificando assim o entendimento desse processo. Segundo BROWN et al. (1976), as curvas podem atender a propósitos descritivos, preditivos e mesmo comparativos. 
Nos últimos anos, a difusão da microinformática tem facilitado o acesso e aplicação de recursos antes restritos às grandes instituições, viabilizando com isso estudos e agilizando procedimentos antes praticamente impossíveis, como o uso de modelos matemáticos. No Brasil a aplicação dos modelos de crescimento em bovinos vem sendo estudada, inclusive relacionando os parâmetros das curvas, referentes à velocidade de crescimento e ao peso à maturidade, com características reprodutivas.

O presente estudo foi realizado objetivando analisar os fatores envolvidos nas relações entre o peso assintótico e a taxa de maturação estimados pelo modelo de Brody, com as características reprodutivas idade ao parto e o intervalo entre eles, em vacas Guzerá. Os quatro primeiros partos foram comparados através de análises independentes. 


\section{REVISÃO DE LITERATURA}

\subsection{Uso de curvas de crescimento em bovinos}

Segundo SANDLAND (1983), Quetelet foi um dos primeiros a utilizar funções matemáticas para representar o crescimento de organismos. Ao perceber que este assemelhava-se ao de crescimento de populações, Quetelet propôs, em 1835, a representação desse processo através de uma curva sigmóide.

Em 1945, Brody propôs uma função não linear para representar o crescimento, baseando-se em que este acontece com uma taxa crescente até determinado ponto, a partir do qual torna-se decrescente até aproximar-se de zero quando o organismo alcança seu tamanho máximo (BRODY, 1945).

$\mathrm{O}$ uso de curvas de crescimento para representar o crescimento de animais ganha importância quando seus parâmetros permitem interpretações biológicas. PEROTTO et al. (1992) considera que o uso de funções não lineares permite que as informações contidas em uma sequência de dados de peso/idade sejam sumarizadas num pequeno número de parâmetros passíveis de serem interpretados biologicamente.

Assim como a equação de Brody, as outras equações usualmente utilizadas em trabalhos com bovinos, fornecem alguns parâmetros comuns, que não raro recebem a mesma interpretação biológica.

A equação de Brody é dada por:

$$
\mathbf{P}_{\mathrm{t}}=\mathrm{A}\left(1-\mathrm{B} e^{-\mathrm{kt}}\right)
$$

Nela o parâmetro A, corresponde ao valor assintótico, também associado ao peso assintótico do animal, ou seja, seu peso máximo teórico, desconsiderando-se as variações decorrentes do ambiente a que está submetido. Usualmente é considerado como o peso à maturidade do animal. 
Para BROWN et al. (1972a) e FITZHUGH JUNIOR (1976), o parâmetro k mede a variação da função exponencial, representando a razão entre a taxa máxima de crescimento e o tamanho adulto. Quando utilizada em animais, corresponde à taxa de maturação, interpretada como a velocidade com que o animal se desenvolve para o seu peso máximo (o seu peso à maturidade). Os primeiros autores sugerem que comparações da taxa de maturação de animais devem ser feitas somente entre animais que se desenvolvem para um mesmo peso adulto.

Já o parâmetro $\mathbf{B}$, constante de integração, não tem significado biológico e está relacionado ao peso inicial do animal. (LUDWIG, 1977). Outros modelos frequentemente utilizados para estudar o crescimento de bovinos são apresentados por BROWN et al. (1976). São as equações de Von Bertalanffy, Gompertz, Richards, e o modelo Logístico. Elas tem sido empregadas também em estudos comparativos com zebuínos no Brasil (DUARTE, 1975; SLVEIRA JÚNIOR, 1976; LUDWIG, 1977).

BROWN et al. (1972b) observam que as curvas de crescimento podem ser usadas basicamente com três objetivos: estimar pesos, descrever o crescimento e comparar os padrões de crescimento de animais. PEROTTO et al. (1992) estudaram os modelos de crescimento com finalidades descritivas em bovinos leiteiros e observaram que nem sempre a média dos parâmetros de crescimento gera curvas não lineares, mas sim que o ajuste da curva às médias das estimativas de pesos do nascimento à maturidade, podem gerar equações melhores para previsões de ordem prática.

O potencial destes parâmetros como características herdáveis tem sido verificado por vários autores, e LUDWIG (1977) considera, a partir das estimativas de herdabilidade, que a forma da curva é mais influenciada pelo ambiente (baixa herdabilidade da taxa de maturação), enquanto que a sua dimensão depende mais da herança genética (média herdabilidade do peso assintótico).

A seleção de bovinos, em geral, baseia-se na busca de animais com capacidade de atingir maior peso em menor idade. A seleção nesse sentido produz fêmeas com maior tamanho adulto, o que aumenta os custos de manutenção dos rebanhos de cria, encarecendo todo o processo produtivo. Apoiados nestes fatos, alguns autores propõem, como solução para esse antagonismo, a alteração da forma da curva de crescimento dos bovinos, buscando o crescimento mais rápido até o alcance do peso de abate e maturidade 
sexual e um peso adulto menor das vacas (CARTWRIGHT, 1970; FITZHUGH JUNIOR \& TAYLOR, 1971).

\subsection{Uso do modelo de Brody}

No Brasil, DUARTE (1975), SLVEIRA JÚNIOR (1976) e LUDWIG (1977), comparando modelos de Brody, Gompertz, Logístico e Von Bertalanffy, o primeiro em dados de animais da raça Ibagé e os demais com a raça Nelore, apontaram o modelo de Brody como o que melhor se ajustou aos dados, considerando o coeficiente de determinação e a variância dos desvios. Para BROWN et al. (1976), o modelo de Brody também apresentou a menor variância dos resíduos, entretanto, o modelo de Richards, também estudado, apresentou alguma vantagem sobre os outros que tendiam a super e subestimar os pesos nas idades iniciais; mas para os autores, a natureza do estudo e a aplicação dos resultados devem ser levados em conta na escolha de modelos.

Estudando os modelos de Brody, Logístico, Richards, Von Bertalanffy, GOONEWARDENE et al. (1981) consideraram os modelos de Brody e Richards como os melhores para descrever o crescimento de gado Hereford e de uma raça sintética. $\mathrm{O}$ modelo de Brody, porém, não foi o melhor para prever os pesos futuros desses animais.

MORROW et al. (1978), estudaram o efeito da idade na estimativa dos parâmetros da curva de Brody, considerando o peso do mesmo grupo de vacas até determinada idade entre 2,5 anos e 8,5 anos, anualmente e estimaram os parâmetros para os sete grupos. Os autores encontraram efeito significativo da idade e também da fase reprodutiva sobre as características peso assintótico e taxa de maturação.

DeNISE \& BRINKS (1985), verificaram que o modelo de Brody se adaptava mais rapidamente aos dados e tinha por isso um custo menor, apesar de considerarem o modelo de Richards melhor quanto à variância dos desvios e à produção de estimativas não tendenciosas dos pesos. Também segundo esses autores, o modelo de Brody se ajusta melhor aos dados quando estes contêm pesos à maturidade e peso ao nascimento, não sendo adequada para estimar pesos em idades fora da amplitude de idades que geraram a curva. 
Também LOPEZ DE TORRE et al. (1992) e PEROTTO et al. (1992), estudando bovinos leiteiros, elegeram Brody entre os dois modelos mais adequados, sendo que PEROTTO et al. (1992) utilizaram o de Richards para estudos futuros (PEROTTO et al., 1994). O número de trabalhos publicados que utilizaram a equação de Brody com bovinos de corte é consideravelmente maior que os que trabalharam com outras equações, conforme apresentado no Quadro I.

QUADRO I: $\quad$ Trabalhos com curvas de crescimento em gado de corte, conforme o tipo de equação utilizada

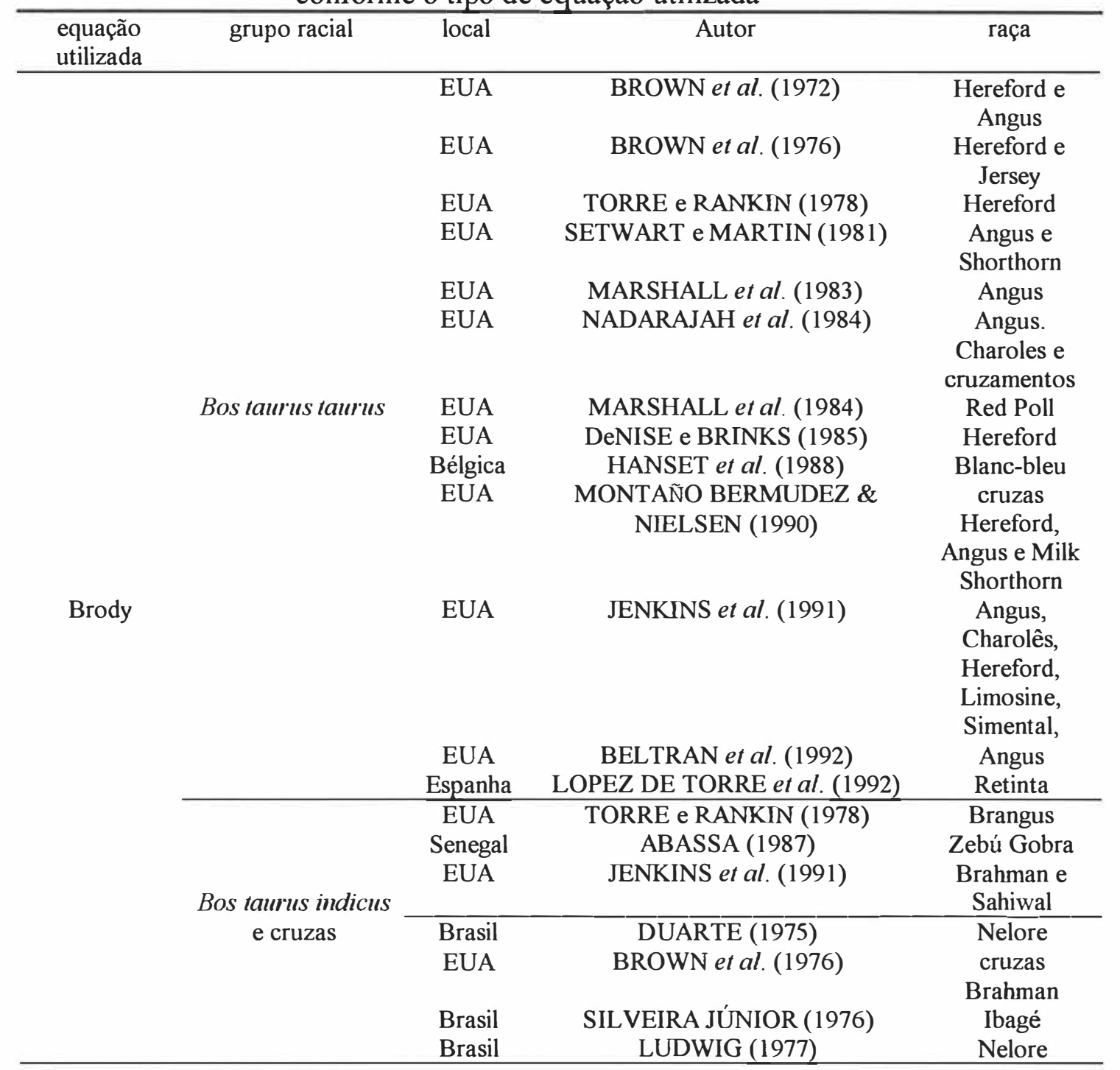


QUADRO I: (continuação) Trabalhos com curvas de crescimento em

\begin{tabular}{|c|c|c|c|c|}
\hline $\begin{array}{l}\text { equação } \\
\text { utilizada }\end{array}$ & grupo racial & local & Autor & raça \\
\hline \multirow{9}{*}{$\begin{array}{l}\text { Von } \\
\text { Bertallnffy }\end{array}$} & \multirow{4}{*}{ Bos taurus taurus } & EUA & BROWN et al. (1976) & $\begin{array}{l}\text { Hereford e } \\
\text { Jersey }\end{array}$ \\
\hline & & Canadá & GOONEWARDENE et al. (1981) & $\begin{array}{l}\text { Hereford e } \\
\text { Cruzadas }\end{array}$ \\
\hline & & Espanha & LOPEZ DE TORRE et al. (1992) & Retinta \\
\hline & & Brasil & CARRIJO (1988) & Chianina \\
\hline & \multirow{5}{*}{$\begin{array}{l}\text { Bos taurus indicus } \\
\text { e cruzas }\end{array}$} & Brasil & DUARTE (1975) & Nelore \\
\hline & & EUA & BROWN et al. (1976) & cruzas \\
\hline & & & & Brahman \\
\hline & & Brasil & LUDWIG (1977) & Nelore \\
\hline & & Brasil & CARRIJO (1988) & Nelore \\
\hline \multirow{4}{*}{ Richards } & \multirow{3}{*}{ Bos taurus taurus } & EUA & BROWN et al. (1976) & $\begin{array}{l}\text { Hereford e } \\
\text { Jersey }\end{array}$ \\
\hline & & Canadá & GOONEWARDENE et al. (1981) & $\begin{array}{l}\text { Hereford e } \\
\text { Cruzadas }\end{array}$ \\
\hline & & $\begin{array}{c}\text { EUA } \\
\text { Espanha }\end{array}$ & $\begin{array}{l}\text { DeNISE e BRINKS (1985) } \\
\text { LOPEZ DE TORRE } \text { et al. }(1992)\end{array}$ & $\begin{array}{c}\text { Hereford } \\
\text { Retinta }\end{array}$ \\
\hline & Bos taurus indicus & $\begin{array}{l}\text { Brasil } \\
\text { EUA }\end{array}$ & $\begin{array}{c}\text { DUARTE (1975) } \\
\text { BROWN et al. (1976) }\end{array}$ & $\begin{array}{c}\text { Nelore } \\
\text { cruzas } \\
\text { Brahman }\end{array}$ \\
\hline \multirow{4}{*}{ Logística } & Bos taurus taurus & EUA & BROWN et al. (1976) & $\begin{array}{l}\text { Hereford e } \\
\text { Jersey }\end{array}$ \\
\hline & & Brasil & DUARTE (1975) & Nelore \\
\hline & Bos taurus indicus & EUA & BROWN et al. (1976) & $\begin{array}{c}\text { cruzas } \\
\text { Brabman }\end{array}$ \\
\hline & e cruzas & $\begin{array}{l}\text { Brasil } \\
\text { Brasil }\end{array}$ & $\begin{array}{l}\text { SIL VEIRA JÚNIOR (1976) } \\
\text { LUDWIG (1977) }\end{array}$ & $\begin{array}{l}\text { Ibagé } \\
\text { Nelore }\end{array}$ \\
\hline \multirow{3}{*}{ Gompertz } & Bos taurus taurus & EUA & BROWN et al. (1976) & $\begin{array}{l}\text { Hereford e } \\
\text { Jersey }\end{array}$ \\
\hline & & EUA & BROWN et al. (1976) & cruzas \\
\hline & $\begin{array}{l}\text { Bos taurus indicus } \\
\text { e cruzas }\end{array}$ & $\begin{array}{l}\text { Brasil } \\
\text { Brasil }\end{array}$ & $\begin{array}{l}\text { SIL VEIRA JÚNIOR (1976) } \\
\text { LUDWIG (1977) }\end{array}$ & $\begin{array}{c}\text { Brahman } \\
\text { Ibagé } \\
\text { Nelore }\end{array}$ \\
\hline
\end{tabular}

O Quadro II apresenta os parâmetros obtidos com o modelo de Brody, por autores que trabalharam com fêmeas zebuínas ou seus cruzamentos.

É frequente entre os autores a observação de que os parâmetros são associados, o que determinaria a forma das curvas de crescimento, indicando que animais com maturação mais precoce apresentam menores pesos à maturidade ou, de outra forma, que animais que crescem para tamanhos menores crescem mais depressa. A alta correlação negativa encontrada entre o peso assintótico e a taxa de maturação é citada pela maioria 
dos autores (TAYLOR \& FITZHUGH, 1971; BROWN et al., 1972a; DUARTE, 1975; BROWN et al., 1976; LUDWIG, 1977; LOPEZ DE TORRE \& RANKIN, 1978; CARRIJO, 1988), assim como a superestimação do peso assintótico obtido pela equação de Brody (PEROTTO et al. 1992).

QUADRO II: $\quad$ Estimativas dos parâmetros do modelo de Brody para fêmeas zebuínas ou suas cruzadas.

\begin{tabular}{cccccc}
\hline autor & país & raça & A & parâmetros \\
& & & 688 & $\mathrm{k}$ \\
\hline DUARTE (1975) & Brasil & Nelore & 6,93 & 0,025 \\
BROWN et al. (1976) & EUA & cruzas & 543 & & 0,057 \\
& & Brahman & 542 & & 0,060 \\
& & & 499 & & 0,073 \\
SILVEIRA JÚNIOR (1976) & Brasil & Ibagé & 297 & 0,92 & 0,089 \\
LUDWIG (1977) & Brasil & Nelore & 424 & 0,92 & 0,058 \\
TORRE e RANKIN (1978) & EUA & Brangus & 432 & 1,05 & 0,071 \\
ABASSA (1987) & Senegal & Zebú Gobra & 399 & 1,01 & 0,169 \\
JENKINS et al. $(1991)$ & EUA & Brahman & 550 & & 0,061 \\
JENKINS et al. $(1991)$ & EUA & Sahiwal & 486 & & 0,062 \\
\hline
\end{tabular}

Outros autores, em função das altas correlações genéticas observadas entre essas características, consideraram possível alterar a forma da curva de crescimento com seleção (BROWN et al., 1972a; FITZHUGH JUNIOR 1976; SMITH \& CANDIFF, 1976).

O Quadro III, a seguir, resume as correlações entre o peso assintótico e a taxa de maturação encontrados por vários autores, para gado de corte.

QUADRO III: $\quad$ Estimativas das correlações fenotípica, genética e ambiental entre peso assintótico e taxa de maturação na equação de Brody.

\begin{tabular}{|c|c|c|c|c|}
\hline \multirow[t]{2}{*}{ autor } & \multirow[t]{2}{*}{ raça } & \multicolumn{3}{|c|}{ correlações } \\
\hline & & fenotípica & genética & ambiental \\
\hline BROWN et al. (1972a) & Hereford & $-0,72$ & $-0,95$ & \\
\hline BROWN et al. (1972b) & Angus & $-0,62$ & $-0,29$ & \\
\hline DUARTE (1975) & Nelore & $-0,60$ & $-1,00$ & $-0,59$ \\
\hline BROWN et al. (1976) & Jersey & $-0,72$ & & \\
\hline LUDWIG (1977) & Nelore & $-0,65$ & & $-0,65$ \\
\hline MORROW et al. (1978) & Angus & $-0,41$ & & \\
\hline MASHALL et al. (1984) & Red Poll & $-0,69$ & & \\
\hline DeNISE \& BRINKS (1985) & Brahman & $-0,71$ & $-1,16$ & $-0,54$ \\
\hline JENKINS et al. (1991) & várias & $-0,52$ & $-0,73$ & $-0,62$ \\
\hline CARRIJO (1988) & Nelore & $-0,70$ & $-0,73$ & $-0,70$ \\
\hline
\end{tabular}




\subsection{Pesos médios de fêmeas da raça Guzerá no Brasil}

Medir as mudanças de peso do animal nas diferentes idades foi a forma primariamente utilizada para acompanhar o seu desenvolvimento. Neste sentido, os processos de seleção de animais fundamentaram-se na busca de animais com maiores pesos nas diversas idades, ou seja, com desenvolvimento mais rápido. As observações geralmente consistem de pesos tomados ao nascimento, à desmama, geralmente padronizado para 205 dias, além dos pesos aos $6,12,18,24$ e 30 meses.

Vários trabalhos publicados relatam correlações positivas entre estes pesos. Por consequência, a seleção para o aumento em qualquer deles está relacionada ao aumento dos demais (PACKER, 1977; CARRIJO, 1988; RAZOOK et al., 1988; RAZOOK et al., 1993). No Brasil, RAZOOK (1988) e RAZOOK et al. (1993) observaram também que esta seleção para peso na fase de crescimento resultou no aumento do peso adulto (550 dias).

Os pesos médios encontrados nas diversas idades de animais da raça Guzerá em estudos no Brasil são apresentados nos Quadros IV e V. Os desvios padrão são tabulados também, quando fornecidos.

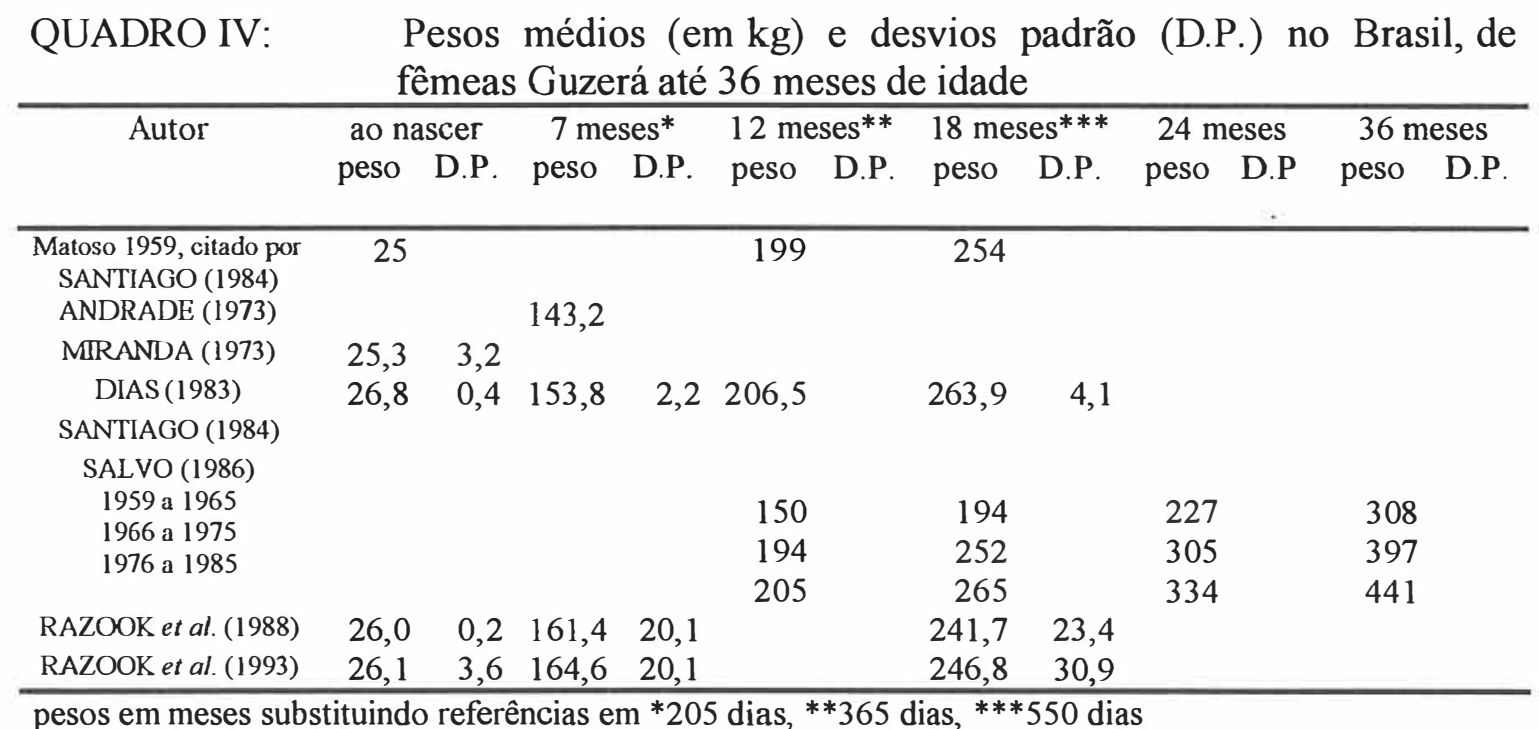


QUADRO V: $\quad$ Pesos médios $(\mathrm{kg})$ no Brasil de fêmeas Guzerá após 36 meses de idade

\begin{tabular}{|c|c|c|c|c|c|c|c|c|c|c|c|}
\hline \multirow[t]{2}{*}{ autor } & \multicolumn{11}{|c|}{ idade da vaca em anos } \\
\hline & 4 & 5 & 6 & 7 & 8 & 9 & 10 & 11 & 12 & 13 & médias \\
\hline $\begin{array}{c}\text { PACKER et al. (1979) } \\
\text { SALVO (1986) }\end{array}$ & & & & & & & & & & & 472 \\
\hline 1965 & & & & & & & & & & 498 & $455,29 *$ \\
\hline $\begin{array}{c}1976 / 80 \\
\text { BARBOSA (1991)+ }\end{array}$ & 437 & 465 & 473 & 481 & 480 & 489 & 492 & 502 & 509 & & $479,43 * *$ \\
\hline
\end{tabular}

O Quadro IV traz Matoso $1959^{\prime}$ citado por SANTIAGO (1984), por ser o último trabalho com dados do rebanho histórico de Uberaba. RAZOOK et al. (1988) e RAZOOK et al. (1993) estudaram rebanho da Estação Experimental de Sertãozinho, SP, integrados ao projeto de seleção da unidade. ANDRADE (1973) estudou 294 animais do mesmo rebanho do presente trabalho, entre os anos de 1966 a 1970, como MIRANDA (1973) com 380 fềmeas entre 1966 e 1970 e DIAS (1983) com fềmeas Guzerá nascidas entre 1971 e 1979. SALVO (1986) informa médias de pesagens e animais do rebanho em diversos períodos.

\subsection{Fatores que interferem no peso em diferentes idades de fêmeas da raça} Guzerá

DIAS (1983) e CARRIJO (1988), entre outros, encontraram efeito significativo do touro pai sobre os pesos ao nascimento, 205, 365 e 550 dias para zebuínos.

$\mathrm{O}$ ano de nascimento é frequentemente citado como uma das causas ambientais consideradas nas análises dos fatores que interferem no peso dos bovinos nas diversas idades. Em gado criado a pasto, seu efeito acontece principalmente devido às variações na disponibilidade de forragens durante o ano, decorrente, principalmente, das variações anuais de intensidade e distribuição da temperatura ambiental e das chuvas. Mudanças de manejo também podem estar representadas no efeito do ano de nascimento. Nesse sentido, BRINKS et al (1962) e BROWN et al. (1972a) já apontavam o ano de nascimento como indicador do conjunto de situações às quais o animal é submetido

\footnotetext{
${ }^{1}$ Matoso 1959 não tem referência bibliográgica em SANTIAGO (1984)
} 
durante a sua vida. A amplitude do efeito ambiental varia com o momento de desenvolvimento do animal quando os recebe. Animais nascidos em um mesmo ano, em um mesmo rebanho, durante o seu crescimento são influenciados pelo ambiente em diferentes intensidades e frequências, de forma própria e peculiar a cada ano, estabelecendo-se, por isso, diversas interações do animal com o meio. Esse efeito foi observado por RAZOOK et al. (1988) que encontrou comportamentos diferentes nos anos, dos grupos de animais participantes do projeto de seleção em estudo e também interações do ano com algumas das características estudadas.

No Brasil, autores que estudaram pesos de zebuínos e ou cruzamentos como OLIVEIRA FLHO (1977), PACKER (1977), BARBOSA et al. (1979), BARBOSA et al. (1980), CARRIJO (1988) e RAZOOK (1988), fizeram também as considerações anteriores. RAZOOK (1988) e PENNA (1990) consideram ainda a possibilidade de que as mudanças genéticas decorrentes até da endogamia da população, possam contribuir para o efeito do ano de nascimento.

Já ROSA (1977), MIRANDA et al. (1979), ALVES NETO et al. (1980), SILVA et al. (1982), também no Brasil e com zebuínos e cruzamentos, não encontraram efeito do ano de nascimento significativo para os pesos em diversas idades de crescimento. Com a raça Guzerá, MATTOSO (1961) não encontrou significância no efeito do ano de nascimento para os pesos durante o crescimento.

Quanto à maturidade, é importante definir o tamanho ou peso da vaca na idade adulta. LONG et al. (1975) e CARPENTER JUNIOR et al. (1978) consideram que o peso da vaca pode ser utilizado como indicação do tamanho à maturidade. Para BULLOCK et al. (1993), a média de todos os pesos obtidos depois que o animal parou de crescer fornece uma boa estimativa do peso à maturidade, mas lembra as dificuldades em se determinar o momento em que o animal pára de crescer, enquanto BROWN et al.(1972a) lembram o fato de ser impossível obter o peso à maturidade em animais que não terminaram seu desenvolvimento.

Segundo BROWN et al. (1972a) as curvas de crescimento devem ser estimadas com pesos de animais até 60 meses. BRINKS et al. (1962) observaram que o peso de vacas Hereford aumentou até os 8 anos, diminuindo um pouco posteriormente e MORROW et al. (1978), considerando também a idade e a parição, verificaram 
estabilização do peso entre 3,5 e 4,5 anos para vacas Angus. NADARAJAH et al. (1984, 1985) não observaram variação do peso adulto com a idade em vacas de origem européia e cruzadas, contrariamente ao que foi verificado por GREGORY et al. (1985), com vacas Zebu e das raças Boran e Ankole, que aumentaram o peso até os 6 anos de idade.

No Brasil, com Canchim, BARBOSA $(1986 a, b)$ observou que as vacas com mais de 6 anos eram mais pesadas que aquelas com idades menores, estabilizando-se os pesos após essa idade. SALVO (1986), em seu relatório sobre o desenvolvimento do rebanho observado neste estudo, indica aumento do peso adulto das vacas dos 4 aos 12 anos indo de $437 \mathrm{~kg}$ a $509 \mathrm{~kg}$, para animais do período de 1976 a 1980 (Quadro V). Considerando a ordem do parto, CROAK BROSSMAN et al. (1984), observaram estabilização do peso de vacas de raças européia puras e cruzadas entre a sexta e a nona parição.

O peso à maturidade também pode ser estimado por diversas funções de crescimento, através do parâmetro A, representativo do peso assintótico. Esta característica é ainda influenciada pelo ano de nascimento, conforme os trabalhos de SMITH et al. (1976), MacNEIL et al. (1984), QUAAS (1985), DeNISE \& BRINKS (1985) e no Brasil DUARTE (1975) com animais da raça Nelore. ROSA et al. (1979), estimaram o peso à maturidade com a curva de Brody, a partir de pesagens bimestrais até os 24 meses de idade, e também observaram efeito significativo do ano de nascimento sobre esta característica.

No caso de vacas de cria, a gestação e sua fase, o aleitamento, o momento do ano e frequência destes eventos, bem como o regime alimentar e o manejo podem ser citados como alguns dos fatores que provocam a variação do peso da vaca. Dentro dos anos, as estações climáticas oferecem condições distintas para o desenvolvimento de forragens, seja pela disponibilidade de água, seja pela temperatura ambiente, Assim, principalmente para animais criados a campo, o efeito da estação do ano tem sido relacionado como importante fator de variação do peso em diversas idades. Da mesma forma que o efeito de ano de nascimento, as interações que acontecem entre a disponibilidade de alimento e a fase de desenvolvimento do animal tornam-se permanentes, afetando todo o desenvolvimento do animal.

No Brasil, o efeito da estação de nascimento foi significativo para o peso ao parto de vacas Canchim, conforme verificado por BARBOSA (1986a,b). Vários autores 
apontam a idade da mãe ao parto como fator que interfere no peso adulto das filhas. ROSA et al. (1979) não observaram esse efeito nos animais que estudaram da raça Nelore. McNEIL et al. (1984), com raças européias e cruzamentos e QUASS (1985), com Hereford, observaram significância deste efeito. Já a idade da vaca ao parto não afetou o peso assintótico estimado pela equação de Brody nos estudos de DeNISE \& BRINKs (1985), enquanto QUASS (1985) verificou que filhas de vacas primíparas foram mais leves na maturidade.

McCURLEY et al. (1984) e LISBOA \& FERNANDES (1987), observaram que vacas com desempenho reprodutivo insatisfatório são mais pesadas à maturidade, do que aquelas com desempenho satisfatório.

2.5. Médias de idade ao parto e intervalo entre partos de vacas da raça Guzerá no Brasil

O Quadro VI apresenta valores médios de trabalhos publicados, para idade ao primeiro parto e intervalo entre partos de raças zebuínas e seus cruzamentos.

QUADRO VI: $\quad$ Número de estimativas (NE), e médias \pm desvio padrão (média) para idade ao primeiro parto e intervalo entre partos de zebuínos e cruzamentos criados em condições tropicais

\begin{tabular}{ccccc}
\hline raça / grupo genético & \multicolumn{2}{c}{ idade ao parto em meses } & \multicolumn{2}{c}{ intervalo entre partos em meses } \\
\cline { 2 - 5 } & NE & média & NE & média \\
\hline Brahman & 11 & $48,60 \pm 0,37$ & 6 & $15,23 \pm 0,70$ \\
Gir & 11 & $44,37 \pm 1,03$ & 11 & $17,30 \pm 0,77$ \\
Guzerá & 13 & $48,70 \pm 2,13$ & 8 & $17,50 \pm 0,57$ \\
Hariana & 6 & $44,97 \pm 1,10$ & 4 & $15,93 \pm 0,50$ \\
Indubrasil & 18 & $44,87 \pm 0,83$ & 15 & $15,67 \pm 1,03$ \\
Nelore & 10 & $41,40 \pm 223$ & 3 & $14,90 \pm 0,43$ \\
Sahiwal & 1 & $42,67 \pm 5,60$ & 1 & $14,80 \pm 3,93$ \\
Tabapuã & 9 & $43,83 \pm 2,73$ & 5 & $15,00 \pm 1,10$ \\
Tharparkar & 18 & $43,53 \pm 2,13$ & 13 & $17,87 \pm 0,80$ \\
Zebu de Corte & 62 & $33,57 \pm 0,57$ & 17 & $14,50 \pm 0,70$ \\
Zebu Leiteiro & \multicolumn{3}{c}{}
\end{tabular}

Fonte: Extraido e adaptado de BARBOSA (1991) 
Segundo BARBOSA (1991) "as raças zebuínas, mais numerosas e abundantes em regiões tropicais, geralmente apresentam a ocorrência do primeiro parto aos 40 meses de idade". BALIEIRO (1976) encontrou 35,1 $\pm 0,28$ meses como idade ao primeiro parto de 637 novilhas do rebanho Guzerá, observando que, de 1953 a 1972, houve uma redução de 39,8 para 28,5 meses. SALVO (1986) relata, para o mesmo rebanho, no período de 1966 a 1972, de 38,55 meses para 265 vacas e, de 1973 a 1982, 36,97 meses média da idade ao primeiro parto, de 200 vacas.

SANTIAGO (1984) publica média de 46,7 meses como resultado de revisão de trabalhos de diversos autores, entre 1973 e 1975, para a idade ao primeiro parto para a raça Guzerá. CARNEIRO et al. (1958), em 129 vacas Guzerá, encontraram 18,0 meses para o intervalo entre partos.

Para o intervalo entre partos CARNEIRO et al. (1958) encontrou 18,5 \pm 0,6 meses como média de 128 animais. PIRES et al. (1967) 16,9 $\pm 0,2$ meses para 302 vacas Guzerá de aptidão leiteira. SILVA (1971) 18,0 $\pm 0,24$ e 16,2 $\pm 0,24$ respectivamente para 337 e 329 vacas. BALIEIRO (1976) estudando vacas do mesmo rebanho, que produziram os dados utilizados no presente trabalho, encontrou 516,0 $\pm 130,6$ dias de intervalo entre partos, para vacas entre os anos de 1953 a 1972. SALVO (1986) relata, para o período de 1976 a 1985, a média de 15,08 meses para o intervalo entre partos das vacas existentes no rebanho.

\subsection{Fatores que interferem na idade ao parto e no intervalo entre partos de} animais criados a campo

Segundo BARBOSA (1991), a idade ao parto tem sido apontada como fator influente sobre o peso ao desmame das crias, não aparecendo significância desse efeito nos estudos de pesos após essa fase. No Brasil RAZOOK et al. (1988), que trabalharam com grupos de seleção da raça Nelore e também um lote de Guzerá, encontraram efeito significativo da idade da mãe para pesos até um ano mas não significativo para o peso aos 550 dias.

Vários autores, como CARTWRIGHT (1970), DICKERSON (1978), citam a dificuldade inerente aos sistemas de produção de bovinos de corte, onde, se por um lado 
são buscadas altas taxas de crescimento que permitam o alcance mais rápido do peso de abate e reprodução, por outro este processo produz fêmeas maiores na idade adulta, acarretando maiores custos de manutenção do rebanho de cria (SMITH \& CUNDIFF, 1976). Além disto ocorrem problemas oriundos do antagonismo genético existente entre a alta velocidade de crescimento e características de reprodução em bovinos. Estes problemas são ainda agravados pela baixa taxa de reprodução dos bovinos, o que faz com que os custos iniciais de produção das fêmeas importem muito no custo final dos animais comercializados.

Existem trabalhos que indicam relação positiva entre o tamanho à maturidade e dificuldade de parto (MONTEIRO, 1969), maior idade ao parto (CARPENTER JUNIOR et al., 1971; FISS \& WILTON, 1989), maiores intervalos entre partos (CARPENTER JUNIOR et al., 1973; FISS \& WILTON, 1992) e menor taxa de fecundação ( LIMA, 1990).

O ano de nascimento (ALENCAR et al., 1982) e o ano do primeiro parto tem sido apontados no Brasil, como fonte de variação também para a idade do primeiro parto, conforme os estudos de LÔBO (1976), VALENTE (1978), OLIVEIRA FILHO et al. (1979), PEREIRA et al. (1979), e ALENCAR \& BARBOSA (1981), SILVA \& PEREIRA (1986), POLASTRE et al. (1987a) e LÔBO et al. (1988), com cruzamentos de zebuínos com raças européias; RAMOS (1979) com Gir; AROEIRA \& ROSA (1982), MIRANDA et al. (1982a) com Nelore, e PENNA (1990) com Tabapuã. Outros autores, entretanto, concluiram diferentemente, como BEOLCH \& CUNHA (1977), ALENCAR et al. (1982), SILVA e PEREIRA (1986) com cruzamentos de zebuínos com raças européias e CAMPOS (1974) e OLIVEIRA FILHO et al. (1975a), com Nelore.

Para o intervalo entre partos, o efeito do ano de parto foi estudado no Brasil por LÔBO (1976), OLIVEIRA FILHO et al. (1979), PEREIRA et al. (1980), ALENCAR et al. (1984), e POLASTRE et al. (1987b), em cruzamentos de zebuínos com raças européias, AROEIRA \& ROSA (1982), MIRANDA et al. (1982b), SILVA e PEREIRA (1986) com Nelore e PENNA (1990) com Tabapuã. Já CAMPOS (1974) e OLIVEIRA FILHO et al. (1975b) encontraram significância do ano do parto para o intervalo entre partos de vacas Nelore. Com Guzerá, SILVA (1971), cita a ordem de parto como fonte de variação para o intervalo entre partos. BALIEIRO (1976) considerou 
significativo o efeito da ordem do parto para o intervalo entre partos, verificando redução do intervalo na medida em que aumenta a ordem do parto, até o nono parto em Guzerá.

No que diz respeito às estações de nascimento e parto, vários autores estudaram sua influência sobre a idade do primeiro parto e o intervalo entre partos. Esses efeitos são estudados considerando o mês, estação ou época, conforme critérios estabelecidos pelos autores. BALIEIRO (1976) encontrou efeito significativo da estação sobre a idade ao primeiro parto, contrário ao observado por SILVA (1971), ambos para Guzerá. Com outras raças zebuínas e cruzamentos, a grande maioria dos estudos realizados no Brasil evidenciou que as estações de nascimento e parto influenciaram o intervalo entre partos sendo que a lactação na seca e a ausência de suplementação tendem a produzir intervalos entre partos maiores que aquelas que ocorrem na época das chuvas ou quando as vacas são suplementadas, em raças zebuínas. (CAMPOS, 1974; OLIVEIRA FILHO et al., 1975b; BALIEIRO, 1976; VIANA \& FERREIRA, 1982; AROEIRA \& ROSA, 1982; MIRANDA et al., 1982b; SILVA e PEREIRA, 1986; PENNA, 1990).

OLIVEIRA FILHO (1977) e ALENCAR et al. (1984), consideram também que intervalos mais longos estão relacionados à menor disponibilidade de forragens, tendo os primeiros observado que vacas paridas na época da chuva apresentaram intervalos mais curtos. BALIEIRO (1976), encontrou significância para os efeitos de ano e mês de nascimento além de outros efeitos classificáveis como climáticos e de manejo alimentar.

A influência do ano e estação de nascimento e cobertura sobre o segundo parto foi estudada fora do Brasil por BOURBON \& BRINKS (1983), AZZAM \& NIELSEN (1987) e SMITH et al. (1989), entre outros, com animais de raças européias puras e cruzadas, tendo estes autores encontrado efeito significativo desses fatores para a idade ao segundo parto. Outros autores, como BUDDENBERG et al. (1989), encontraram significância do ano de nascimento somente em uma das três raças inglesas estudadas.

Os trabalhos publicados sobre zebuínos no Brasil indicam que os intervalos entre partos variam nos diferentes partos, sendo que o intervalo entre o primeiro e segundo partos foi mais longo que os demais, que em geral diminuiram gradativamente nos partos seguintes. OLIVEIRA FILHO (1977) verificou que a ordem de parto foi o fator mais importante sobre o intervalo entre partos. Com a raça guzerá isso foi observado por PIRES et al. (1967) e SILVA (1971). 


\subsection{Correlações entre pesos e reprodução de vacas}

McCURLEY et al. (1984) encontraram uma diminuição linear significativa do número de bezerros produzidos com o aumento do peso à maturidade de vacas Angus, nos EUA. FISS \& WILTON (1989) analisando dados de raças européias e cruzas, classificadas quanto ao tamanho em três grupos, não observaram efeito do peso à maturidade sobre o desempenho reprodutivo; entretanto os animais foram criados em regime de confinamento. Os mesmos autores (FISS \& WILTON 1992), trabalhando com dados de vários grupos genéticos onde diversas raças européias foram cruzadas para compor animais de diversos tamanhos, verificaram que o aumento do peso da vaca foi associado à diminuição da sua fertilidade.

No Brasil, vacas pequenas vazias na segunda estação de monta foram mais férteis que as grandes, também vazias, isto em animais cruzados Charolês, sendo próxima de $65 \mathrm{~kg}$ a diferença entre os grupos. (LISBOA \& FERNANDES, 1987).

Já DEARBORN et al. (1987) consideram que as decisões para a seleção do tamanho ideal da vaca dependem dos sistemas de produção utilizados e dos recursos genéticos e ambientais disponíveis.

O Quadro VII apresenta um resumo das correlações entre peso em diversas idades com idade ao parto e intervalo entre partos. BARBOSA (1991) sugere que possivelmente os genes que favorecem o crescimento influenciam desfavoravelmente a idade ao parto e estejam associados a maiores intervalos entre partos.

QUADRO VII: Correlações fenotípicas e genéticas médias entre idade ao parto, intervalo entre partos e pesos em diversas idades

\begin{tabular}{ccccc}
\hline $\begin{array}{c}\text { característica } \\
\text { reprodutiva }\end{array}$ & peso na idade & $\begin{array}{c}\text { número de } \\
\text { observações }\end{array}$ & $\begin{array}{c}\text { correlação } \\
\text { fenotípica }\end{array}$ & $\begin{array}{c}\text { correlação } \\
\text { genéitca }\end{array}$ \\
\hline \multirow{4}{*}{ idade ao parto } & nascer & 7 & $-0,03$ & 0,20 \\
& desmama & 5 & $-0,02$ & 0,09 \\
& 12 meses & 4 & 0,00 & 0,12 \\
& 18 meses & 1 & $-0,11$ & 0,21 \\
& 24 meses & 1 & $-0,13$ & 0,12 \\
\hline \multirow{4}{*}{ intervalo entre partos } & nascer & 1 & 0,01 & 0,77 \\
& desmama & 1 & 0,06 & 0,81 \\
& 12 meses & $1^{*}$ & 0,07 & 0,60 \\
& 18 meses & 1 & 0,03 & 0,37 \\
\hline
\end{tabular}

Adaptado de BARBOSA (1991) 


\section{MATERIAL E MÉTODOS}

As análises constantes do presente trabalho foram desenvolvidas a partir de dados de animais puros da raça Guzerá, criados na Fazenda Canoas, em Curvelo, Minas Gerais.

Curvelo situa-se em zona característica de cerrado, apresentando basicamente duas estações, seca (abril a setembro) e das chuvas (outubro a março), com clima caracterizado como tropical úmido, subtipo AW, segundo a escala Koppen.

\subsection{O rebanho}

SALVO (1986) descreve detalhes da seleção, performance e o manejo desenvolvido na fazenda no período de 1956 a 1985, na qualidade de proprietário do rebanho. Os animais são mantidos em regime de pasto dos capins jaraguá (Hiparrhenia rufa, Stapf) e gordura (Melinis minutiflora, Pal. de Beav.), existindo ainda áreas de pastos de pouco valor nutritivo e alguma suplementação forrageira com milho e mandioca. Vacas em lactação e novilhas recebem concentrados como suplementação, na seca.

As vacas são cobertas em monta natural, tendo havido diferentes estações de monta no período de coleta dos dados considerados neste estudo. Foram realizadas pesagens a cada 2 meses, em fevereiro, abril, junho, agosto, outubro e dezembro, desde o nascimento até 36 meses de idade. A partir dessa idade as pesagens aconteceram a cada 4 meses, em fevereiro, junho e outubro. (SALVO, 1986)

\subsection{Os dados}

A partir das fichas de controle dos animais, foram coletadas todas as pesagens e respectivas datas, a filiação das vacas e crias, bem como datas de nascimento e dos partos. Os arquivos originais contêm 22.317 pesagens, identificação de 1.144 vacas e 
de 3.754 partos.

Uma análise de consistência foi realizada objetivando a eliminação de pesos discrepantes. Foram desconsiderados os pontos que excediam a média no limite de três vezes e o desvio padrão encontrado em cada grupo de idade em meses (COOK \& WEISBERG, 1982).

Foram calculadas as idades nas pesagens, nos partos e os intervalos entre o parto em questão e o anterior. Em todas as análises, a idade foi considerada em meses, obtida da parte inteira da divisão da diferença entre o evento e o nascimento em dias, dividida por 30 .

Foram gerados arquivos independentes para cada um dos quatro primeiros partos. Cada arquivo continha somente informações das vacas com registros de data do parto em questão e de suas pesagens anteriores à data do parto.

\subsection{A metodologia para obtenção dos parâmetros da equação de Brody}

Foi utilizado o modelo de BRODY (1945), dado pela equação:

$$
\mathbf{P}=\mathbf{A}\left(\mathbf{1}-\mathbf{B} e^{-k t}\right)+\varepsilon
$$

onde :

$\mathbf{P}_{\mathbf{t}}$ o peso estimado na idade $\mathbf{t}$,

A a assíntota da curva, correspondente ao peso assintótico,

k uma constante que indica a velocidade de crescimento e

$\varepsilon$ a estimativa do desvio ou erro experimental.

Foram estimados os parâmetros da curva de crescimento para cada vaca, nos quatro arquivos. Foi estimada também uma curva única (global) representativa de cada arquivo.

Utilizou-se o procedimento "PROC NLIN" do SAS (SAS INSTITUTE, 1987) para obter as estimativas dos parâmetros da equação de Brody, sendo usado o 
método da máxima verossimilhança (Marquardt) usado por PEROTTO et al. (1992) e PEROTTO et al. (1994), com limite de 400 iterações.

Os quatro arquivos foram processados em três etapas, sendo que na primeira foram utilizados valores iniciais médios da literatura; na segunda e terceira etapas os valores iniciais foram obtidos dos valores médios de cada arquivo, obtidos após o processamento da etapa anterior.

Foram descartados animais com parâmetros biologicamente inviáveis $(\mathbf{A}<300$ ou $\mathbf{A}>850$ e $\mathbf{k}<0,001$ ou $\mathbf{k}>1)$ e discrepantes (COOK \& WEISBERG, 1982). Para evitar confundimento de fontes de variação, foram analisados somente os dados de vacas cujos pais tinham no mínimo três filhas em cada grupo de ordem de parto ou duas em cada ano de nascimento.

O Quadro VIII apresenta dados finais dos quatro arquivos, denominados $1^{\circ}$ parto; $2^{\circ}$ parto; $3^{\circ}$ parto e $4^{\circ}$ parto.

QUADRO VIII: Informações sobre os arquivos de grupos de partos

\begin{tabular}{ccccc}
\hline característica & $1^{\circ}$ parto & $2^{\circ}$ parto & $3^{\circ}$ parto & $4^{\circ}$ parto \\
\hline número de vacas & 377 & 373 & 315 & 266 \\
número de pesagens & 5.705 & 7.449 & 7.563 & 7.500 \\
número de pesagens por vaca & 15,1 & 20,0 & 24,0 & 28,2 \\
\hline
\end{tabular}

As análises para os quatro partos foram realizadas separada e independentemente, pelo método dos quadrados mínimos descritos por HARVEY (1960), através dos procedimentos "PROC GLM", SAS (1987) com o objetivo de estimar os efeitos fixos, os componentes de variância dos modelos descritos e as medidas ajustadas pelos quadrados mínimos.

\subsection{Análise das estimativas dos parâmetros da equação de Brody}

Para análise dos efeitos ambientais que atuam sobre os parâmetros Peso Assintótico e a Taxa de Maturação, foi usado o seguinte modelo linear:

$$
\mathbf{P}_{\mathrm{ijklm}}=\mu+\mathbf{A N}_{\mathrm{i}}+\mathbf{E N}_{\mathrm{j}}+\mathbf{E P}_{\mathrm{k}}+\mathbf{T} \mathbf{O}_{\mathrm{l}}+\mathbf{b}\left(\mathrm{ID}_{\mathrm{ijklm}}-\mathrm{ID}_{\text {média }}\right)+\mathbf{c}_{\mathrm{ijklm}}
$$


onde:

$$
\mathbf{P}_{\mathbf{i j k l m}} \text { é o parâmetro } \mathbf{A} \text { ou } \mathbf{k} \text { indicadores respectivamente do peso }
$$
assintótico ou taxa de maturação da $\boldsymbol{m}$-ésima vaca, obtidos no $\boldsymbol{i}$-ésimo ano de nascimento, na $\boldsymbol{j}$-ésima estação do ano de nascimento, na $\boldsymbol{k}$-ésima estação do ano de parto e de vaca filha do $l$-ésimo touro, na idade ao parto $\mathbf{I D}_{\mathbf{i j k d m}}$;

sendo:

$$
\begin{array}{ll}
\mu & =\text { constante para o parâmetro } \mathbf{A} \text { ou } \mathbf{k} \\
\mathbf{A N} & =\text { efeito do ano de nascimento da vaca; } \\
\mathbf{E N} & =\text { efeito da estação do ano de nascimento da vaca; } \\
\mathbf{E P} & =\text { efeito da estação do ano de parto; } \\
\mathbf{T O} & =\text { efeito do touro; } \\
\mathbf{b} & =\text { coeficiente parcial de regressão linear entre } \mathbf{A} \text { ou } \mathbf{k}, \text { e } \mathbf{I D} ; \\
\mathbf{e}_{\mathbf{i j k l m}} & =\text { o erro aleatório de cada observação. }
\end{array}
$$

\subsection{Análise das variáveis idade ao parto e intervalo entre partos}

\subsubsection{Idade ao parto}

Para análise dos efeitos ambientais que atuam sobre a idade ao parto, foi usado o seguinte modelo linear:

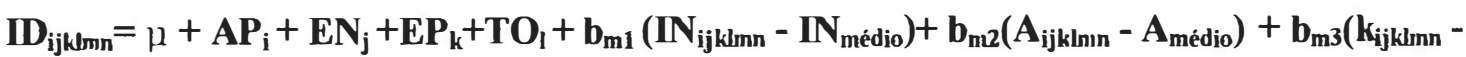

$$
\begin{aligned}
& \left.\mathbf{k}_{\text {médio }}\right)+\mathbf{e}_{\mathbf{i j k} \mathbf{m}}
\end{aligned}
$$

onde:

$\mathbf{I}_{\mathrm{ij} k l m n}$ é a idade ao parto da $\boldsymbol{n}$-ésima vaca, ocorrido no $\boldsymbol{i}$-ésimo ano de parto, na $\boldsymbol{j}$-ésima estação do ano de nascimento, na $\boldsymbol{k}$-ésima estação do ano de parto, de vaca filha do l-ésimo touro, com o $\mathbf{I N}_{\mathrm{ijk} l m n}$ intervalo entre partos, com o peso assintótico $\mathbf{A}_{\mathrm{ijk} \mid \mathrm{l} m}$ e a taxa de maturação $\mathbf{k}_{\mathrm{j} j \mathrm{k} \mid \mathrm{m} n}$; 
sendo:

$\mu$ = constante da população para a característica idade ao parto;

AP = efeito do ano de parto;

EN = efeito da estação de nascimento da vaca;

EP = efeito da estação do parto;

TO = efeito do pai da vaca;

$\mathbf{b}_{\mathbf{m} 1}, \mathbf{b}_{\mathbf{m} 2}, \mathbf{b}_{\mathbf{m} 3}=$ os coefícientes de regressão linear parcial

IN = intervalo entre partos;

A = parâmetro A, indicador do peso assintótico;

$\mathbf{k}$ = parâmetro $\mathbf{k}$, indicador da taxa de maturação da vaca; $\mathrm{e}$

$\mathbf{e}_{\mathrm{ijklmn}}=$ erro aleatório de cada observação.

Este modelo foi aplicado nos quatro grupos de partos (primeiro ao quarto partos), sendo que no grupo do primeiro parto não existiu o efeito do intervalo entre partos.

\subsubsection{Intervalo entre partos}

Para análise dos efeitos ambientais que atuam sobre o intervalo entre partos, foi usado o seguinte modelo linear:

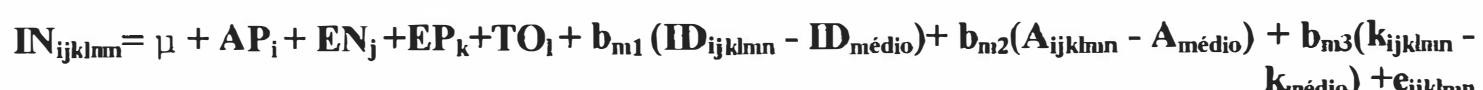

onde:

$\mathbf{I N}_{\mathrm{ijklmn}}$ é o intervalo entre partos da $\boldsymbol{n}$-ésima vaca, ocorrido no $\boldsymbol{i}$-ésimo ano de parto, na $\boldsymbol{j}$-ésima estação do ano de nascimento, na $\boldsymbol{k}$-ésima estação do ano de parto, de vaca filha do $l$-ésimo touro, com a $\mathbf{I D}_{\mathrm{ijk} \mid m n}$ idade ao parto, com o peso assintótico $\mathbf{A}_{\mathbf{i j k} \mathrm{mn}}$ e a taxa de maturação $\mathbf{k}_{\mathrm{j} k \mathrm{k} m \mathrm{~m}}$; 
sendo:

$\mu \quad=$ constante da população para a característica idade ao parto;

$\mathbf{A P}=$ efeito do ano de parto;

EN = efeito da estação de nascimento da vaca;

$\mathbf{E P}=$ efeito da estação do parto;

TO = efeito do pai da vaca;

$\mathbf{b}_{\mathrm{m} 1}, \mathbf{b}_{\mathbf{m} 2}, \mathbf{b}_{\mathrm{m} 3}=$ os coeficientes de regressão linear parcial

IN = intervalo entre partos;

A = parâmetro A, indicador do peso assintótico;

$\mathbf{k}=$ parâmetro $\mathbf{k}$, indicador da taxa de maturação da vaca; e

$\mathbf{e}_{\mathrm{ijklmn}}=$ erro aleatório de cada observação.

Este modelo foi aplicado nos três últimos grupos de partos (segundo ao quarto partos), já que não existe intervalo anterior ao primeiro parto. 


\section{RESULTADOS E DISCUSSÃO}

\subsection{Pesos médios nas diversas idades}

Os pesos médios não ajustados dos animais analisados são apresentados no Quadro IA, do Apêndice, conforme os grupos de parto. O Quadro IX contém os números de pesos, pesos médios e desvios padrão, nas idades mais comumente estudadas.

QUADRO IX: Número de pesos, pesos médios não ajustados e desvio padrão por idade, por parto

\begin{tabular}{|c|c|c|c|c|c|c|c|c|c|c|c|c|}
\hline \multirow[b]{2}{*}{$\begin{array}{l}\text { idade } \\
\text { em } \\
\text { meses }\end{array}$} & \multicolumn{3}{|c|}{$1^{\circ}$ parto } & \multicolumn{3}{|c|}{$2^{\circ}$ parto } & \multicolumn{3}{|c|}{$3^{\circ}$ parto } & \multicolumn{3}{|c|}{$4^{\circ}$ parto } \\
\hline & NP* & $\begin{array}{c}\text { peso } \\
\text { médio } \\
(\mathrm{kg})\end{array}$ & $\begin{array}{c}\text { desvio } \\
\text { padrão } \\
(\mathrm{kg})\end{array}$ & NP* & $\begin{array}{c}\text { peso } \\
\text { médio } \\
(\mathrm{kg})\end{array}$ & $\begin{array}{c}\text { desvio } \\
\text { padrão } \\
(\mathrm{kg})\end{array}$ & $\mathrm{NP}^{*}$ & $\begin{array}{c}\text { peso } \\
\text { médio } \\
(\mathrm{kg})\end{array}$ & $\begin{array}{c}\text { desvio } \\
\text { padrão } \\
(\mathrm{kg})\end{array}$ & NP* & $\begin{array}{l}\text { peso } \\
\text { médio } \\
(\mathrm{kg})\end{array}$ & $\begin{array}{c}\text { desvio } \\
\text { padrão } \\
(\mathrm{kg})\end{array}$ \\
\hline 0 & 223 & 27,82 & 3,13 & 220 & 27,64 & 3,05 & 181 & 27,46 & 3,13 & 164 & 27,51 & 3,26 \\
\hline 7 & 124 & 167,36 & 18,26 & 122 & 165,29 & 17,45 & 104 & 164,05 & 17,53 & 93 & 163,56 & 17,21 \\
\hline 12 & 98 & 221,89 & 28,57 & 95 & 219,22 & 28,65 & 75 & 216,17 & 27,69 & 68 & 214,69 & 26,03 \\
\hline 18 & 102 & 275,90 & 28,14 & 97 & 271,23 & 26,74 & 75 & 271,31 & 27,88 & 71 & 270,48 & 26,90 \\
\hline 24 & 106 & 341,46 & 35,32 & 100 & 339,40 & 36,59 & 78 & 340,53 & 36,38 & 72 & 340,49 & 36,26 \\
\hline 30 & 125 & 382,10 & 58,19 & 118 & 382,03 & 54,91 & 89 & 383,52 & 53,51 & 79 & 385,52 & 55,69 \\
\hline 36 & 87 & 398,22 & 90,01 & 106 & 412,33 & 83,73 & 85 & 411,45 & 80,91 & 70 & 424,00 & 84,45 \\
\hline 48 & 23 & 399,48 & 62,77 & 98 & 402,55 & 61,70 & 79 & 405,35 & 65,95 & 66 & 414,44 & 62,16 \\
\hline 60 & 2 & 416,50 & 94,05 & 50 & 457,24 & 76,56 & 71 & 447,30 & 60,79 & 56 & 452,66 & 66,31 \\
\hline 72 & - & - & - & 6 & 412,33 & 52,58 & 52 & 464,35 & 76,75 & 54 & 472,19 & 77,56 \\
\hline 84 & - & - & - & 2 & 539,00 & 7,07 & 11 & 486,09 & 65,62 & 44 & 480,50 & 64,74 \\
\hline 96 & - & - & - & - & - & - & 3 & 494,00 & 65,02 & 17 & 518,29 & 65,04 \\
\hline $40+$ & 403 & 382,99 & - & 1795 & 405,00 & - & 2643 & 418,39 & - & 2965 & 431,94 & - \\
\hline
\end{tabular}

* número de pesos

+ média ponderada das pesagens não ajustadas em idades iguais ou superiores a 40 meses extraida do Quadro IA do Apêncide

Os pesos médios ao nascer, para os quatro grupos de parto, respectivamente de 27,82 $\pm 3,13 \mathrm{~kg}$; $27,64 \pm 3,05 \mathrm{~kg}$.; $27,46 \pm 3,13 \mathrm{~kg}$. e 27, $51 \pm 3,26$ $\mathrm{kg}$., foram mais altos que todos apresentados no Quadro IV. Esta diferença pode ser explicada pelo fato de se tratarem de animais selecionados, que permaneceram no rebanho até o parto, portanto, provavelmente os melhores dentro do ano em que nasceram. Para verificar o efeito de incremento na qualidade do manejo das vacas, que também pode ter 
contribuído para esta diferença, outros estudos teriam que ser conduzidos. Os relatos de SALVO (1986) endossam estas considerações.

Os pesos aos 7 meses (aproximadamente 205 dias), 12, 18 (aproximadamente 550 dias) e 24 meses também são superiores aos relatados na literatura e cabem as mesmas justificativas dadas para os pesos ao nascer. A partir dos 36 meses, entretanto, os pesos médios não ajustados das vacas deste estudo foram em geral menores que os observados na literatura. Já o aumento observado nos pesos médios não ajustados, a partir de 40 meses (idade média do primeiro parto), com a evolução dos partos, de 382,99 $\mathrm{kg} ; 405,00 \mathrm{~kg} ; 418,39 \mathrm{~kg}$ e $431,94 \mathrm{~kg}$; respectivamente para $1^{\circ}, 2^{\circ}, 3^{\circ}$ e $4^{\circ}$ grupos de parto, vai ao encontro dos relatos de que o peso da vaca adulta tende a aumentar com a idade (MORROW et al., 1978; BARBOSA, 1986b; SALVO, 1986);

\subsection{Estimativa dos parâmetros da equação de Brody}

O Quadro X apresenta os valores médios das estimativas dos parâmetros para cada grupo de parto e os parâmetros das curvas globais, ajustadas aos conjuntos de dados. Estudos preliminares evidenciaram a inexistência de relação entre o número de pesagens por animal, o número de iterações do algorítimo utilizado no processo iterativo, e a variância do erro dentro dos grupos de parto.

QUADRO X: $\quad$ Média dos parâmetros das curvas individuais e curva global, por parto

\begin{tabular}{|c|c|c|c|c|c|c|}
\hline curva & $\begin{array}{l}\text { grupo de } \\
\text { pesos }\end{array}$ & A & B & $\mathrm{k}$ & $\begin{array}{l}\text { número de } \\
\text { iterações }\end{array}$ & $\begin{array}{c}\text { quadrado } \\
\text { médio do } \\
\text { resíduo }\end{array}$ \\
\hline média & $1^{\circ}$ parto & 574,214 & 1,0027 & 0,0349 & $49+$ & $1026+$ \\
\hline das & $2^{\circ}$ parto & 510,328 & 0,9668 & 0,0404 & $69+$ & $1600+$ \\
\hline estimativas & $3^{\circ}$ parto & 487,831 & 0,9706 & 0,0436 & $70+$ & $1773+$ \\
\hline individuais & $4^{\circ}$ parto & 476,790 & 0,9855 & 0,0465 & $69+$ & $1779+$ \\
\hline global & $1^{\circ}$ parto & 438,092 & 0,9665 & 0,0602 & 114 & 2578 \\
\hline (ajustada ao & $2^{\circ}$ parto & 440,198 & 0,9635 & 0,0580 & 129 & 2891 \\
\hline conjunto & $3^{\circ}$ parto & 449,018 & 0,9535 & 0,0532 & 117 & 2973 \\
\hline dos dados) & $4^{\circ}$ parto & 461,149 & 0,9483 & 0,0497 & 102 & 2965 \\
\hline
\end{tabular}

tcorrespondente à média dos valores individuais em cada grupo de parto

A primeira curva resulta da média das estimativas individuais dos parâmetros, em cada grupo de parto; a segunda, curva global única, resulta do ajustamento 
simultâneo a todas as vacas, em cada arquivo. As curvas geradas para os quatro partos à partir dos valores listados no Quadro X são apresentados nas Figuras 1 e 2.

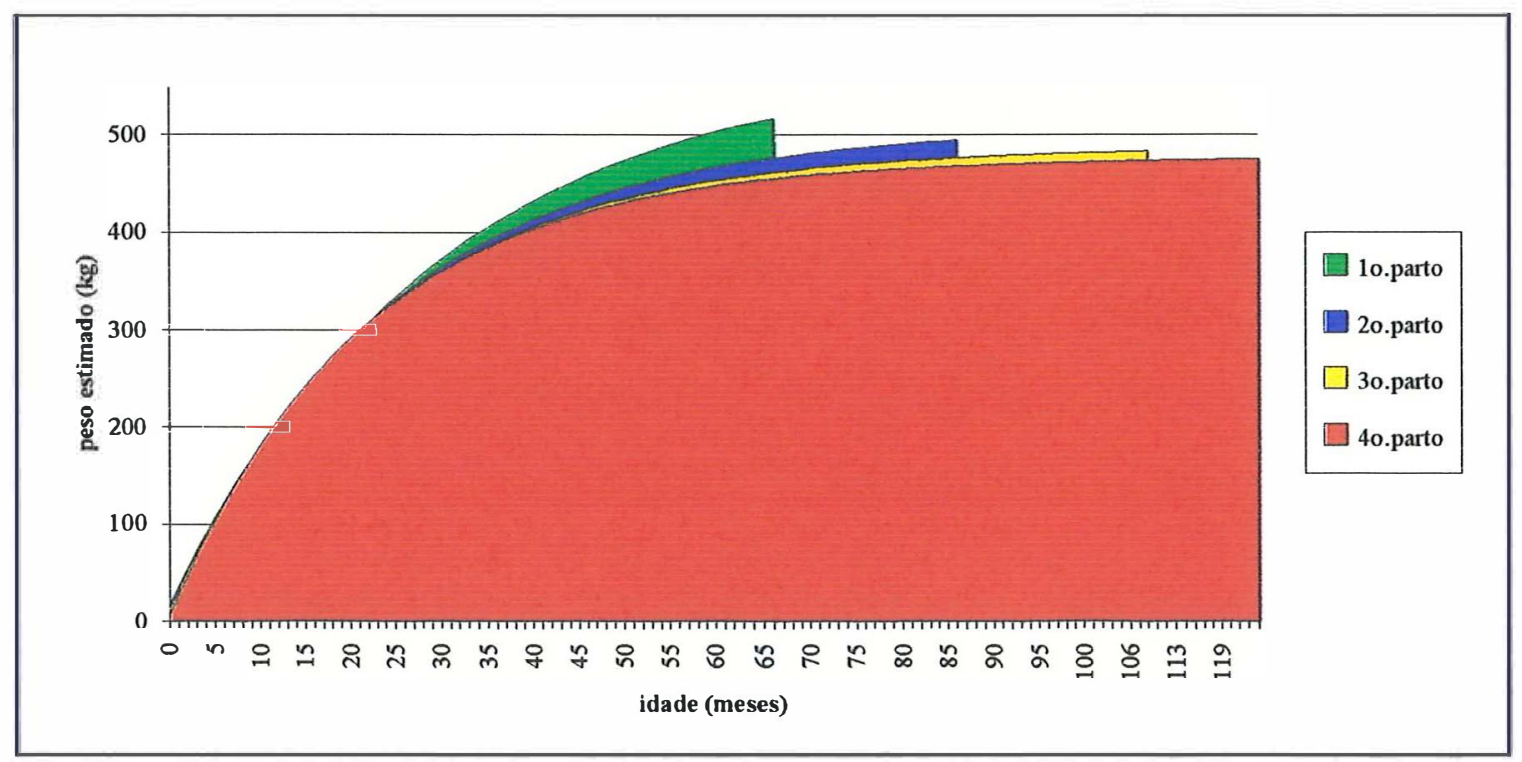

FIGURA 1: Curvas das médias das estimativas dos parâmetros individuais, por parto.

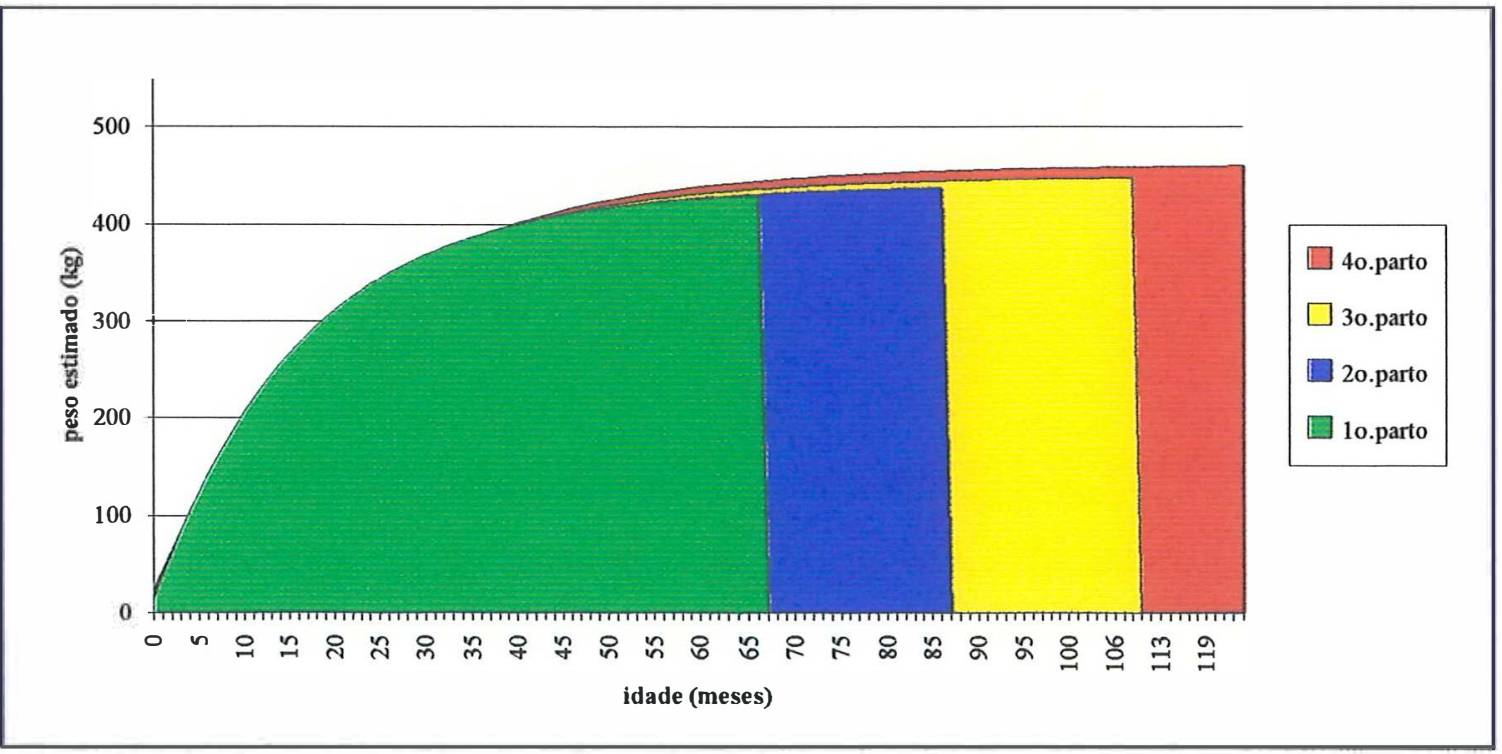

FIGURA 2: Curvas globais, por parto.

Observando-se o Quadro X é possível notar que o peso assintótico e a taxa de maturação têm comportamentos opostos, ou seja, o aumento de um é acompanhado pela redução do outro. Este fato esta de acordo com a literatura (DUARTE, 1975; LUDWIG, 
1977; CARRIJO, 1988) que aponta para a relação negativa existente entre os dois parâmetros, evidenciada também no Quadro XI, onde se verifica que as correlações fenotípicas entre os parâmetros estimados nos quatro partos são negativas.

QUADRO XI: Correlação fenotípica entre peso assintótico e a taxa de maturação, por parto.

\begin{tabular}{cccc}
\hline $1^{\circ}$ parto & $2^{\circ}$ parto & $3^{\circ}$ parto & $4^{\circ}$ parto \\
\hline$-0,298$ & $-0,4065$ & $-0,5509$ & $-0,3774$ \\
\hline
\end{tabular}

A Figura 3 ilustra a relação negativa observada entre estes dois parâmetros.

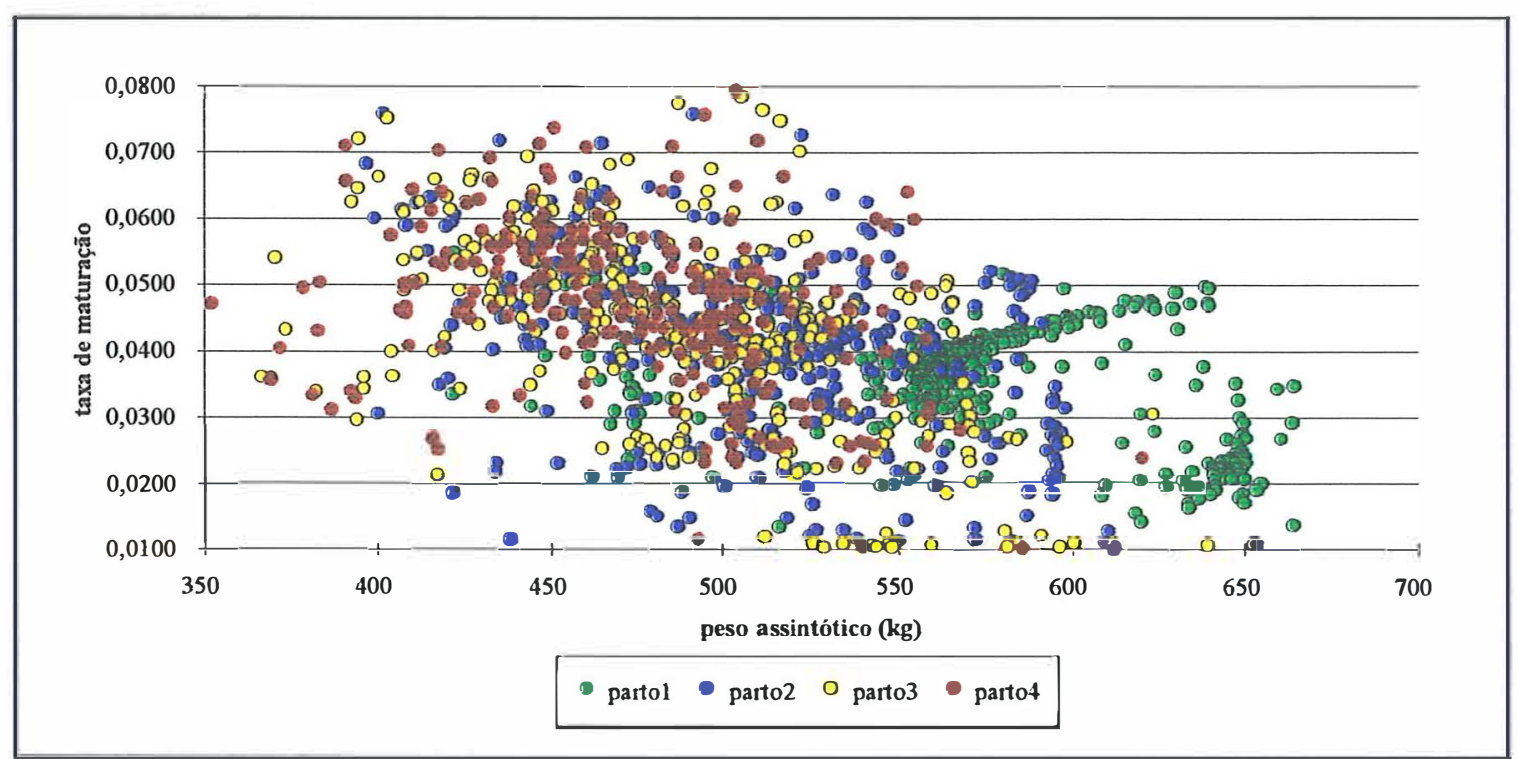

FIGURA 3: Taxa de maturação em função do peso assintótico, por parto.

Analisar o ajustamento da equação de Brody aos dados não é objetivo principal deste trabalho, cabendo porém algumas considerações sobre evidências observadas. A evolução dos partos é acompanhada pelo acréscimo do número de pesagens posteriores ao primeiro parto, e também pelo aumento do peso médio à maturidade (Quadro IX).

Os resultados apresentados no Quadro X, entretanto, contrariam essa tendência. Verificando-se, as médias não ajustadas dos parâmetros, é possível notar que na medida em que evoluem os partos, diminui o peso assintótico médio e aumenta a taxa de 
maturação. Somente nas curvas globais que representam, de forma geral, cada um dos quatro conjuntos de dados, observa-se o esperado aumento dos pesos assintóticos e a redução das taxas de maturação com a evolução dos partos.

Estes fatos evidenciam as diferenças do ajuste da equação aos quatro grupos de parto, seja o ajuste ao conjunto dos pesos ou o ajuste individual, aos pesos de cada animal, ilustradas nas Figuras 1 e 2. Assim, se por um lado o aumento do peso médio à maturidade nos partos é acompanhado e superestimado pelo peso assintótico no ajuste global, por outro lado as médias dos pesos assintóticos ajustados individualmente diminuem, mas ainda com superestimativas.

A quantidade de pesos em idades posteriores ao primeiro parto produz diferenças nos ajustes da equação de Brody. Também fica claro que esta equação superestima tanto mais o peso assintótico individual, quanto menor for a idade máxima em que são tomados os pesos do animal. A superestimativa do peso assintótico foi observada por vários autores (BROWN et al., 1976; LOPEZ DE TORRE et al., 1992), entre outros. Também a observação de GOONEWARDENE et al. (1981), de que esse modelo não foi o mais adequando para estimar pesos nos limites externos aos dos dados utilizados no ajustamento, vem ao encontro destas observações.

As Figuras 4, 5, 6 e 7 ilustram as curvas e os pesos médios por idade, separadamente para o $1^{\circ}, 2^{\circ}, 3^{\circ}$ e $4^{\circ}$ partos, respectivamente. Nelas é possível verificar que no primeiro parto (Figura 4) a equação de Brody ajusta-se somente aos pesos anteriores ao parto, já que, no ajuste individual, somente estes foram computados por animal. Pode-se observar melhoria gradual no ajuste da curva aos pesos nos partos seguintes, com a inclusão de mais pesos decorrente do avanço da idade.

É possível observar também a tendência das curvas se igualarem com o avanço dos partos e consequente acréscimo de pesos em idades maiores. Isto indica que o modelo de Brody falha mais ao estimar o peso assintótico de bovinos quando o número de pesos em idades adultas é pequeno, produzindo talvez por isso superestimativas maiores do peso assintótico nesses casos.

Por esta tendência, comparações de pesos assintóticos de bovinos, estimados a partir de pesagens até diferentes idades ou ordens de parto podem levar a conclusões equivocadas. Este estudo evidenciou que as análises devem ser realizadas 
dentro de grupos de pesagens ou seja, com agrupamentos de animais com pesagens até uma mesma idade ou ordem de parto.

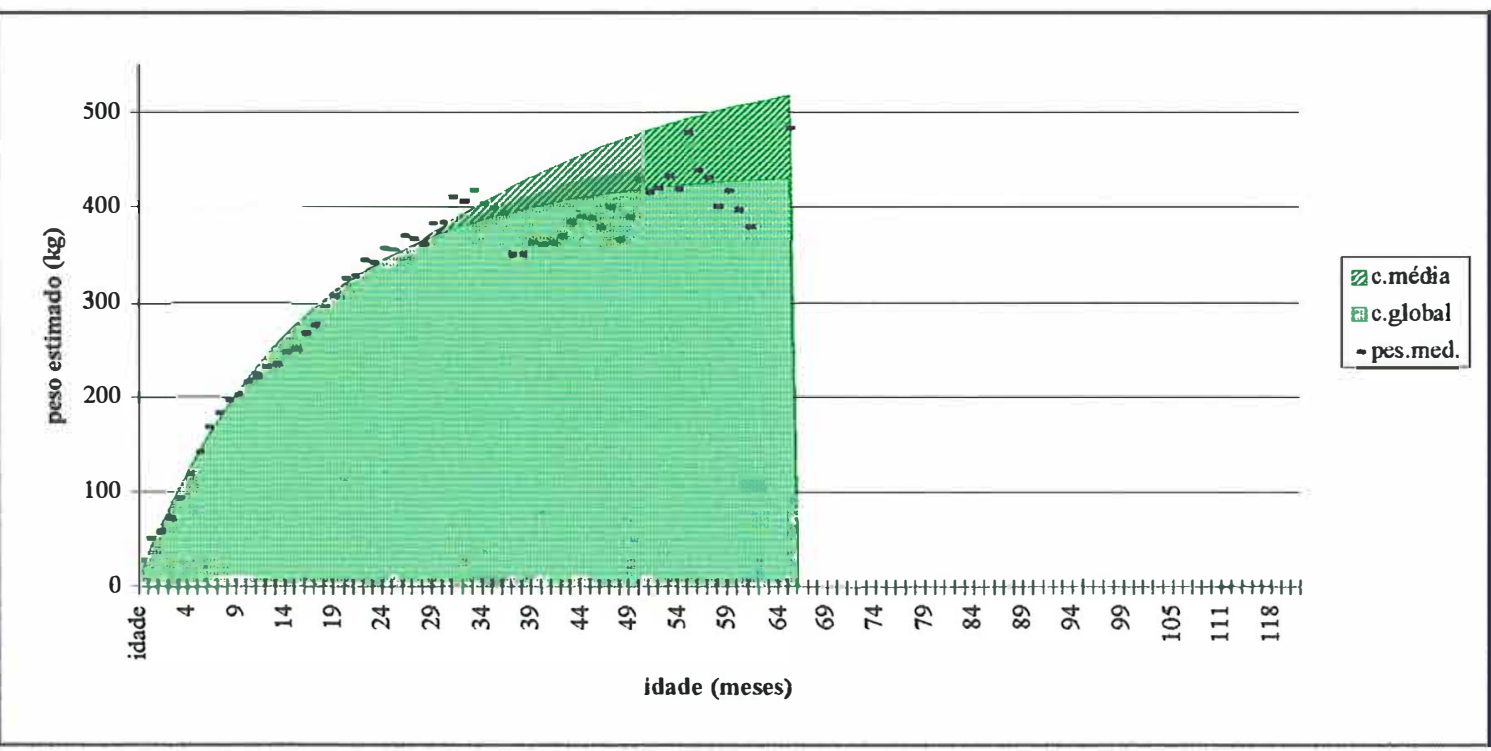

FIGURA 4: Pesos médios e curvas global e média no $1^{\circ}$ parto.

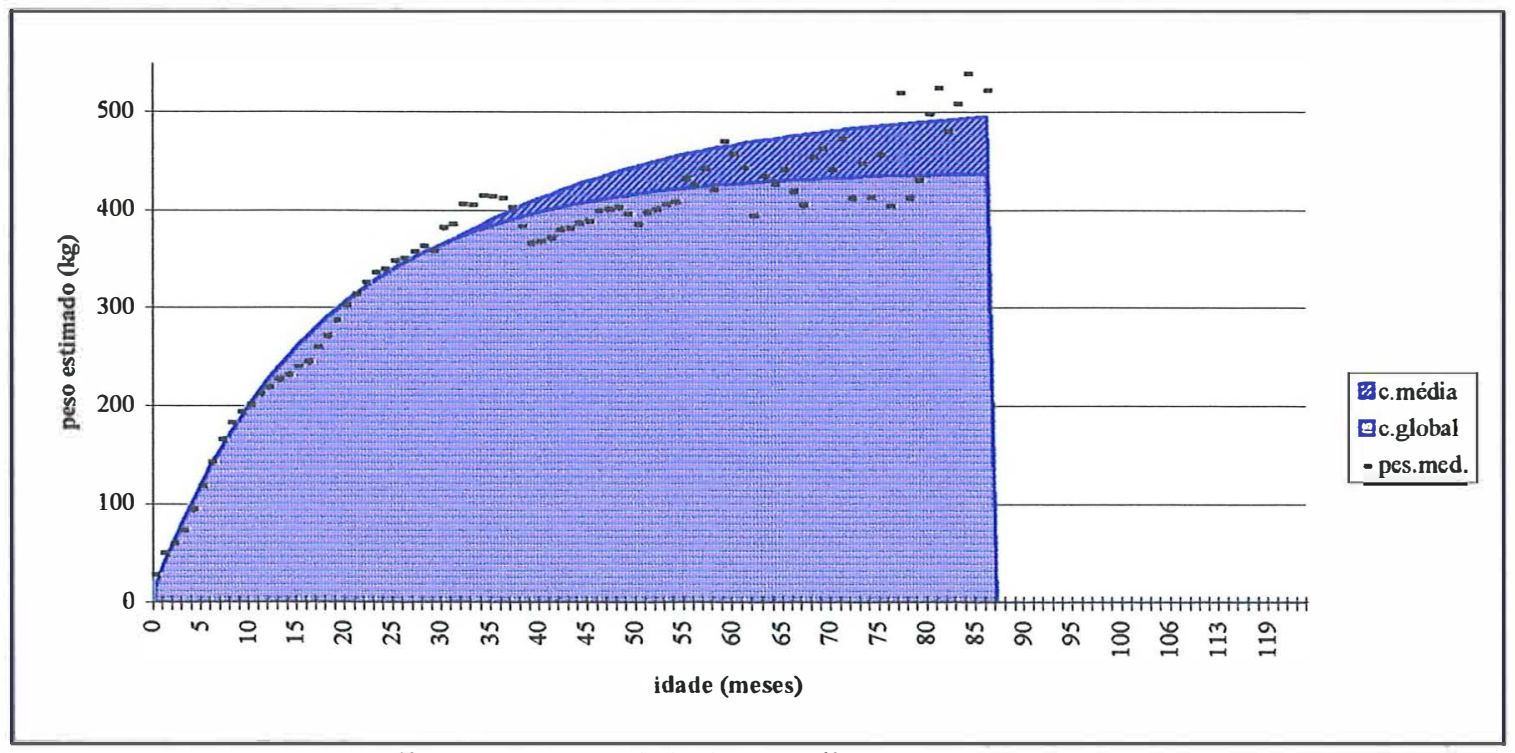

FIGURA 5: Pesos médios e curvas global e média no $2^{\circ}$ parto. 


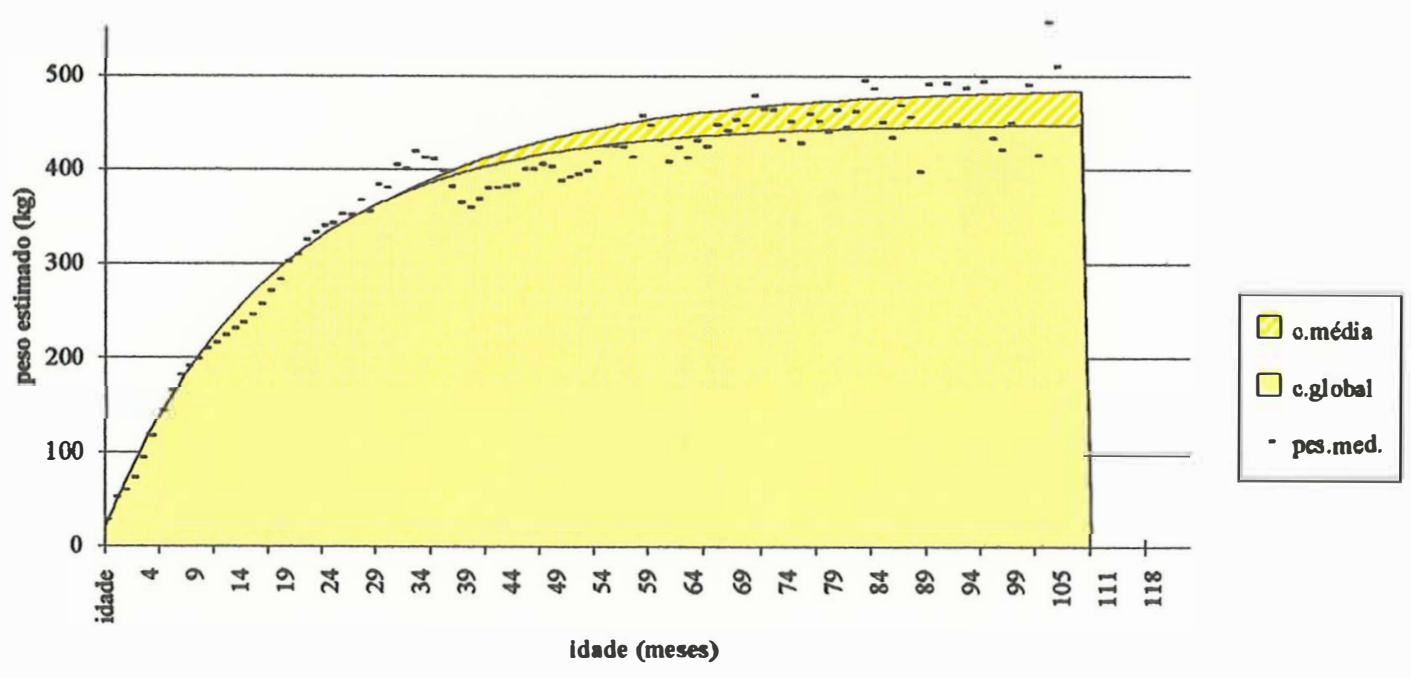

FIGURA 6: Pesos médios e curvas global e média no $3^{\circ}$ parto.

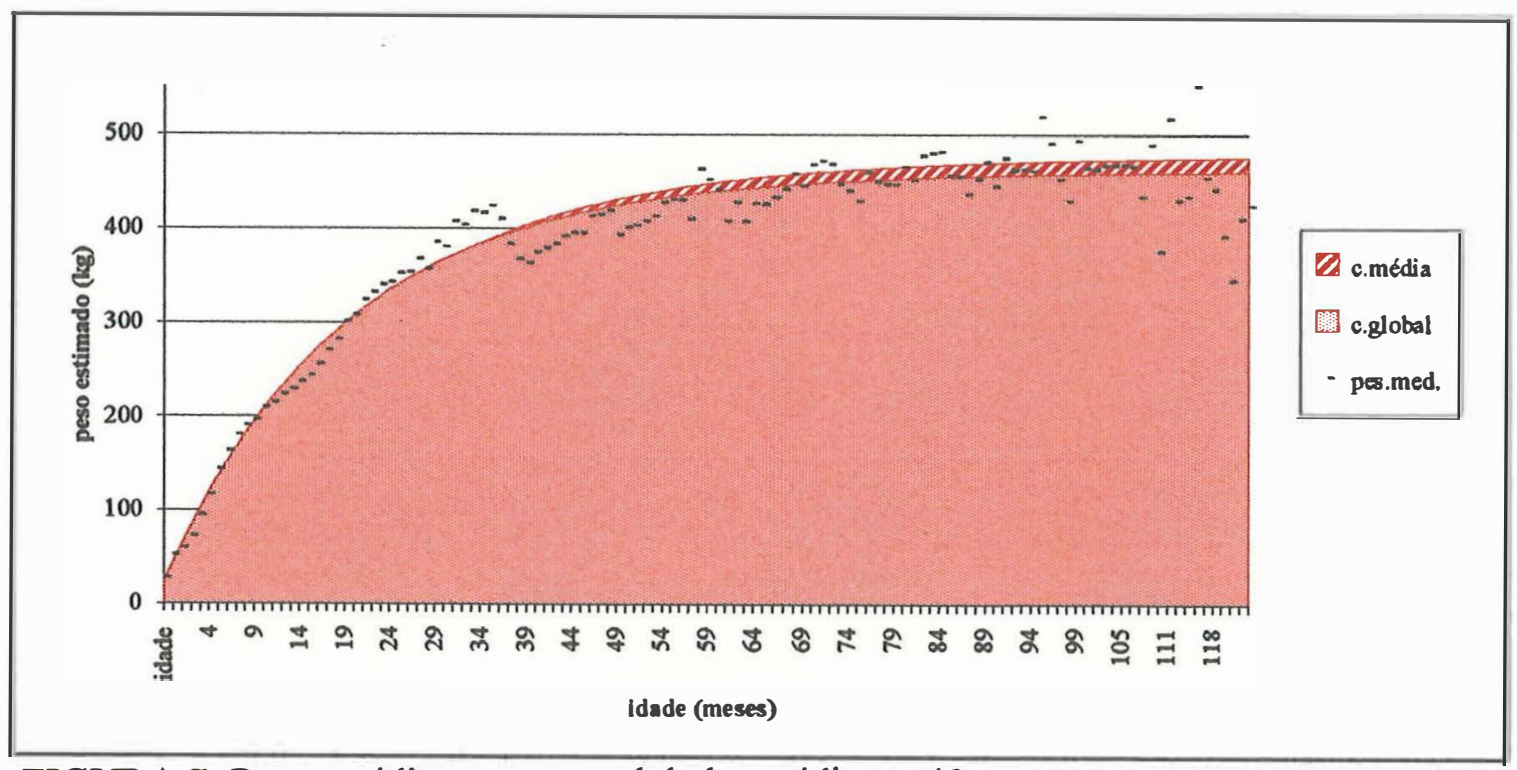

FIGURA 7: Pesos médios e curvas global e média no $4^{\circ}$ parto.

\subsection{Fatores que interferem no peso assintótico e na taxa de maturação}

Os Quadros XII e XIII mostram as análises de variância das estimativas do peso assintótico e taxa de maturação. 
QUADRO XII: $\quad$ Análises de variância do peso assintótico, por parto.

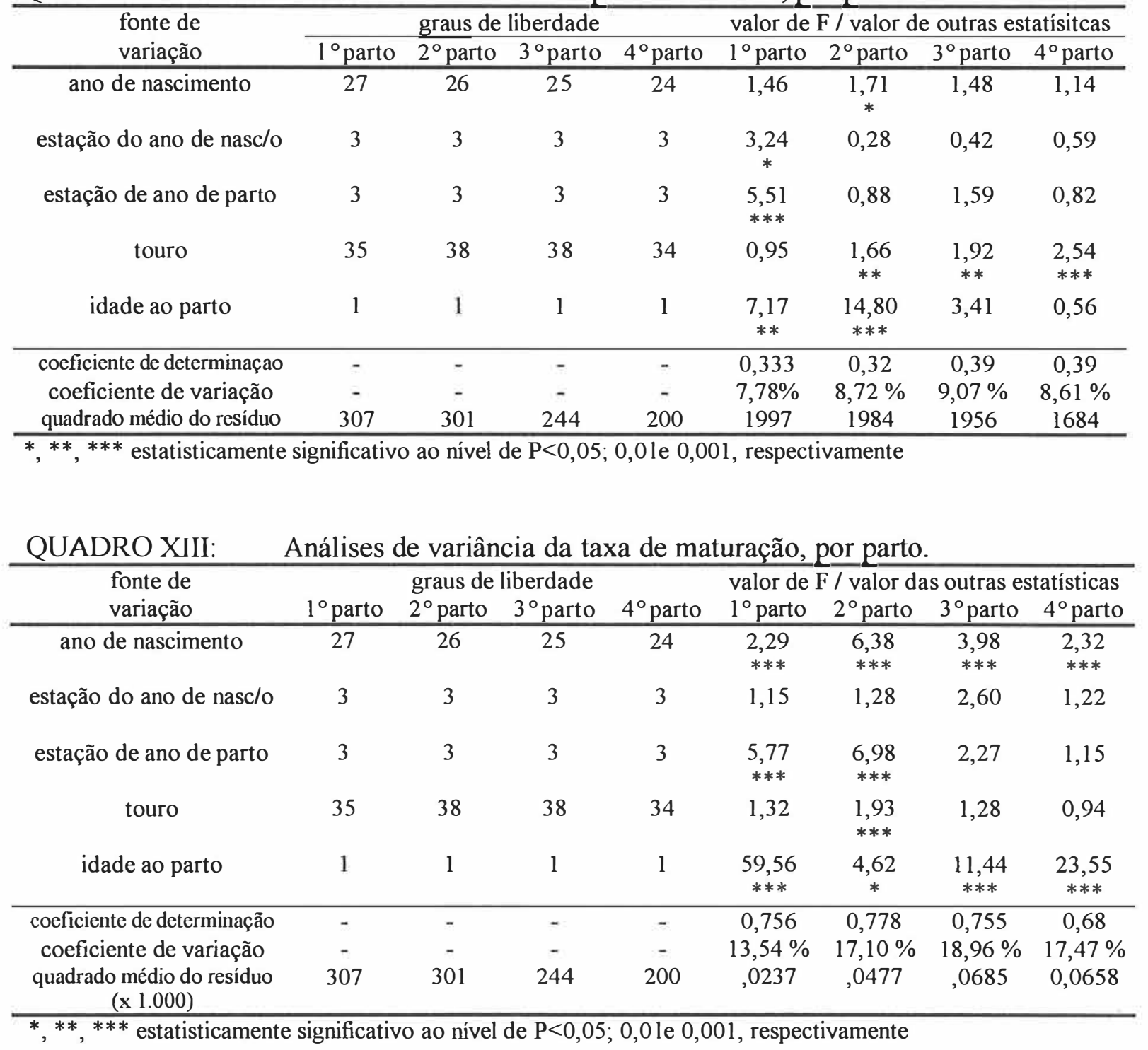

\subsubsection{Efeito da idade ao parto sobre o peso assintótico e taxa de maturação}

Nas duas análises observa-se que a idade ao parto é importante fonte de variação na estimativa dos parâmetros $\mathbf{A}$ e $\mathbf{k}$, sendo que para a taxa de maturação foi significativa nos quatro partos, enquanto que para o peso assintótico, nos dois primeiros. $\mathrm{O}$ Quadro XIV apresenta os coeficientes de regressão linear obtidos entre a idade ao parto e os dois parâmetros. 
QUADRO XIV: Coeficientes de regressão linear da idade ao parto sobre o peso assintótico e a taxa de maturação, por parto.

\begin{tabular}{|c|c|c|c|c|}
\hline & $1^{\circ}$ parto & $2^{\circ}$ parto & $3^{\circ}$ parto & $4^{\circ}$ parto \\
\hline $\begin{array}{l}\text { coeficiente de regressão } \\
\text { sobre o peso assintótico }\end{array}$ & $\begin{array}{c}1,4725 \\
* *\end{array}$ & $\begin{array}{c}-1,5920 \\
* * *\end{array}$ & $-0,6670$ & $-0,2294$ \\
\hline $\begin{array}{l}\text { coeficiente de regressão } \\
\text { sobre taxa de maturação }\end{array}$ & $\begin{array}{l}-0,000449 \\
* * *\end{array}$ & $\begin{array}{c}-0,000138 \\
*\end{array}$ & $\begin{array}{c}-0,000229 \\
* * *\end{array}$ & $\begin{array}{c}-0,000294 \\
* * *\end{array}$ \\
\hline
\end{tabular}

A partir dos coeficientes de regressão apresentados, pode-se estimar que, no segundo parto, o aumento de 1 unidade na idade ao parto ( 1 mês) implica na redução de $1,592 \mathrm{~kg}$. do peso assintótico. Da mesma forma, o aumento de 1 mês esta relacionado à redução de 0,000138 unidades a taxa de maturação.

Quanto à relação negativa com o peso assintótico, considera-se que ao aumento da idade ao parto corresponde o distanciamento da última pesagem em relação à origem da curva (nascimento) e, em muitos casos também ao aumento do número de pesagens à maturidade. Considerando a observada superestimativa do peso assintótico ocorrida neste estudo, a maior idade ao parto favorece o ajustamento da curva aos pesos posteriores ao primeiro parto, reduzindo o peso assintótico estimado.

Já a correlação positiva observada no primeiro parto decorre do prolongamento da fase de pesos crescentes que vem desde o nascimento, e que neste parto forçou o ajuste da curva aos pesos iniciais (Figura 4). Este resultado vai ao encontro dos obtidos por LUDWIG (1977) que, trabalhando com pesos em idades anteriores à maturidade, verificou o mesmo efeito linear do número de pesagens, observando, entretanto, que esse efeito ocorreu principalmente sobre o peso assintótico.

Para a relação negativa da taxa de maturação cabe o mesmo princípio, ou seja, a inclusão de pesos maiores mais tardiamente eleva o ponto assintótico e produz uma queda da curva ou no componente que retrata esta queda: a taxa de maturação. Assim, é possível concluir que neste estudo a idade ao parto reflete a importância que pesagens mais tardias tem sobre os parâmetros da curva, mesmo considerado o efeito de ordem de parto. 


\subsubsection{Efeito do ano de nascimento sobre o peso assintótico e a taxa de maturação}

Para o peso assintótico, somente no segundo parto pode-se observar os efeitos de ano de nascimento (Quadro XII), enquanto que no Quadro XIII pode-se observar que os efeitos do ano de nascimento foram muito importantes na taxa de maturação, nos quatro partos cabendo considerar que este efeito sintetiza um conjunto de fatores não só ambientais, (OLIVEIRA FLHO, 1977; PACKER, 1977; BARBOSA et al., 1979; BARBOSA et al., 1980; CARRIJO, 1988); RAZOOK, 1988; e RAZOOK et al. 1988) como também de manejo e até mesmo mudanças genéticas (RAZOOK, 1988 e PENNA, 1990).

QUADRO XV: Pesos assintóticos e taxas de maturação médios ajustados aos anos de nascimento, por parto.

\begin{tabular}{|c|c|c|c|c|c|c|c|c|}
\hline \multirow{2}{*}{$\begin{array}{c}\text { ano de } \\
\text { nasci-mento }\end{array}$} & \multicolumn{4}{|c|}{ peso assintótico ajustado } & \multicolumn{4}{|c|}{ taxa de maturação ajustada } \\
\hline & partol & $\begin{array}{c}\text { parto2 } \\
*\end{array}$ & parto3 & parto4 & $\begin{array}{c}\text { partol } \\
* * *\end{array}$ & $\underset{* * *}{\operatorname{parto} 2}$ & $\underset{* * *}{\text { parto3 }}$ & $\begin{array}{l}\text { parto4 } \\
* * *\end{array}$ \\
\hline 1955 & 592 & 482 & 500 & 457 & 0,026 & 0,035 & 0,040 & 0,063 \\
\hline 1956 & 634 & 516 & 474 & 474 & 0,031 & 0,028 & 0,035 & 0,042 \\
\hline 1957 & 576 & 569 & 518 & 510 & 0,031 & 0,030 & 0,037 & 0,035 \\
\hline 1958 & 598 & 500 & 533 & 505 & 0,029 & 0,033 & 0,028 & 0,040 \\
\hline 1959 & 546 & 522 & 557 & 538 & 0,033 & 0,023 & 0,022 & 0,035 \\
\hline 1960 & 535 & 535 & 508 & 501 & 0,029 & 0,022 & 0,029 & 0,036 \\
\hline 1961 & 574 & 572 & 494 & 457 & 0,031 & 0,019 & 0,023 & 0,037 \\
\hline 1968 & 545 & 503 & 427 & 465 & 0,030 & 0,035 & 0,045 & 0,039 \\
\hline 1969 & 581 & 602 & 495 & 524 & 0,030 & 0,033 & 0,042 & 0,038 \\
\hline 1970 & 618 & 509 & 442 & 465 & 0,029 & 0,046 & 0,053 & 0,052 \\
\hline 1971 & 584 & 505 & 457 & 491 & 0,033 & 0,044 & 0,049 & 0,047 \\
\hline 1972 & 559 & 512 & 456 & 493 & 0,033 & 0,044 & 0,049 & 0,044 \\
\hline 1973 & 570 & 519 & 472 & 500 & 0,036 & 0,048 & 0,051 & 0,050 \\
\hline 1974 & 562 & 539 & 492 & 516 & 0,035 & 0,041 & 0,044 & 0,042 \\
\hline 1975 & 542 & 508 & 465 & 484 & 0,039 & 0,049 & 0,052 & 0,050 \\
\hline 1976 & 568 & 532 & 485 & 496 & 0,033 & 0,043 & 0,046 & 0,045 \\
\hline 1977 & 586 & 511 & 463 & 472 & 0,036 & 0,047 & 0,052 & 0,052 \\
\hline 1978 & 588 & 501 & 453 & 475 & 0,038 & 0,054 & 0,058 & 0,058 \\
\hline 1979 & 574 & 498 & 460 & 483 & 0,038 & 0,053 & 0,058 & 0,050 \\
\hline 1980 & 553 & 492 & 474 & 468 & 0,035 & 0,046 & 0,047 & 0,047 \\
\hline 1981 & 577 & 495 & 475 & 486 & 0,035 & 0,047 & 0,049 & 0,048 \\
\hline 1982 & 571 & 488 & 456 & 445 & 0,036 & 0,050 & 0,056 & 0,051 \\
\hline 1983 & 565 & 475 & 465 & 456 & 0,037 & 0,054 & 0,053 & 0,053 \\
\hline 1984 & 585 & 483 & 474 & 457 & 0,038 & 0,059 & 0,061 & 0,059 \\
\hline 1985 & 585 & 523 & 489 & 503 & 0,040 & 0,050 & 0,054 & 0,045 \\
\hline 1986 & 585 & 522 & 491 & - & 0,041 & 0,055 & 0,058 & - \\
\hline 1987 & 593 & 499 & - & - & 0,038 & 0,057 & - & - \\
\hline 1988 & 581 & - & - & - & 0,038 & - & - & - \\
\hline
\end{tabular}


Para o peso assintótico, os efeitos de ano foram importantes fontes de variação para a sua estimativa somente no segundo parto. O Quadro XV mostra a evolução do peso assintótico e da taxa de maturação nos anos. As Figuras 8 e 9 ilustram essa evolução.

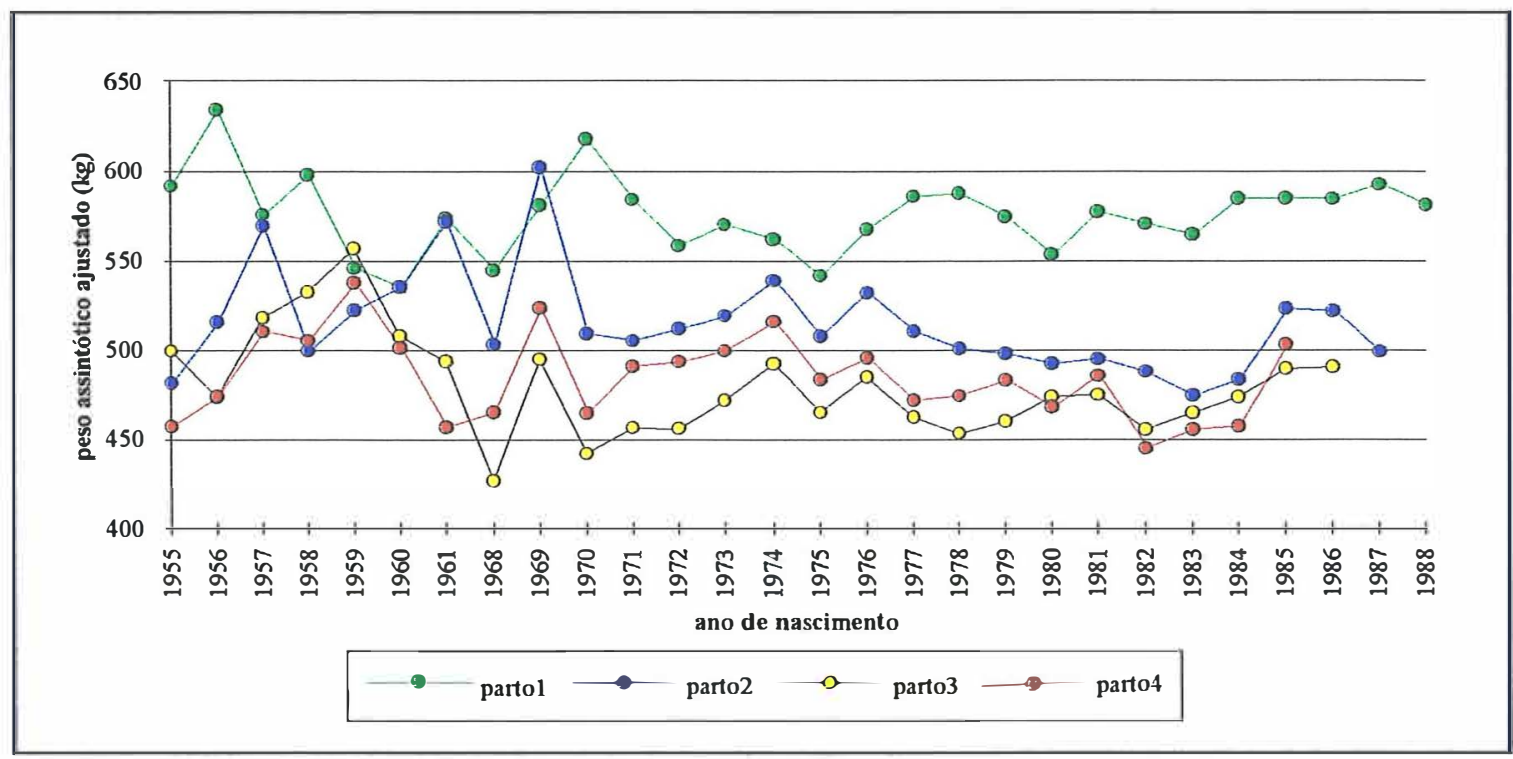

FIGURA 8: Pesos assintóticos médios ajustados ao ano de nascimento, por parto.

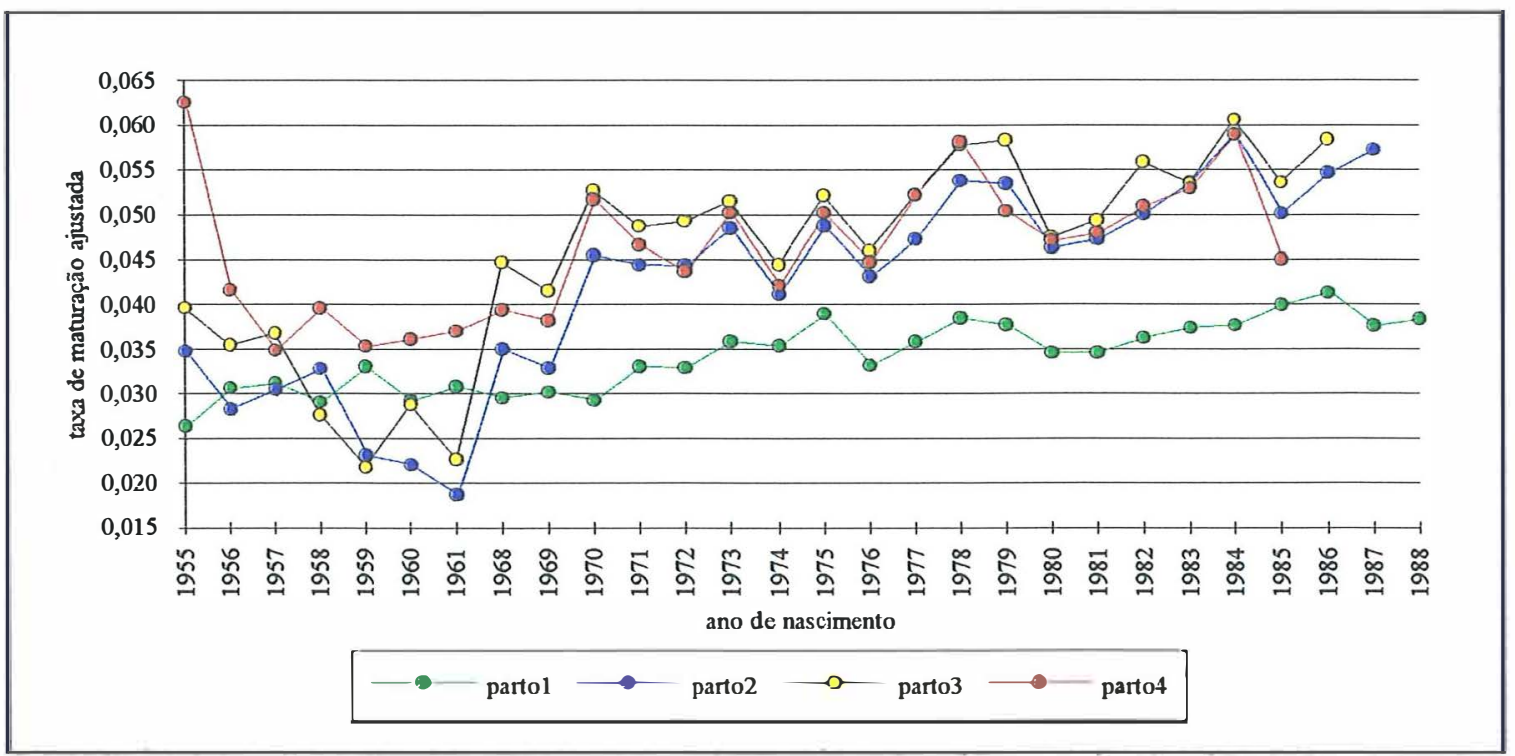

FIGURA 9: Taxas de maturação médias ajustadas ao ano de nascimento, por parto. 
A taxa de maturação indica a velocidade de crescimento de um animal, ou a velocidade com que ele caminha para seu peso adulto. Se dois animais caminham para um mesmo peso adulto com taxas de maturação distintas, o que apresentar maior taxa de maturação terá crescimento mais rápido.

Pode-se verificar o aumento da taxa de maturação com o passar dos anos, podendo-se supor que isto resulta tanto de mudanças nas condições de alimentação e manejo, como de possíveis efeitos de seleção para os pesos iniciais, não sendo possível, porém, determinar qual dos fatores foi o mais importante (Figuras 8 e 9).

Observa-se que não fica evidenciada a evolução do peso assintótico. O fato de não se verificar neste conjunto de dados a esperada relação negativa entre o peso assintótico e a taxa de maturação nas médias anuais, pode ser atribuido à viabilização da expressão do potencial já existente da taxa de maturação através de melhores condições de manejo nutricional na fase de desenvolvimento, sem produzir efeito no peso assintótico.

Considerando, entretanto, a correlação positiva entre os pesos iniciais e o peso à maturidade, conforme aponta a literatura, ganhos genéticos nos pesos iniciais relacionam-se com ganhos também nos pesos à maturidade. Pelo observado neste estudo, porém, os ganhos nos pesos iniciais refletiram somente no aumento da taxa de maturação estimada nos anos, sem relação direta com o peso assintótico, o que contraria estudos de SMITH et al. (1976), MacNEIL et al. (1984), QUASS (1985), DeNISE \& BRINKS (1985), DUARTE (1975) e ROSA et al. (1979).

\subsubsection{Efeitos das estações de nascimento e de parto sobre o peso assintótico e a taxa de maturação}

Os efeitos das estações do ano de nascimento e de parto sobre o peso assintótico foram importantes somente no primeiro parto (Quadro XII), que conforme já visto tem suas estimativas mais influenciadas pelos pesos iniciais. Por estes resultados pode-se deduzir que após o segundo parto as variações estacionais que sintetizam principalmente a disponibilidade de forragens próximas ao nascimento e ao parto não afetam a estimativa do peso assintótico.

Nas análises da taxa de maturação (Quadro XIII), o efeito da estação do 
ano de nascimento não foi identificado, indicando que, em termos gerais, as variações sazonais ocorridas principalmente na fase de desenvolvimnto não interferem nas estimativas da taxa de maturação. Já a estação do ano de parto teve efeito significativo nos dois primeiros partos, indicando que até estes partos os pesos próximos a ele interferem na estimativa da taxa de maturação, o que não acontece nos partos seguintes.

Estes resultados evidenciam que a maior participação de pesos próximos ou posteriores ao parto, com o avanço dos partos, reduz a importância dos efeitos estacionais pelos quais passam as vacas, sobre a estimativa dos parâmetros da curva de Brody.

\subsubsection{Efeitos do touro sobre o peso assintótico e a taxa de maturação}

Para o peso assintótico, o efeito de touro foi significativo nos três últimos partos, $(\mathrm{P}<0,001 ; \mathrm{P}<0,01 ; \mathrm{P}<0,001 \%)$, o que sugere a existencia de potencial para transmissão dessa característica geneticamente. O Quadro XVI sintetiza os resultados das médias do peso assintótico ajustadas para touro no segundo parto, mostrando diferenças entre os touros.

QUADRO XVI: Distribuição de touros conforme as médias ajustadas dos pesos assintóticos de suas filhas no $2^{\circ}, 3^{\circ}$ e $4^{\circ}$ partos.

\begin{tabular}{lcccccccccc}
\hline $\begin{array}{c}\text { média ajustada do } \\
\text { peso assintótico } \\
\text { das filhas }\end{array}$ & $\begin{array}{c}-\mathrm{a} \\
435\end{array}$ & $436 \mathrm{a}$ & $451 \mathrm{a}$ & $466 \mathrm{a}$ & $481 \mathrm{a}$ & $496 \mathrm{a}$ & $511 \mathrm{a}$ & $526 \mathrm{a}$ & $541 \mathrm{a}$ & $556 \mathrm{~kg}$ \\
\hline $\begin{array}{c}\text { número de touros } \\
\text { no } 2^{\circ} \text { parto }\end{array}$ & - & - & 2 & & 5 & 8 & 9 & 7 & 4 & 2 \\
$\begin{array}{c}\text { número de touros } \\
\text { no } 3^{\circ} \text { parto }\end{array}$ & 3 & 3 & 7 & 5 & 9 & 3 & 9 & - & - & - \\
$\begin{array}{c}\text { número de touros } \\
\text { no } 4^{\circ} \text { parto }\end{array}$ & 2 & 5 & 5 & 3 & 2 & 10 & 3 & 3 & 1 & 1 \\
\hline
\end{tabular}

O efeito de touro sobre a taxa de maturação foi identificado somente no segundo parto. O Quadro XVII apresenta a distribuição dos touros pelas médias ajustadas das taxas de maturação de suas filhas. 
QUADRO XVII: Distribuição de touros conforme as médias ajustadas das taxas de maturação de suas filhas no $2^{\circ}$ parto.

\begin{tabular}{ccccccccccccc}
\hline $\begin{array}{c}\text { média ajustada das } \\
\text { taxas de maturação } \\
\text { das filhas }\end{array}$ & - & 0,038 & 0,040 & a & a & 0,046 & a & a & a & \\
& 0,036 & & & 0,042 & 0,044 & & 0,048 & 0,050 & 0,052 & \\
\hline $\begin{array}{c}\text { número de touros } \\
\text { no 2 }{ }^{\circ} \text { parto }\end{array}$ & 1 & 6 & 8 & 9 & 4 & 2 & - & 4 & 3 & 2 \\
\hline
\end{tabular}

Estes resultados sugerem que o peso assintótico apresenta potencial para seleção genética, enquanto que a taxa de maturação é aparentemente mais influenciada por características de ambiente.

\subsection{Fatores que interferem na idade ao parto}

É frequente em nosso meio, principalmente com animais criados em pastagens, ocorrer que o desenvolvimento do animal seja o principal indicador do momento em que as novilhas devam ser expostas ao touro. Entretanto, a idade do primeiro parto tem sido utilizada com frequência como indicador de precocidade das fêmeas devido ao seu desenvolvimento corporal e amadurecimento reprodutivo.

Os valores médios não corrigidos para idade ao parto foram 40,62 meses; 58,93 meses; 75,81 meses e 91,57 meses, respectivamente para $1^{\circ}, 2^{\circ}, 3^{\circ}$ e $4^{\circ}$ partos. Observando o resumo dos dados encontrados na literatura consultada (Quadro VI) quanto ao primeiro parto, pode-se notar que a média observada neste trabalho foi menor que as médias de trabalhos publicados e coincide com o valor citado por BARBOSA (1991) como médio para zebuínos em regiões tropicais.

Comparado aos resultados de BALIEIRO (1976) e SALVO (1986), referentes ao mesmo rebanho, a idade ao primeiro parto encontrada no presente trabalho foi superior. Ambos relatam redução da idade nos períodos estudados, períodos estes menores que o deste estudo onde considerou-se os partos dos anos de 1960 a 1991.

O Quadro XVIII apresenta as análises de variância da idade ao parto para os quatro partos. No Quadro IIA (Apêndice) é apresentada a análise de variância desconsiderando o intervalo entre partos como covariável, onde podem ser comparados os 
quatro partos quando submetidos ao modelo utilizado para o primeiro parto, que não tem o fator intervalo entre partos. Observando os dois quadros, pode-se verificar que o uso de modelos distintos não comprometeu os resultados das análises.

QUADRO XVIII: Análises de variância da idade ao parto, por parto.

\begin{tabular}{|c|c|c|c|c|c|c|c|c|}
\hline \multirow{2}{*}{$\begin{array}{l}\text { fonte de } \\
\text { variação }\end{array}$} & \multicolumn{4}{|c|}{ graus de liberdade } & \multicolumn{4}{|c|}{$\begin{array}{c}\text { valor de F / valor de outras } \\
\text { estatísticas }\end{array}$} \\
\hline & $1^{\circ}$ parto & $2^{\circ}$ parto & $3^{\circ}$ parto & $4^{\circ}$ parto & $1^{\circ}$ parto & $2^{\circ}$ parto & $3^{\circ}$ parto & $4^{\circ}$ parto \\
\hline ano de parto & 26 & 26 & 25 & 25 & $\begin{array}{l}5,41 \\
* * *\end{array}$ & $\begin{array}{l}3,22 \\
* * *\end{array}$ & $\begin{array}{l}2,84 \\
* * *\end{array}$ & $\begin{array}{l}2,78 \\
* * *\end{array}$ \\
\hline estação do ano de nasc/o & 3 & 3 & 3 & 3 & 1,64 & 1,04 & 2,26 & 1,12 \\
\hline estação de ano de parto & 3 & 3 & 3 & 3 & $\begin{array}{c}2,96 \\
*\end{array}$ & 0,41 & 1,08 & 1,53 \\
\hline touro & 35 & 38 & 38 & 34 & $\begin{array}{c}2,80 \\
* * *\end{array}$ & $\begin{array}{l}3,24 \\
* * *\end{array}$ & $\begin{array}{c}1,89 \\
* *\end{array}$ & $\begin{array}{c}1,79 \\
* *\end{array}$ \\
\hline intervalo entre partos & - & 1 & 1 & 1 & - & $\begin{array}{c}248,18 \\
* * *\end{array}$ & $\begin{array}{c}138,72 \\
* * *\end{array}$ & $\begin{array}{c}73,34 \\
* * *\end{array}$ \\
\hline peso assintótico & 1 & 1 & 1 & 1 & 0,01 & 3,32 & $\begin{array}{c}15,72 \\
* * *\end{array}$ & 2,20 \\
\hline taxa de maturação & 1 & 1 & 1 & 1 & $\begin{array}{c}50,50 \\
* * *\end{array}$ & $\begin{array}{c}20,38 \\
* * *\end{array}$ & $\begin{array}{c}26,66 \\
* * *\end{array}$ & $\begin{array}{c}37,69 \\
* * *\end{array}$ \\
\hline coeficiente de determinação & - & - & - & - & 0,80 & 0,83 & 0,78 & 0,76 \\
\hline $\begin{array}{l}\text { coeficiente de variação } \\
\text { quadrado médio do residuo }\end{array}$ & 376 & 298 & - & 197 & $\begin{array}{c}9,65 \% \\
15,36\end{array}$ & $\begin{array}{c}7,14 \% \\
17,75\end{array}$ & $\begin{array}{c}7,35 \% \\
31,12\end{array}$ & $\begin{array}{c}7,47 \% \\
46,85\end{array}$ \\
\hline
\end{tabular}

\subsubsection{Efeitos do ano de parto sobre a idade ao parto}

O ano de parto apareceu como importante fonte de variação para todas as idades ao parto, vindo ao encontro das indicações da literatura. Pode-se deduzir que o conjunto de fatores caracterizados no ano de parto, como disponibilidade de forragens durante o ciclo reprodutivo anterior e eventuais mudanças de manejo do rebanho, tem efeito perceptível sobre a idade na qual as vacas apresentam parto. Cabe a confirmação das indicações de BALIEIRO (1976) e SALVO (1986), de que a idade ao parto vem sendo reduzida com o passar dos anos, observando-se entretanto um atraso nessa redução com a evolução dos partos devido ao efeito retardado de uma possível seleção nos primeiros partos.

O Quadro XLX, que apresenta as médias de idades ao parto corrigidas para os anos de parto analisados neste estudo. 
QUADRO XIX: Idades ao parto médias, em meses, ajustadas para os anos de parto, por parto.

\begin{tabular}{ccccc}
\hline ano de parto & $1^{\circ}$ parto & $2^{\circ}$ parto & $3^{\circ}$ parto & $4^{\circ}$ parto \\
\hline 1960 & 44,0 & 59,5 & - & - \\
1961 & 49,5 & 58,8 & 64,0 & - \\
1962 & 44,5 & 64,7 & 73,4 & 73,6 \\
1963 & 46,2 & 64,1 & 83,1 & 96,5 \\
1964 & 50,7 & 62,6 & 79,2 & 84,9 \\
1965 & 56,2 & 63,4 & 78,7 & 94,1 \\
1966 & 65,3 & 68,3 & 77,7 & 98,2 \\
1967 & - & 74,9 & 83,2 & 90,9 \\
1968 & - & - & 90,9 & 96,5 \\
1972 & 38,4 & - & - & 102,8 \\
1973 & 34,3 & 58,7 & - & 110,1 \\
1974 & 34,4 & 54,5 & 70,4 & - \\
1975 & 36,6 & 53,4 & 69,4 & 80,1 \\
1976 & 37,4 & 56,8 & 67,9 & 80,7 \\
1977 & 37,3 & 57,3 & 64,9 & 78,6 \\
1978 & 40,8 & 57,4 & 71,9 & 80,6 \\
1979 & 36,6 & 59,0 & 72,1 & 85,2 \\
1980 & 34,5 & 56,9 & 73,2 & 87,5 \\
1981 & 39,2 & 56,1 & 73,2 & 86,0 \\
1982 & 36,7 & 56,1 & 70,5 & 86,3 \\
1983 & 37,9 & 55,5 & 72,2 & 85,8 \\
1984 & 35,7 & 55,3 & 70,4 & 88,8 \\
1985 & 37,3 & 59,7 & 70,1 & 87,2 \\
1986 & 37,5 & 55,7 & 75,9 & 88,4 \\
1987 & 36,9 & 57,8 & 71,5 & 91,5 \\
1988 & 37,8 & 57,8 & 73,3 & 91,3 \\
1989 & 38,8 & 55,9 & 75,4 & 93,9 \\
1990 & 36,7 & 57,5 & 73,1 & 95,1 \\
1991 & 37,9 & 56,0 & 72,6 & 95,1 \\
\hline
\end{tabular}

\subsubsection{Efeitos das estações do ano de nascimento e de parto sobre a idade ao parto}

Já as estações do ano de nascimento de parto não podem ser consideradas como importantes para a idade ao parto, exceto no primeiro grupo, onde se pode supor que as condições ambientais próximas ao parto (no período de cobertura) atuam sobre a primeira concepção e, consequentemente, na idade do primeiro parto. Este resultado confirma o trabalho de BALIEIRO (1976), que estudou a idade ao primeiro parto. O Quadro XX apresenta as médias ajustadas das estações de nascimento para o primeiro parto, indicando que os partos acontecem mais precocemente nas novilhas cobertas no início da estação seca, ou seja, entre abril e junho, as quais parem de janeiro a março. Isto 
se explica por estarem as novilhas bem nutridas em função das águas terem sido a estação anterior à exposição à cobertura.

QUADRO XX: $\quad$ Média ajustada da idade ao primeiro parto, conforme a estação do ano de parto

\begin{tabular}{cccc}
\hline $\begin{array}{c}\text { início das águas } \\
\text { outubro a dezembro }\end{array}$ & $\begin{array}{c}\text { final das águas } \\
\text { janeiro a março }\end{array}$ & $\begin{array}{c}\text { inicio da seca } \\
\text { abril a junho }\end{array}$ & $\begin{array}{c}\text { final da seca } \\
\text { julho a setembro }\end{array}$ \\
\hline 41,32 meses & 39,32 meses & 41,33 meses & 40,85 meses \\
\hline
\end{tabular}

\subsubsection{Efeitos do touro sobre a idade ao parto}

A influência do touro ficou evidenciada em todos os partos. Este fato pode ser justificado pela herdabilidade média de 0,39 para esta característica em zebuínos (Quadro VI). BALIEIRO (1976) estimou herdabilidade de 0,20 para Guzerá, evidenciando a possibilidade dos touros estarem contribuindo diferentemente com os potenciais das filhas para a expressão desta característica neste rebanho e sugerindo a possibilidade da idade ao parto ser melhorada geneticamente nestes animais.

Os Quadros XXI, XXII, XXIII e XXIV apresentam a distribuição dos touros pelas médias ajustadas das idades ao parto de suas filhas para $01^{\circ}, 2^{\circ}, 3^{\circ}$ e $4^{\circ}$ parto respectivamente.

QUADRO XXI: Distribuição de touros conforme as médias ajustadas das idades ao parto de suas filhas, no $1^{\circ}$ parto.

\begin{tabular}{cccccccccc}
\hline média ajustada da & & 32,1 & 34,1 & 36,1 & 38,1 & 40,1 & 42,1 & 44,1 & 46,1 \\
idade ao parto & - & $\mathrm{a}$ & $\mathrm{a}$ & $\mathrm{a}$ & $\mathrm{a}$ & $\mathrm{a}$ & $\mathrm{a}$ & $\mathrm{a}$ & + \\
das filhas (meses) & 32 & 34 & 36 & 38 & 40 & 42 & 44 & 46 & \\
\hline $\begin{array}{c}\text { número de touros } \\
\text { no } 1^{\circ} \text { parto }\end{array}$ & 1 & 2 & 1 & 2 & 6 & 12 & 8 & 2 & 2 \\
\hline
\end{tabular}


QUADRO XXII: Distribuição de touros conforme as médias ajustadas das idades ao parto de suas filhas, no $2^{\circ}$ parto.

\begin{tabular}{cccccccccc}
\hline média ajustada da & & 52,1 & 54,1 & 56,1 & 58,1 & 60,1 & 62,1 & 64,1 & 66,1 \\
idade ao parto & - & $\mathrm{a}$ & $\mathrm{a}$ & $\mathrm{a}$ & $\mathrm{a}$ & $\mathrm{a}$ & $\mathrm{a}$ & $\mathrm{a}$ & + \\
das filhas (meses) & 52 & 54 & 56 & 58 & 60 & 62 & 64 & 66 & \\
\hline $\begin{array}{c}\text { número de touros } \\
\text { no } 2^{\circ} \text { parto }\end{array}$ & - & 2 & 5 & 5 & 16 & 7 & 1 & 2 & 1 \\
\hline
\end{tabular}

QUADRO XXIII: Distribuição de touros conforme as médias ajustadas das idades ao parto de suas filhas, no $3^{\circ}$ parto.

\begin{tabular}{cccccccccc}
\hline média ajustada da & & 66,1 & 68,1 & 70,1 & 72,1 & 74,1 & 76,1 & 78,1 & 80,1 \\
idade ao parto & - & $\mathrm{a}$ & $\mathrm{a}$ & $\mathrm{a}$ & $\mathrm{a}$ & $\mathrm{a}$ & $\mathrm{a}$ & $\mathrm{a}$ & + \\
das filhas (meses) & 66 & 68 & 70 & 72 & 74 & 76 & 78 & 80 & \\
\hline $\begin{array}{c}\text { número de touros } \\
\text { no } 3^{\circ} \text { parto }\end{array}$ & - & 2 & 5 & 5 & 11 & 6 & 5 & 3 & 2 \\
\hline
\end{tabular}

QUADRO XXIV: Distribuição de touros conforme as médias ajustadas das idades ao parto de suas filhas, no $4^{\circ}$ parto.

\begin{tabular}{cccccccccc}
\hline média ajustada da & & 82,1 & 84,1 & 86,1 & 88,1 & 90,1 & 92,1 & 94,1 & 96,1 \\
idade ao parto & - & $\mathrm{a}$ & $\mathrm{a}$ & $\mathrm{a}$ & $\mathrm{a}$ & $\mathrm{a}$ & $\mathrm{a}$ & $\mathrm{a}$ & + \\
das filhas (meses) & 80 & 84 & 86 & 88 & 90 & 92 & 94 & 96 & \\
\hline $\begin{array}{c}\text { número de touros } \\
\text { no } 4^{\circ} \text { parto }\end{array}$ & 3 & 2 & 7 & 4 & 2 & 5 & 6 & 3 & 3 \\
\hline
\end{tabular}

\subsubsection{Efeitos do intervalo entre partos sobre a idade ao parto}

Pelos resultados da análise de variância, é correto concluir que o intervalo entre partos é uma covariável da idade do parto, nos quatro primeiros partos. Os coeficientes de regressão parcial estimados neste estudo são apresentados no Quadro XXV. 
QUADRO XXV: Coeficientes de regressão linear entre o intervalo entre partos e a idade ao parto, por parto.

\begin{tabular}{lccc}
\hline & $2^{\circ}$ parto & $3{ }^{\circ}$ parto & $4^{\circ}$ parto \\
\hline $\begin{array}{l}\text { coeficiente de regressão do } \\
\text { intervalo entre partos } \\
\text { sobre a idade ao parto }\end{array}$ & 0,911 & 0,926 & 0,963 \\
& $* * *$ & $* * *$ & $* * *$ \\
\hline${ }^{* * *},{ }^{* * *}$ estatisticamente significativo ao nível de $\mathrm{P}<0,05 ; 0,01 \mathrm{e} 0,001$, respectivamente
\end{tabular}

Esses resultados indicam que as características estão diretamente relacionadas e exemplificando, indicam que com aumento de 1 mês no intervalo entre o primeiro e o segundo partos pode-se esperar o aumento de 0,911 meses na idade ao segundo parto.

A Figura 10 ilustra a relação entre a idade ao parto e o intervalo entre partos na qual, graficamente pode-se observar a relação positiva e, de certa forma, esperada entre estas características já que, maiores intervalos retardam a idade do parto seguinte ou, de outra forma, atrasos da fecundação e, consequentemente, dos partos e da idade em que este ocorre, produzem intervalos maiores entre os partos próximos.

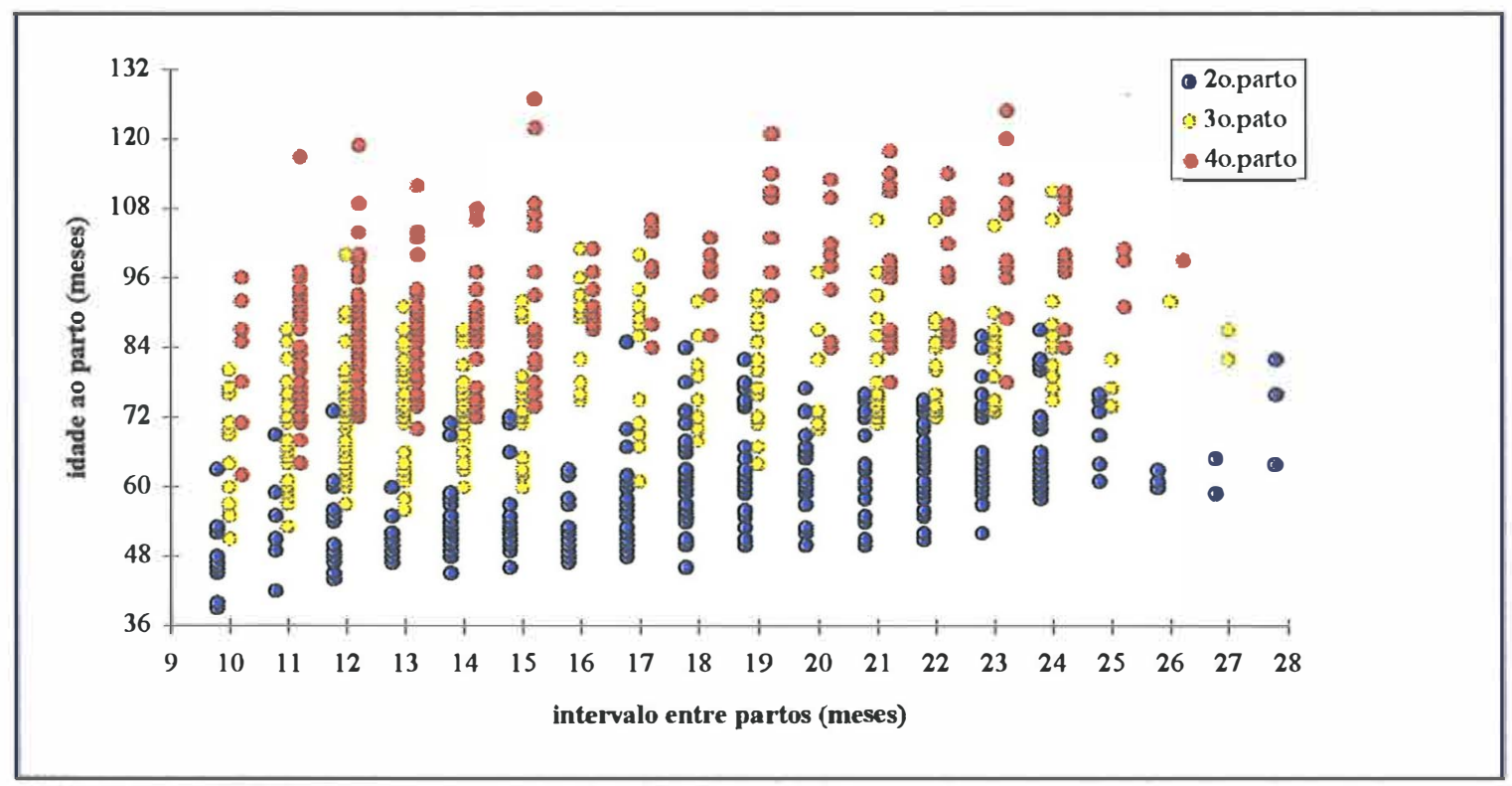

FIGURA 10: Idade ao parto em função do intervalo entre partos, por parto.

partos.

Cabe destacar ainda a semelhança da relação das variáveis em todos os 


\subsubsection{Efeitos do peso assintótico sobre a idade ao parto}

O peso assintótico aparece com importância para a idade ao parto somente no terceiro parto. Cabe aqui considerar as diferenças encontradas nas duas análises, onde a inclusão da covariável intervalo entre partos absorveu grande parte da variabilidade do conjunto, tornando a análise insensível à importância do peso assintótico no $2^{\circ}$ e $4^{\circ}$ partos (Quadro IIA). Observando-se os gráficos que ilustram as relações entre peso assintótico e a idade ao parto, apresentados a seguir (Figura 11), é possível notar que as variações do peso assintótico não estão acompanhadas, de forma significativa pela idade ao parto, sendo a relação percebida somente pelo modelo que considerava a covariável intervalo entre partos. O coeficiente de regressão linear estimado para o terceiro parto foi de $-0,038$, estimando que o aumento de um quilo no peso assintótico implica na redução de 0,038 meses $(1,14$ dias) na idade ao terceiro parto.

Apesar de não significativos na análise considerada, os coeficientes de regressão parcial nos quatro partos são apresentados no Quadro XXVI, onde é possível verificar a existência de relação positiva somente no primeiro parto.

QUADRO XXVI: Coeficientes de regressão linear entre a idade ao parto e o peso assintóico, por parto.

\begin{tabular}{lcccc}
\hline & $1{ }^{\circ}$ parto & $2{ }^{\circ}$ parto & $3{ }^{\circ}$ parto & $4{ }^{\circ}$ parto \\
\hline $\begin{array}{c}\text { coeficiente de regressão } \\
\text { do peso assintótico } \\
\text { sobre a idade ao parto }\end{array}$ & 0,0006 & $-0,0108$ & $-0,0379$ & $-0,0191$ \\
\hline
\end{tabular}

*,**, *** estatisticamente significativo ao nível de $\mathrm{P}<0,05 ; 0,01$ e 0,001 , respectivamente

As relações negativas nos três úlimos partos indicam a tendência de vacas maiores terem partos mais precocemente, indo ao encontro das correlações negativas entre os pesos em diversas idades e a idade ao parto (Quadro VII).

A idades ao parto, em função do peso assintótico são apresentadas na Figura 11.

Cabe aqui destacar a tendência de paralelismo que pode ser observada entre os quatro partos quanto ao efeito do peso assintótico nas idades ao parto, sugerindo comportamento semelhante dessa variável nos partos, apesar de as análises terem sido realizadas em diferentes grupos de pesos. 


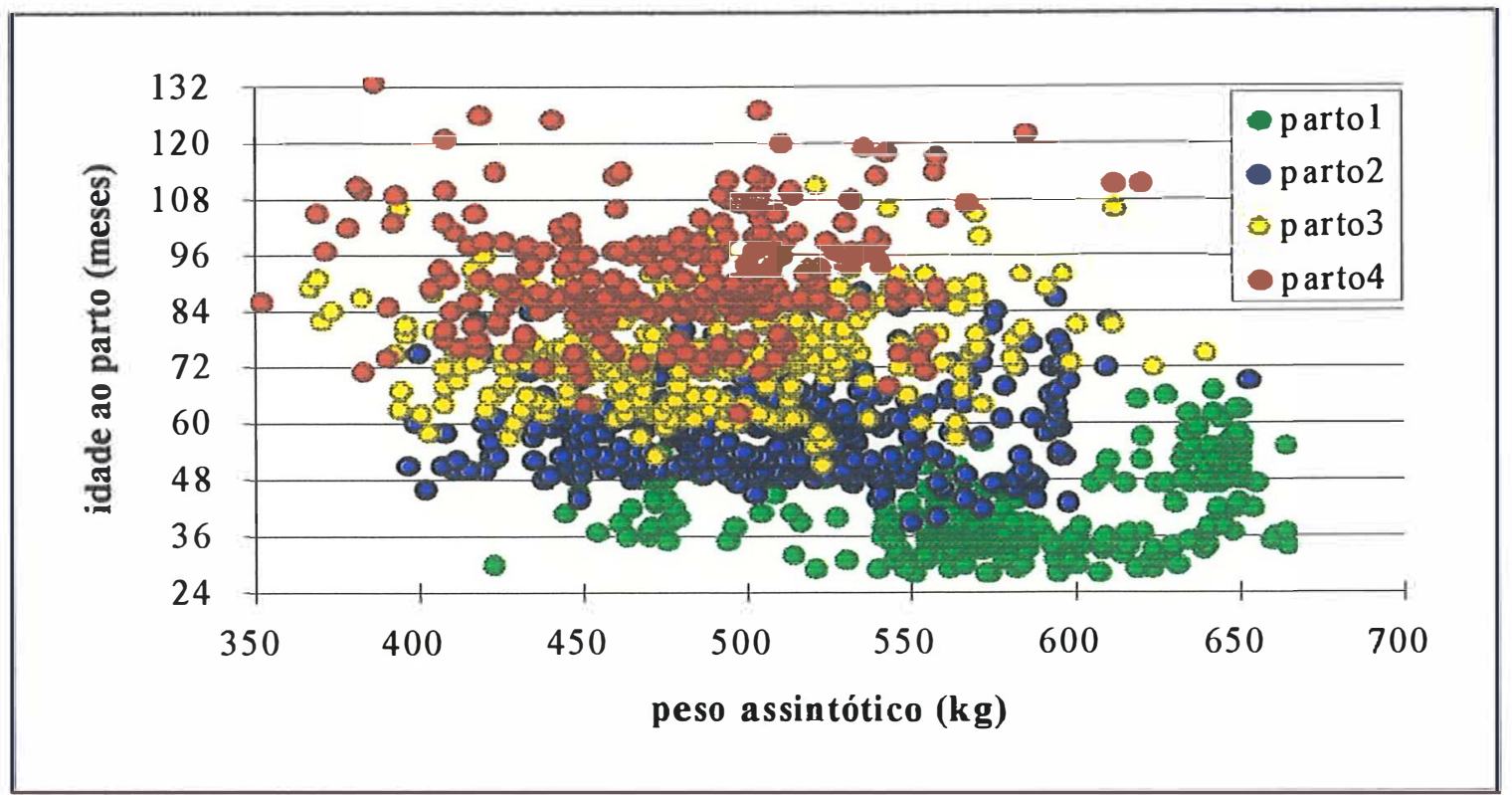

FIGURA 11: Idade ao parto em função do peso assintótico, por parto.

\subsubsection{Efeitos da taxa de maturação sobre a idade ao parto}

Já a taxa de maturação aparece como uma importante fonte de variação para a idade ao parto, verificada nos quatro partos. O Quadro XXVII apresenta os coeficientes parciais de regressão linear encontradas entre a taxa de maturação e a idade ao parto.

QUADRO XXVII: Coeficientes de regressão linear da taxa de maturação e a idade ao parto, por parto.

\begin{tabular}{cccc}
\hline $1^{\circ}$ parto & $2^{\circ}$ parto & $3^{\circ}$ parto & $4^{\circ}$ parto \\
\hline$-321,565$ & $-164,387$ & $-243,296$ & $-371,233$ \\
$* * *$ & $* * *$ & $* * *$ & $* * *$ \\
\hline
\end{tabular}

${ }^{*},{ }^{* *},{ }^{* * *}$ estatisticamente significativo ao nível de $\mathrm{P}<0,05 ; 0,01 \mathrm{e} 0,001$, respectivamente

Destes dados pode-se, por exemplo, inferir que no terceiro parto, um aumento de um 0,001 unidade na taxa de maturação reduza em 0,243 meses (7,29 dias) a idade ao parto, indo este resultado ao encontro do esperado, de que fêmeas com maior potencial de velocidade para atingir o seu peso assintótico tenham partos mais precocemente. Também a Figura 12 ilustra a idade ao parto em função da taxa de maturação observada para as vacas analisadas. 


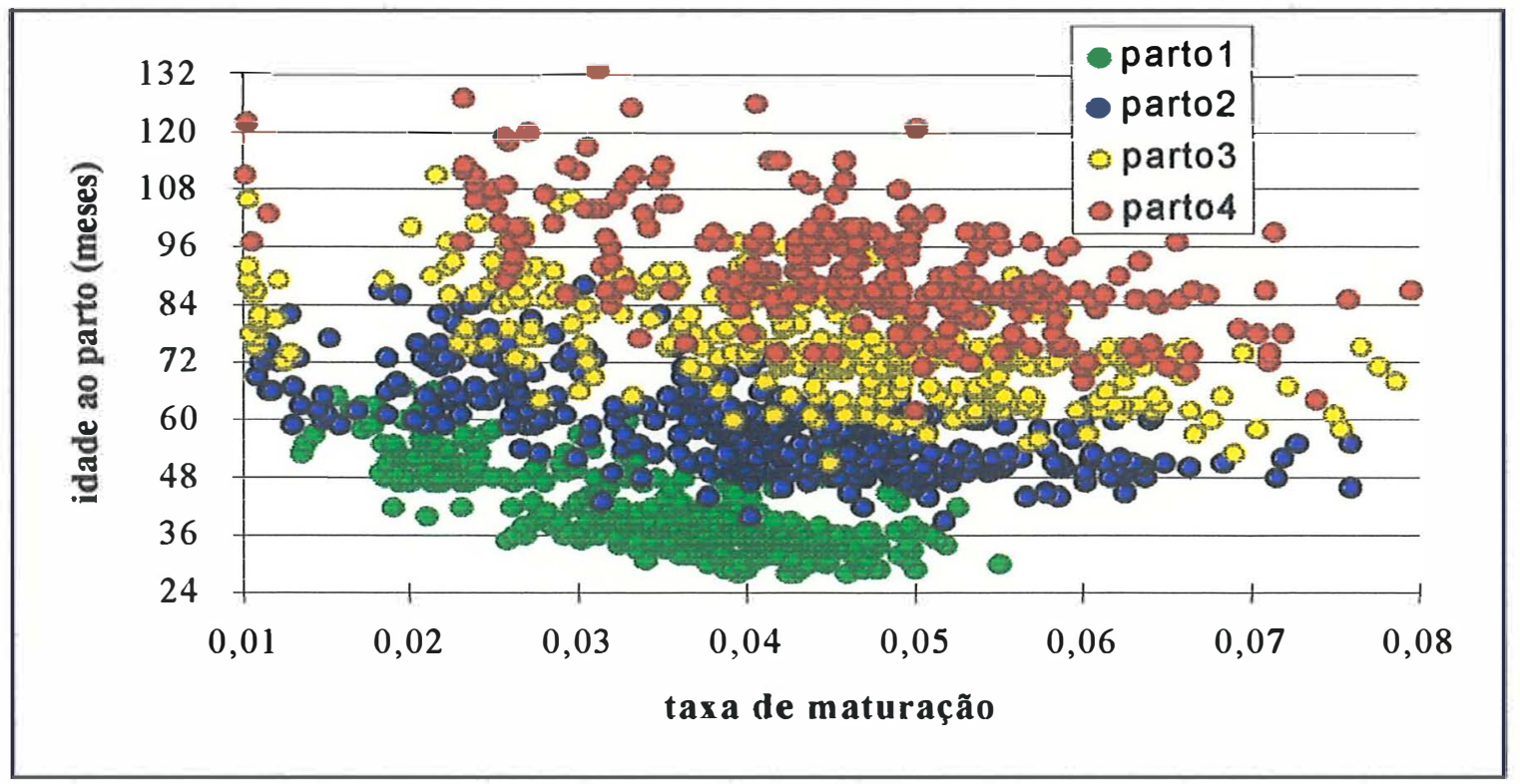

FIGURA 12: Idade ao parto em função da taxa de maturação, por parto.

Novamente é possível notar na Figura 12 uma tendência de paralelismo nas relações entre a taxa de maturação e o intervalo entre partos nos quatro partos, indicando a influencia semelhante desta variável nos quatro conjuntos de dados.

\subsection{Fatores que interferem no intervalo entre partos}

A média não ajustada dos intervalos entre partos foi de 18,33 meses para o primeiro intervalo (entre o primeiro e o segundo partos), 16,09 meses para o segundo e 15,66 meses para o terceiro, confirmando a esperada tendência de redução do intervalo entre partos com a evolução dos partos, sendo estes resultados intermediários aos valores publicados (Quadro VI), superiores aos encontrados por BALIEIRO (1976) para o primeiro e terceiro intervalos e igual para o segundo, e também superiores aos de SALVO (1986) nos tres casos. Pode-se atribuir estas diferenças aos períodos estudados neste e naquele trabalho. Estes resultados são inferiores aos encontrados por CARNEIRO et al. (1958) e compatíveis com os de PIRES et al. (1967) e SILVA (1971).

A análise de variância para o intervalo entre partos em meses para os quatro partos é apresentada no Quadro XXVIII. 
QUADRO XXVIII: Análise de variância do intervalo entre partos em meses, por parto.

\begin{tabular}{|c|c|c|c|c|c|c|}
\hline \multirow{2}{*}{$\begin{array}{l}\text { fonte de } \\
\text { variação }\end{array}$} & \multicolumn{3}{|c|}{ graus de liberdade } & \multicolumn{3}{|c|}{ valor de F / valor de outras estatísticas } \\
\hline & $\begin{array}{c}2^{\circ} \text { parto } \\
1^{\circ} \text { intervalo }\end{array}$ & $\begin{array}{c}3^{\circ} \text { parto } \\
2^{\circ} \text { intervalo }\end{array}$ & $\begin{array}{c}4^{\circ} \text { parto } \\
3^{\circ} \text { intervalo }\end{array}$ & $\begin{array}{c}2^{\circ} \text { parto } \\
1^{\circ} \text { intervalo }\end{array}$ & $\begin{array}{c}3^{\circ} \text { parto } \\
2^{\circ} \text { intervalo }\end{array}$ & $\begin{array}{c}4^{\circ} \text { parto } \\
3^{\circ} \text { intervalo }\end{array}$ \\
\hline ano de parto & 26 & 25 & 25 & 1,41 & 1,48 & 0,80 \\
\hline estação do ano de nasc/o & 3 & 3 & 3 & 1,27 & 2,15 & 0,78 \\
\hline estação de ano de parto & 3 & 3 & 3 & $\begin{array}{c}3,83 \\
* *\end{array}$ & 0,59 & $\begin{array}{c}2,80 \\
*\end{array}$ \\
\hline touro & 38 & 38 & 34 & $\begin{array}{c}1,69 \\
* *\end{array}$ & 1,17 & 0,66 \\
\hline idade ao parto & 1 & 1 & 1 & $\begin{array}{c}248,18 \\
* * *\end{array}$ & $\begin{array}{c}138,72 \\
* * *\end{array}$ & $\begin{array}{c}73,54 \\
* * *\end{array}$ \\
\hline peso assintótico & 1 & 1 & 1 & $\begin{array}{c}3,86 \\
*\end{array}$ & 1,27 & 1,92 \\
\hline taxa de maturação & 1 & 1 & 1 & $\begin{array}{c}3,91 \\
*\end{array}$ & 2,26 & $\begin{array}{c}8,23 \\
* *\end{array}$ \\
\hline coeficiente de determinação & - & - & - & 0,63 & 0,56 & 0,51 \\
\hline coeficiente de variação & - & - & - & $17,0 \%$ & $22,61 \%$ & $23,65 \%$ \\
\hline quadrado médio do resíduo & 298 & 242 & 198 & 9,72 & 13,23 & 13,72 \\
\hline
\end{tabular}

${ }^{*},{ }^{* *},{ }^{* * *}$ estatisticamente significativo ao nível de $\mathrm{P}<0,05 ; 0,01 \mathrm{e} 0,001$, respectivamente

\subsubsection{Efeitos do ano de parto e estações de nascimento e de parto sobre o intervalo entre parto}

O ano de parto e estação do ano de nascimento não foram significativas fontes de variação em nenhum dos partos. A estação do ano de parto é significativa no segundo e quarto partos, mas não no terceiro.

A sazonalidade da oferta de forragens teve papel importante no primeiro intervalo entre partos. Sendo este um período em que, concluida a gestação, a vaca precisa suprir as exigências da lactação e também as exigências para finalizar o seu crescimento. $\mathrm{O}$ não atendimento à essas exigências compromete sua fertilidade, provocando o alargamento do primeiro intervalo entre partos que, segundo citado na literatura é maior que os intervalos subsequentes. Este resultado confirma a maior suscetibilidade das vacas primíparas à disponibilidade de alimentos na fase próxima ao parto.

O Quadro XXIX traz as médias ajustadas dos intervalos entre partos, para estações do ano de parto. 
QUADRO XXIX: Médias ajustadas do intervalo entre partos, conforme a estação do ano, por parto

\begin{tabular}{ccccc}
\hline & $\begin{array}{c}\text { início das águas } \\
\text { outubro a dezembro }\end{array}$ & $\begin{array}{c}\text { final das águas } \\
\text { janeiro a março }\end{array}$ & $\begin{array}{c}\text { inicio da seca } \\
\text { abril a junho }\end{array}$ & $\begin{array}{c}\text { inal da seca } \\
\text { julho a setembro }\end{array}$ \\
\hline $2^{\circ}$ parto $/ 1^{\circ}$ interv. & 16,82 meses & 16,80 meses & 18,85 meses & 17,88 meses \\
$4^{\circ}$ parto $/ 3^{\circ}$ interv. & 14,37 meses & 16,54 meses & 16,66 meses & 14,72 meses \\
\hline
\end{tabular}

Por estes resultados pode-se deduzir que as vacas que parem no início das águas conseguem suprir melhor as exigências da lactação e mantêm-se em condições de conceber mais precocemente, encurtando o intervalo entre partos. De modo contrário, as vacas paridas no início da seca amamentam em fase de déficit nutricional e com isto retardam o aparecimento de cio e, consequentemente, de concepção, alargando assim o intervalo entre partos.

\subsubsection{Efeitos do touro sobre o intervalo entre partos}

O efeito de touro aparece com importância significativa, somente no segundo parto ( $1^{\circ}$ intervalo), indicando que os mesmos transmitem potenciais diferenciados para o intervalo entre o primeiro e o segundo partos. O Quadro XXX traz a distribuição dos touros pelas médias ajustadas dos intervalos entre partos de suas filhas.

QUADRO XXX: Distribuição de touros conforme as médias ajustadas dos intervalos entre partos de suas filhas, no $1^{\circ}$ intervalo (entre $01^{\circ}$ e $2^{\circ}$ partos).

\begin{tabular}{cccccccccc}
\hline média ajustada da & & 13,1 & 14,1 & 15,1 & 16,1 & 17,1 & 18,1 & 19,1 & 20,1 \\
interv. entre partos & - & $\mathrm{a}$ & $\mathrm{a}$ & $\mathrm{a}$ & $\mathrm{a}$ & $\mathrm{a}$ & $\mathrm{a}$ & $\mathrm{a}$ & + \\
das filhas (meses) & 13 & 14 & 15 & 16 & 17 & 18 & 19 & 20 & \\
\hline $\begin{array}{c}\text { número de touros } \\
\text { no } 1^{\circ} \text { intervalo }\end{array}$ & 2 & 1 & 1 & 2 & 5 & 12 & 12 & 1 & 3 \\
\hline
\end{tabular}

\subsubsection{Efeitos da idade ao parto sobre o intervalo entre partos}

Conforme esperado e discutido anteriormente, a idade ao parto apresentou efeito altamente significativo. Os coeficientes de regressão linear estão no Quadro XXXI. 
QUADRO XXXI: Coeficientes de regressão linear entre a idade ao parto e o intervalo entre partos, por parto.

\begin{tabular}{|c|c|c|c|}
\hline & $2^{\circ}$ parto & $3^{\circ}$ parto & $4^{\circ}$ parto \\
\hline $\begin{array}{l}\text { coeficiente de regressão da } \\
\text { idade ao parto } \\
\text { sobre o intervalo entre partos }\end{array}$ & $\begin{array}{c}0,499 \\
* * *\end{array}$ & $\begin{array}{c}0,393 \\
* * *\end{array}$ & $\begin{array}{c}0,282 \\
* * *\end{array}$ \\
\hline
\end{tabular}

Esta relação foi ilustrada na Figura 10. Estes dados permitem estimar que com o aumento de 1 mês na idade ao segundo parto espera-se o aumento de 0,499 meses $( \pm 15$ dias) no intervalo entre partos.

\subsubsection{Efeitos do peso assintótico sobre o intervalo entre partos}

O peso assintótico apresenta efeito significativo somente no primeiro dos intervalos, com coeficiente de regressão linear parcial de $-0,086$ indicando que com o aumento de 10 quilos no peso assintótico estimado no segundo parto, deve-se esperar redução no primeiro intervalo entre partos de 0,086 meses ( $\pm 2,6$ dias). Assim, verifica-se que vacas mais pesadas no segundo parto, que supostamente foram melhor atendidas em suas necessidades de término de crescimento e primeira lactação, conceberam mais precocemente, apresentando por isso menor intervalo entre partos. A Figura 13 ilustra a distribuição dos intervalos entre partos em função do peso assintótico.

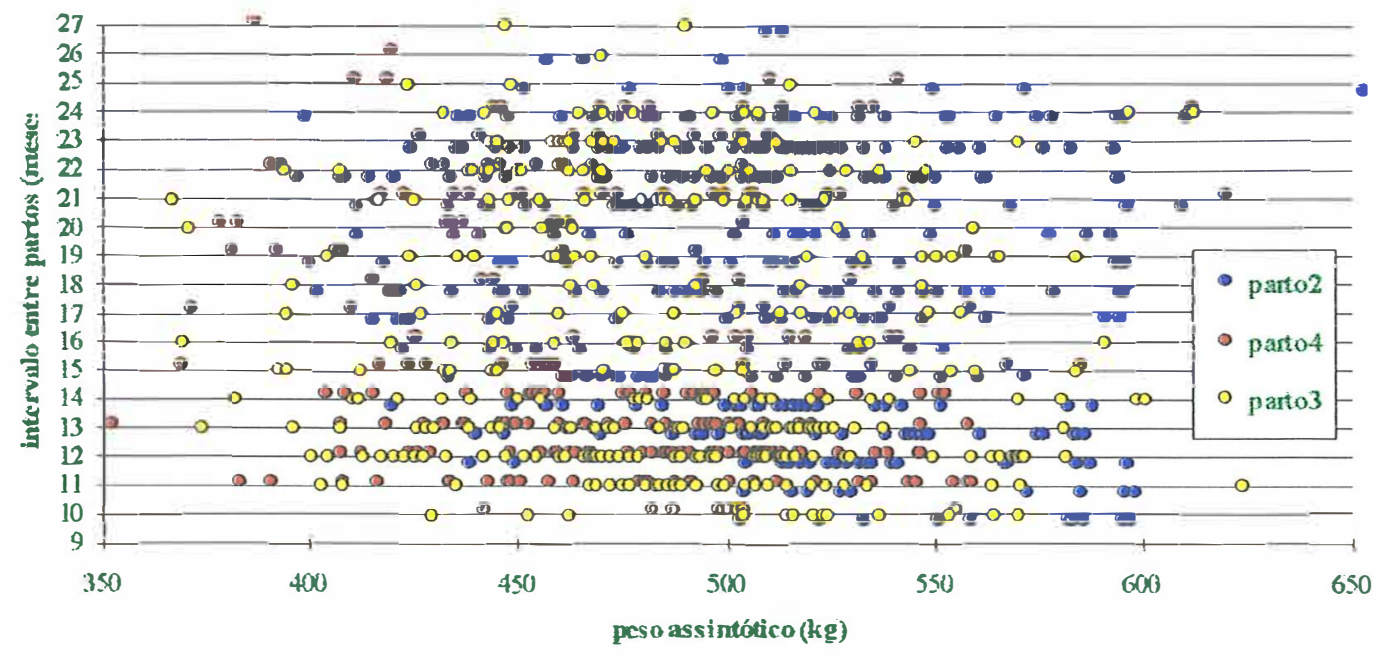

FIGURA 13: Intervalo entre partos em função do peso assintótico, por parto. 


\subsubsection{Efeitos da taxa de maturação sobre o intervalo entre partos}

Os intervalos entre partos como função da taxa de maturação são ilustradas na Figura 14.

A taxa de maturação é importante fonte de variação no primeiro e terceiro intervalos, apresentando coeficientes lineares de regressão parcial de 54,712 e 100,386, respectivamente, para o primeiro e terceiro intervalos. Estes coeficientes indicam que no primeiro intervalo, um aumento de 0,01 unidades na taxa de maturação estimada no segundo parto aumenta em 0,54 meses (16,2 dias) o intervalo entre o primeiro e o segundo partos.

Disto pode-se supor que vacas que crescem mais rapidamente para seu peso assintótico tendem a conceber mais precocemente e apresentar por isso maiores dificuldades para o atendimento às exigências decorrentes da reprodução, resultando em atraso na próxima concepção

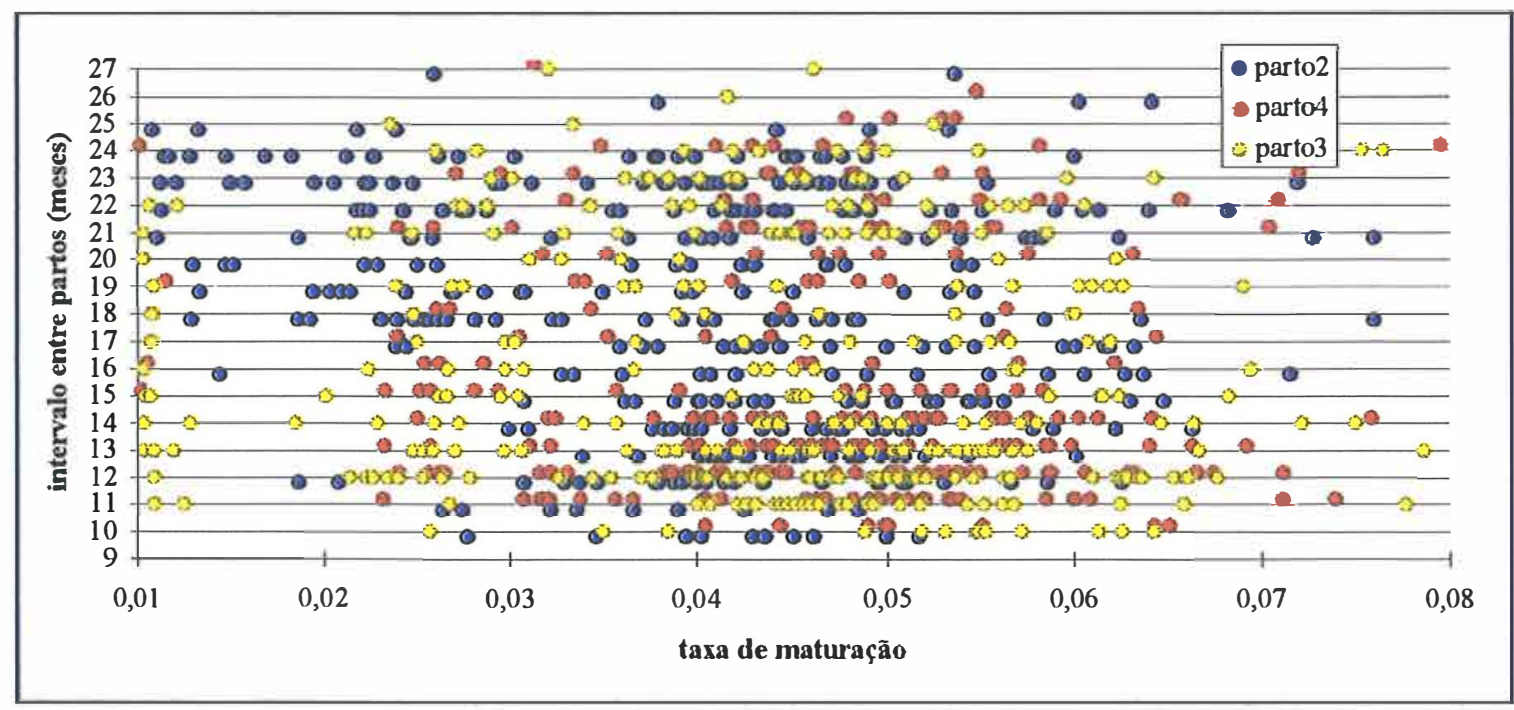

FIGURA 14: Intervalos entre partos em função da taxa de maturação, por parto.

Cabe a observação de que neste estudo a equação de Brody não se prestou para a previsão de pesos futuros mas permitiu análises consitentes sobre as relações entre os dos padrões de crescimento de vacas Guzerá e características reprodutivas dos quatro primeiros partos. 


\section{CONCLUSÕES}

A equação de Brody produz diferentes estimativas do peso assintótico e da taxa de maturação, para as quatro ordens de parto. As estimativas do peso assintótico são superiores à média dos pesos posteriores ao primeiro parto, sendo a dimensão da superestimativa inversamente proporcional à ordem dos partos. De forma inversa, as estimativas da taxa de maturação são diretamente proporcionais à ordem dos partos.

As análises gráficas evidenciaram uma tendência de paralelismo entre os quatro partos, entretanto, considerando as diferenças observadas nos parâmetros estudados é recomendável que nos estudos que utilizem a equação de Brody a ordem do parto, e mesmo a idade da última pesagem sejam consideradas como importantes fontes de variação. A equação de Brody mostrou-se inadequada aos propósitos preditivos de pesos futuros, em períodos externos aos considerados no ajuste.

$\mathrm{O}$ efeito de touro sobre o peso assintótico foi observado nas estimativas dos três últimos partos e sobre a idade ao parto nos quatro partos, permitindo inferir sobre a possibilidade do potencial para expressão desse parâmetro ser melhorado geneticamente.

Uma consistente relação negativa entre o taxa de maturação e a idade ao parto permite afirmar que vacas que atingem mais rapidamente seu peso adulto apresentam os quatro primeiros partos mais precocemente que as de crescimento lento.

O efeito da estação do ano de nascimento não foi significativo para a taxa de maturação e para o peso assintótico apresentou significância somente no terceiro parto, permitindo concluir que os efeitos sazonais por que passaram as vacas, próximos principalmente ao nascimento, em geral, não interferem nas características das curvas de crescimento os quatro primeiros partos. Tampouco a estação do ano de nascimento teve qualquer influência significativa sobre as duas características reprodutivas. 


\section{REFERÊNCIAS BIBLIOGRÁFICAS}

ABASSA, K.P. Analysis of growth curve parameters of Gobra Zebu females in Senegal. Tropic Animal Health \& Production, 19: 2238, 1987.

ALENCAR, M.M. \& BARBOSA, P.F. Fertilidade de um rebanho Canchim criado em regime exclusivo de pasto. Revista da Sociedade Brasileira de Zootecnia, Viçosa, 10(1): 88-102, 1981.

ALENCAR, M.M.; BEOLCHI, E.A.; COSTA, J.L.; CUNHA, P.G. Herdabilidade da idade ao primeiro parto de vacas da raça Canchim. Pesquisa Agropecuária Brasileira, Brasília, 17: 1233-6, 1982.

ALENCAR, M.M.; BEOLCHI, E.A.; COSTA, J.L.; CUNHA, P.G. Intervalo entre partos de vacas Canchim. Pesquisa Agropecuária Brasileira, Brasília, 19: 237-41, 1984.

ALVES NETO, F.; DUARTE, F.A.M.; BEZERRA, L.A.F. Pesos médios em raças zebuínas no controle de desenvolvimento ponderal da Sociedade Rural Brasileira. A Rural, São Paulo, 566: 88-1 10, 1980.

ANDRADE, V.J. Efeitos do meio e herança sobre o peso de bezerros da raça Guzerá aos 205 dias de idade. Belo Horizonte, 1973. p.104 (Mestrado Faculdade de Veterinária/UFMG).

ANUALPEC 95. ANUÁRIO ESTATíSTICO dA PECUÁRIA DE CORTE, São Paulo, p.30, 1995.

AROEIRA, J.A.D.C. \& ROSA, A.N. Desempenho reprodutivo de um rebanho Nelore criado no Planalto Sul-Matogrossense. Pesquisa Agropecuária Brasileira, Brasília, 17: 337-706, 1982.

AZZAM, S.M \& NIELSEN, M.K. Genetic parameters for gestation legth, birth date and first breeding date in beef cattle. Journal of Animal Science, Albany, 64(2): 348-56, 1987.

BALIEIRO, E.S. Herança e meio como causas de variação de idade à primeira fecundação e do intervalo entre partos em vacas da raça Guzerá. Belo Horizonte, 1976. p.92 (Mestrado - Faculdade de Veterinária/UFMG). 
BARBOSA, P.F. Influência de fatores genéticos e de ambiente no peso ao parto de vacas da raça Canchim. In: REUNIÃO ANUAL DA SOCIEDADE BRASILEIRA DE ZOOTECNIA, 17., Campo Grande, 1986. Anais. Campo Grande, SBZ, 1986a. p.305.

BARBOSA, P.F. Causas de variação do peso de vacas Canchim à desmama do bezerro. In: REUNIÃO ANUAL DA SOCIEDADE BRASILEIRA DE ZOOTECNIA, 17., Campo Grande, 1986. Anais. Campo Grande, SBZ, 1986b. p.306.

BARBOSA, P.F. Análise genético-quantitativa de características de crescimento e reprodução em fêmeas da raça Canchim. Ribeirão Preto, 1991. 237p. (Doutorado - Faculdade de Medicina de Ribeirão Preto/USP).

BARBOSA, P.F.; PACKER, I.U.; SILVA, A.H.G. Causas de variação sobre o crescimento até os 30 meses de animais da raça canchim. In: REUNIÃO ANUAL DA SOCIEDADE BRASILEIRA DE ZOOTECNIA, 16., Curitiba, 1979. Anais. Curitiba, SBZ, 1979. p. 128.

BARBOSA, P.F.; SILVA, A.H.G.; PACKER, I.U. Causas de variação de pesos e ganhos de peso em fêmeas da raça canchim. In: REUNIÃO ANUAL DA SOCIEDADE BRASILEIRA DE ZOOTECNIA, 17., Fortaleza, 1980. Anais. Fortaleza, SBZ, 1980. p.167.

BELTRÁN J.J.; BUTTS, W.T.; OLSON, T.A.; KOGER, M. Growth patterns of two lines of Angus cattle selected using predicted growth parameters. Journal of Animal Science, Albany, 70: 734-41, 1992.

BEOLCHI, E.A. \& CUNHA, P.G. A idade por ocasião do primeiro parto, de novilhas cruzadas (5/8 Charolês-Zebu) e Canchim, em regime de criação extensiva. Boletim da Indústria Animal, Nova Odessa, 34:217-21, 1977.

BOURBON, R.M. \& BRINKS, J.S. Calving date versus calving interval as a reproductive measure in beef cattle. Journal of Animal Science, Albany, 57: $1412-7,1983$.

BRINKS, J.S.; CLARK, R.T.; KIEFFER, N.M.; QUESENBERRY, J.R. Mature weight in Hereford range cows - heritability, repeatibility and relationships to cow performance. Journal of Animal Science, Albany, 21(3): 501-4, 1962.

BRODY, S. Bioenergetics and growth; with special reference to the efficiency complex of domestic animals. New York, Hafner Press, 1945. 1023p.

BROWN, J.E.; BROWN, C.J.; BUTSS, W.T. A discussion of the genetic aspects of weight, mature weigth and rate of maturing in Hereford and Angus cattle. Journal of Animal Science, Albany, 34(4): 526-36, 1972a. 
BROWN, J.E.; BROWN, C.J.; BUTSS, W.T. Relationships among weights, gains and earliness of maturing Hereford and Angus females. Journal of Animal Science, Albany, 35(3): 507, 1972b.

BROWN, J.E.; FITZHUGH JUNIOR, H.A.; CARTWRIGHT, T.C. A comparison of nonlinear models for describing weight-age relations in cattle. Journal of Animal Science, Albany, 42(4): 810-8, 1976.

BUDDENBERG, B.J.; BROWN, C.J.; JOHNSON, Z.B.; DUNN, J.E.; PETERSON, H.P. Heritability estimates of pregnancy rate in beef cows under natural mating. Journal of Animal Science, Albany, 67: 2589-94, 1989.

BULLOCK, K.D.; BERTRAND, J.K.; BENYSHEK, L.L. Genetic and environmental parameters for mature weight and other growth measures in Polled Hereford cattle. Journal of Animal Science, Albany, 71: 1737-41, 1993.

CAMPOS, F.A.A. Alguns aspectos da eficiência reprodutiva no rebanho Nelore da Estação Experimental de Uberaba. Belo Horizonte, 1974. (Mestrado Faculdade de Veterinária/UFMG).

CARNEIRO, G.G.; BROWN, P.P.; MEMÓRIA, J.M.P. Aspectos da função reprodutiva do gado Zebú. Arq.Esc.Sup.Veterinária., Belo Horizonte, 11: 81-7, 1958.

CARPETER JUNIOR, J.A.; BROWN, J.E.; FITZHUGH JUNIOR, H.A.; Growth curve parameters and productifity of beef cows. In: ANNUAL MEETING OF THE AMERICAN SOCIETY OF ANIMAL SCIENCE, 63., 1971. Abstracts. Journal of Animal Science, Albany, 32(1): 374, 1971.

CARPERER JUNIOR, J.A.; FITZHUGH JUNIOR, H.A.; CARTWRIGHT, T.C.; THOMAS, R.C. Relationships between performance and mature size of beef cow. In: ANNUAL MEETING OF THE AMERICAN SOCIETY OF ANIMAL SCIENCE, 65., 1973. Abstracts. Journal of Animal Science, Albany, 37(1): $231,1973$.

CARPERER JUNIOR, J.A.; FITZHUGH JUNIOR, H.A.; CARTWRIGHT, T.C.; THOMAS, R.C.; MELON, A.A. Principal components for cow size and shape. Journal of Animal Science, Albany, 46: 370-5, 1978.

CARRIJO, S.M. Descrição e comparação de parâmetros de crescimento de animais das raças Chianina e Nelore. Ribeirão Preto, 1988. 116p. (Mestrado Faculdade de Medicina de Ribeirão Preto/USP).

CARTWRIGHT, T.C. Selection criteria for beef cattle for the future. Journal of Animal Science, Albany, 30: 706-11, 1970. 
COOK, R.D. \& WEISBERG, S. Residuals and influence in regression. New York, Chapman \& Hall, 1982. 230p.

CROAK-BROSSAMAN, S.T.; MARTIN, T.C.; NELSON, L.A. Lifetime productivity of purebred and crossbred cows of Angus and milking Shorthorn parentage; weights and scores. Journal of Animal Science, Albany, 59(6): $1451-8,1984$.

DeNISE, R.S.K. \& BRINKS, J.S. Genetic and environmental aspects of the growth curve parameterns in beef cows. Journal of Animal Science, Albany, 61(6): 1431-40, 1985.

DEARBORN, D.D.; GREGORY, K.E.; CUNDIFF, L.V.; KOCH, R.M. Heterosis and breed maternal and trasmitted effects in beef cattle; V. weight and condition score of females. Journal of Animal Science, Albany, 64: 706-13, 1987.

DIAS, D.S.O. Avaliação dos efeitos de meio e estimativas de parâmetros genéticos de crescimento pré e pós desmama em fêmeas da raça Guzerá. Belo Horizonte, 1983. 90p. (Mestrado - Faculdade de Veterinária/UFMG).

DICKERSON, G.E. Animal size and efficiency; basic concepts. Animal Production, Edinburgh, 27(1): 367-79, 1978.

DUARTE, F.A.M. Estudo da curva de crescimento de animais da raça Nelore. Ribeirão Preto, 1975. 284p. (Livre Docencia - Faculdade de Medicina de Ribeirão Preto/USP).

FISS, C.F. \& WILTON, J.W. Effects of breeding system, cow weight and milk yield on reproductive performance in beef cattle. Journal of Animal Science, Albany, 67: 1714-21, 1989.

FISS, C.F. \& WILTON, J.W. Contribution of breed, cow weight, and milk yield to the traits of heifers and cows in four beef breeding systems. Journal of Animal Science, Albany, 70: 3666-96, 1992.

FITZHUGH JUNIOR, H.A. Analysis of growth curves and strategies for altering their shape. Journal of Animal Science, Albany, 42(4): 1036-51, 1976.

FITZHUGH JUNIOR, H.A. \& TAYLOR, C.S. Genetic analysis of degree of maturity. Journal of Animal Science, Albany, 33(4): 717-25, 1971.

GOONEWARDENE, L.A.; BERG,R.T.; HARDIN, R.T. A growth study of beef cattle. Canadian Journal of Animal Science, Otawa, 61: 1041-8, 1981. 
GREGORY, K.E.; TRAIL, J.C.M.; MARPLES, H.J.S.; KAKONGE, J. Caracterization of breeds of Bos indicus and Bos taurus cattle for maternal and individual traits. Journal of Animal Science, Albany, 60: 1165-74, 1985.

HANSET, R.; MICHAUX, C.; DETAL, G. Une étude sur la croissanse de taureaux de race Blanc-Bleu Belge. Ann. Méd. Vét., 132:577-91, 1988.

HARVEY, W.Y. Least square analysys of data with unequal subclasse numbers. Washington DC, U.S. Government Brinting Office, 1960. 157p.

JENKINS, T.G.; KAPS, M.; CUNDIF, L.V.; FERREL, C.L. Evaluation of betweenand within-breed variation in measures of weight-age relationships. Journal of Animal Science, Albany, 69: 3118-28, 1991.

LIMA, F.P. Parâmetros importantes para a criação do Nelore do século XXI. In: ENCONTRO DE PESQUISADORES EM MELHORAMENTO GENÉTICO E CRIADORES DE NELORE, 1., Ribeirão Preto, 1990. Anais. Associação dos Criadores de Nelore do Brasil, 1990.

LISBOA, S.R. \& FERNANDES, L.C.O. Efeito do tamanho corporal na fertilidade da primeira e segunda estação de monta, e na produtividade de fêmeas Charolês. Revista da Sociedade Brasileira de Zootecnia, Viçosa, 16: 204-14, 1987.

LÔBO, R.B. Estudo genético da performance reprodutiva de bovinos da raça Pitangueiras. Ribeirão Preto, 1976. 171p. (Doutorado - Faculdade de Medicina de Ribeirão Preto/USP).

LÔBO, R.B.; REIS, J.C.; DUARTE, F.A.M.; WILCOX, C.J. Reproductive performance of Pitangueiras cattle in Brasil. Revista Brasileira de Genética, Ribeirão Preto, 11: 51-61, 1988.

LONG, C.R.; CARTWRIGHT, T.C.; FITZHUGH JUNIOR, H.A. Systems analysis of sources of genetic and environmental variation in efficiency of beef production; Cow size and herd management. Journal of Animal Science, Albany, 40: 409, 1975.

LÓPEZ DE TORRE, G. \& RANKIN, B.J. Factors afecting growth curve parameters of Hereford and Brangus cows. Journal of Animal Science, Albany, 46: 604-13, 1978.

LÓPEZ DE TORRE, G.; CANDOTTI, J.J.; REVERTER, A.; BELLIDO, M.M.; VASCO, P.; GARCIA, L.J.; BRINKS, J.S. Effects of growth curve parameters on cow efficiency. Journal of Animal Science, Albany, 70: 2666-72, 1992. 
LUDWIG, A. Ajustamento de curvas exponenciais ao crescimento de gado Nelore e análise de seus parâmetros. Viçosa, 1977. 84p. (M.S. - Universidade Federal de Viçosa).

MacNEIL, M.D.; CUNDIFF, L.V.; DINKEL, C.A.; KOCH, R.M. Genetic correlations of reprodutive and maternal traits with growth and carcass traits in beef cattle. Journal of Animal Science, Albany, 58: 1171-80, 1984.

MARSHALL, T.E.; STEWART, T.S.; MARTIN, T.G. Optimal mature size of Angus cows for maximum cow productivity. In: INDIANA BEEF ASSOCIATION ANNUAL CONVENTION, 10., West Lafayette, 1983. Proceedings. 1983. p.43-8.

MARSHALL, T.E.; MOHLER, M.A.; STEWART, T.S. Relationship of lifetime productivity with mature weight and maturition rate in Red Poll cows. Animal Production, Edinburgh, 39: 383-7, 1984.

MATTOSO, J. Aspectos do crescimento de Zebus na Fazenda Experimental de Criação de Uberaba. Experimentae, Viçosa, 1(3): 65-118, 1961.

McCURLEY, J.R.; BUTTS JUNIOR, W.T.; BOVARD, K.P. Growth patterns of Angus, Hereford and Shorthorn cattle; I. comparison of inbreed and noninbreed lines, changes in patterns over time and effects of levels of inbreeding and reproductive performance. Journal of Animal Science, Albany, 59: 1194-204, 1984.

MIRANDA, J.J.F. Efeito da herança e meio sobre o peso de bezerros da raça Guzerá ao nascimento. Belo Horizonte, 1973. 79p. (Mestrado - Faculdade de Veterinária/UFMG).

MIRANDA, J.J.F.; CARNEIRO, G.G.; PENNA, V.M.; FONSECA, C.G. Estudo dos fatores ambientais relacionados com idade à primeira cria. Arquivos da Escola Veterinária UFMG, Belo Horizonte, 34(2): 375-80, 1982a.

MIRANDA, J.J.F.; FONSECA, C.G.; CARNEIRO, G.G.; BERGMANN. J.A.G. Fatores ambientes e genéticos relacionados com o intervalo entre partos na raça Nelore. Arquivos da Escola Veterinária UFMG, Belo Horizonte, 34(2): 381-7, 1982b.

MIRANDA, J.J.F.; TORRES, J.R.; PEREIRA, J.C.C.; CARNEIRO, G.G.; SAMPAIO, I.B.M. Fatore que afetam o peso de bezerros da raça Nelore ao nascimento, em diferentes estados do Brasil. Arquivos da Escola Veterinária UFMG, Belo Horizonte, 31: 51-61, 1979. 
MONTAÑO BERMUDEZ, M. \& NIELSEN, M.K. Reproductive performance and variation in body weight during annual cycles for crossbred beef cows with different genetic potential for milk. Journal of Animal Science, Albany, 68: 2289-96, 1990.

MONTEIRO, L.S. The relative size of calf and dam and frequency of calving difficulties. Animal Production, Edinburgh, 11(3): 293-306, 1969.

MORROW, G.A.; McLAREN, J.B.; BUTTS, T.W. Effectsd of age on estimates of bovine growth-curve parameters. Journal of Animal Science, Albany, 47: 352-7, 1978.

NADARAJAH, K.; MALOWE, T.J.; NOTTER, D.R. Growth patterns of Angus, Charolais, Charolais $\mathrm{x}$ Angus and Holstein $\mathrm{x}$ Angus cows from birth to maturity. Journal of Animal Science, Albany, 59: 957-66, 1984.

NADARAJAH, K.; MALOWE, T.J.; NOTTER, D.R. Growth patterns of cows sired by british and continental beef and american dairy bulls and out ot Hereford dams. Journal of Animal Science, Albany, 60: 890-901, 1985.

OLIVEIRA FILHO, E.B. Contribuição para o estudo genético quantitativo da fertilidade de um rebanho Canchim. Ribeirão Preto, 1977. 126p. (Doutorado - Faculdade de Medicina de Ribeirão Preto/USP).

OLIVEIRA FILHO, E.B.; DUARTE, F.A.M.; KOBER, M. Genetic effects of reproduction in Canchim cattle. Revista Brasileira de Genética, Ribeirão Preto, 2(4): 291-3, 1979.

OLIVEIRA FILHO, E.B.; CARNEIRO, G.G.; MOREIRA, H.A.; SZÉCHI, A.M. Idade à primeira cria em um rebanho Nelore. Arquivos da Escola Veterinária UFMG, Belo Horizonte, 27: 141-53, 1975a.

OLIVEIRA FILHO, E.B.; CARNEIRO, G.G.; MOREIRA, H.A.; MIRANDA, J.J.F.; SZÉCHI, A.M. Período de serviço e intervalo entre partos em um rebanho Nelore. Arquivos da Escola Veterinária UFMG, Belo Horizonte, 27: 253-68, $1975 b$.

PACKER, I.U. Análise genética do crescimento até a desmama de bezerros Canchim. Piracicaba, 1977. 173p. (Livre Docência - Escola Superior de Agricultura "Luiz de Queiroz"/USP).

PACKER, I.U.; CAMPOS, B.E.S.; RAZOOK, A.G. Efeito do peso de vacas Guzerá sobre a performance até a desmama de bezerros mestiços. In: REUNIÃO ANUAL DA SOCIEDADE BRASILEIRA DE ZOOTECNIA, 16., Curitiba, 1979. Anais. Curitiba, SBZ, 1979. p.64. 
PENNA, V.M. Endogamia na raça Tabapuã. Ribeirão Preto, $1990.88 \mathrm{p}$. (Doutorado - Faculdade de Medicina de Ribeirão Preto/USP).

PEREIRA, J.C.C.; PEREIRA, C.S.; LEM0S, A.M. Fatores ambientes e genéticos que influem sobre a idade ao primeiro parto em fêmeas da raça Caracú. Arquivos da Escola Veterinária UFMG, Belo Horizonte, 31:205-10, 1979.

PEREIRA, J.C.C.; PEREIRA, C.S.; LEMOS, A.M. Estudo de fatores ambientes e genéticos relacionados com o intervalo entre partos na raça Caracú. Arquivos da Escola Veterinária UFMG, Belo Horizonte, 32:81-91, 1980.

PEROTTO, D,; CUE, R.I.; LEE, A.J. Comparisson of nonlinear functions for describing the growth curve of three genotypes of dairy cattle. Canadian Journal of Animal Science, Otawa, 72: 773-82, 1992.

PEROTTO, D.; CUE, R.I.; LEE, A.J.; McALLISTER, A.J.; BATRA, T.R.; LIN, C.Y.; ROY, G.L.; WAUTHY, J.M. Additive and non-additive genetic effects if growth-curve parameters of Holstein, Ayrshire and crossbred females. Canadian Journal of Animal Science, Otawa, 74: 401-9, 1994.

PIRES, F.L.; BENITENDI, R.P.; SANTIAGO, A.A. Idade na época da primeira cria e intervalo inter-parto em bovinos da raça Guzerá, de seleção leiteira. Boletim da Indústria Animal, Nova Odessa, 24:123-7, 1967.

POLASTRE, R.; MILAGRES, J.C.; TEIXEIRA, N.M.; CASTRO, A.C.G. Fatores genéticos e de ambiente do desempenho de vacas mestiças Holandês-Zebu; I. idade ao primeiro parto. Revista da Sociedade Brasileira de Zootecnia, Viçosa, 16: 227-32, 1987a.

POLASTRE, R.; MILAGRES, J.C.; TEIXEIRA, N.M.; CASTRO, A.C.G. Fatores genéticos e de ambiente do desempenho de vacas mestiças Holandês-Zebu; II. intervalo entre partos. Revista da Sociedade Brasileira de Zootecnia, Viçosa, 16: $233-41,1987 b$.

QUAAS, R.L. Genetic variation in growth curves of Hereford females. Animal Breeeding Abstract, Edinburgh, 53: 95-6, 1985.

RAMOS, A.A. Estudos genético-quantitativos das características reprodutivas e produtivas de um plantel da raça Gir. Ribeirão Preto, 1979. 298p. (Doutorado - Faculdade de Medicina de Ribeirão Preto/USP).

ROSA, A.N. Análise genética de parâmetros de crescimento e proposição de índices de seleção para animais da raça Nelore. Viçosa, 1977. (M.S. Universidade Federal de Viçosa). 
ROSA, A.N.; SILVA, M.A.; SILVA, J.C.; BARBOSA, H.M. Análise genética do peso à maturidade e do grau de maturidade de animais da raça Nelore. Revista da Sociedade Brasileira de Zootecnia, Viçosa, 8(1): 43-56, 1979.

RAZOOK, A.G.; BONILHA NETO, L.M.; FIGUEIREDO, L.A.; PACKER, I.U.; PACOLA, L.J.; CANDIDO, J.G.; Selecão para peso pos-desmame em bovinosNelore e Guzerá; II. respostas direta e correlacionadas. Boletim da Indústria Animal, Nova Odessa, 45(2): 273-315, 1988.

RAZOOK, A.G.; FIGUEIREDO, L.A.; BONILHA NETO, L.M.; TROVO, J.B.F.; PACKER, I.U.; PACOLA, L.J.; CANDIDO, J.G. Intensidade de seleção e respostas direta e correlacionadas em 10 anos de progênies de bovinos das raças Nelore e Guzerá selecionadas para peso pós-desmame. Boletim da Indústria Animal, Nova Odessa, 50(2): 147-63, 1993.

SALVO, A.E.W. O Guzerá: Fazenda Canoas; relatório de trinta anos 1956/1985. s.l., s.ed., 1986. 54p.

SANDLAND, R.L. Mathematics and the growth of organisms; some historical impressions. Mathematic Scientistic, 8:11-30, 1983.

SANTIAGO, A.A. O Guzerá. Recife, Tropical, 1984. 450p.

SAS INSTITUTE. SAS/stat guide; for personal computers. 6.ed. Cary, Sas Institute, 1987.

SILVA, J.S.; PEREIRA, C.S.; FONSECA, C.G.; PEREIRA, R.G.A.; LEDIC, I.L. Peso ao nascimento, aos 90 dias de idade e à desmama (205 dias) de um rebanho Nelore da Zona da Mata de Pernambuco; 1. peso ao nascimento. In: ENCONTRO DE PESQUISA DA ESCOLA DE VETERINÁRIA DA UFMG, 10., Belo Horizonte, 1982. Anais. Belo Horizonte, UFMG, 1982. p. 55.

SILVA, S.B. Idade à primeira cria e intervalo entre partos na raça Guzerá. Belo Horizonte, 1971. (Mestrado - Faculdade de Veterinária/UFMG).

SILVA, M.A. \& PEREIRA, F.A. Fatores de meio e genéticos que influem no desempenho reprodutivo de fêmeas Zebu e mestiços Chianino-Zebu. Revista da Sociedade Brasileira de Zootecnia, Viçosa, 15: 132-41, 1986.

SILVEIRA JUNIOR, P. Estudo de alguns modelos exponenciais no crescimento de bovinos da raça Ibagé. Piracicaba, 1976. 174p. (Mestrado - Escola Superior

SMITH, B.A.; BRINKS, J.S.; RICHARDSON, G.V. Estimation of genetic parameters among reproductive and growth traits in yearling heifers. Journal of Animal Science, Albany, 32: 127-31, 1989. 
SMITH, G.M. \& CUNDIFF, LO.V. Genetic analysis of relative growth rate in crossbred an stratighbred Hereford, Angus and Shorthorn steers. Journal of Animal Science, Albany, 43:1171-5, 1976.

SMITH, G.M.; FITZHUGH JUNIOR, H.A.; CUNDIFF, L.V.; CARTWRIGHT, T.C.; GREGORY, K.E. A genetic anaysis of maturing patterns in straightbred and crossbred Hereford, Angus and Shorthorn cattle. Journal of Animal Science, Albany, 43: 389-95, 1976.

STEWART, T.S. \& MARTIN, T.G. Mature weight, maternal performance and their interrelationships in purebred and crossbred cows of Angus and Milking Shorthorn parentage, Journal of Animal Science, Albany, 52(1): 51-6, 1981.

TAYLOR, C.S. \& FITZHUGH JUNIOR, H.A.J. Genetic relationship between mature weight and time to mature within a bred. Journal of Animal Science, Albany, 33(4): 726-31, 1971.

VALENTE, J. Efeitos de meio e herança sobre a idade à primeira fecundação e intervalo entre partos num rebanho mestiço euro-zebu. Belo Horizonte, 1978. 77p. (Mestrado - Faculdade de Veterinária/UFMG).

VIANA, H.A. \& FERREIRA, P.R.C. Efeitos de alguns fatores de meio no intervalo entre partos de fềmeas Nelore. Pesquisa Agropecuária Brasileira, Brasília, 17:1227-32, 1982. 


\section{APÊNDICE}

QUADRO IA: $\quad$ Número de pesos, pesos médios e desvio padrão por grupo de parto.

\begin{tabular}{|c|c|c|c|c|c|c|c|c|c|c|c|c|}
\hline \multirow[b]{2}{*}{$\begin{array}{c}\text { idade } \\
\text { em } \\
\text { meses }\end{array}$} & \multicolumn{3}{|c|}{$1^{\circ}$ parto } & \multicolumn{3}{|c|}{$2^{\circ}$ parto } & \multicolumn{3}{|c|}{$3^{\circ}$ parto } & \multicolumn{3}{|c|}{$4^{\circ}$ parto } \\
\hline & pesos & $\begin{array}{l}\text { peso } \\
\text { médio } \\
(\mathrm{kg})\end{array}$ & $\begin{array}{c}\text { desvio } \\
\text { padrão } \\
(\mathrm{kg})\end{array}$ & pesos & $\begin{array}{l}\text { peso } \\
\text { médio } \\
(\mathrm{kg})\end{array}$ & $\begin{array}{c}\text { desvio } \\
\text { padrão } \\
(\mathrm{kg})\end{array}$ & pesos & $\begin{array}{l}\text { peso } \\
\text { médio } \\
(\mathrm{kg})\end{array}$ & $\begin{array}{c}\text { desvio } \\
\text { padrão } \\
(\mathrm{kg})\end{array}$ & pesos & $\begin{array}{l}\text { peso } \\
\text { médio } \\
(\mathrm{kg})\end{array}$ & $\begin{array}{c}\text { desvio } \\
\text { padrão } \\
(\mathrm{kg})\end{array}$ \\
\hline 0 & 223 & 27,82 & 3,13 & 220 & 27,64 & 3,05 & 181 & 27,46 & 3,13 & 164 & 27,51 & 3,26 \\
\hline 1 & 41 & 50,05 & 7,63 & 38 & 50,40 & 7,38 & 31 & 52,29 & 7,90 & 29 & 52,21 & 8,18 \\
\hline 2 & 103 & 58,61 & 8,12 & 103 & 59,54 & 8,81 & 82 & 59,83 & 9,21 & 74 & 59,97 & 9,43 \\
\hline 3 & 115 & 72,37 & 11,14 & 114 & 73,10 & 11,02 & 95 & 72,23 & 11,49 & 86 & 72,23 & 11,38 \\
\hline 4 & 102 & 93,55 & 13,33 & 100 & 94,26 & 14,43 & 79 & 93,89 & 13,50 & 71 & 95,00 & 14,45 \\
\hline 5 & 121 & 118,18 & 16,68 & 119 & 117,98 & 16,23 & 100 & 116,46 & 15,75 & 91 & 116,54 & 15,12 \\
\hline 6 & 93 & 141,66 & 16,59 & 93 & 142,31 & 18,06 & 72 & 142,14 & 17,50 & 66 & 143,35 & 18,64 \\
\hline 7 & 124 & 167,36 & 18,26 & 122 & 165,29 & 17,45 & 104 & 164,05 & 17,53 & 93 & 163,56 & 17,21 \\
\hline 8 & 97 & 182,85 & 19,53 & 97 & 182,22 & 19,10 & 75 & 181,20 & 19,08 & 69 & 181,04 & 19,55 \\
\hline 9 & 127 & 196,68 & 19,60 & 123 & 193,45 & 17,92 & 104 & 190,91 & 17,39 & 93 & 190,33 & 17,39 \\
\hline 10 & 94 & 202,86 & 21,48 & 95 & 200,93 & 20,68 & 75 & 198,65 & 19,95 & 69 & 196,36 & 18,31 \\
\hline 11 & 124 & 216,83 & 25,18 & 122 & 212,52 & 22,62 & 104 & 209,78 & 21,37 & 94 & 209,38 & 21,68 \\
\hline 12 & 98 & 221,89 & 28,57 & 95 & 219,22 & 28,65 & 75 & 216,17 & 27,69 & 68 & 214,69 & 26,03 \\
\hline 13 & 127 & 231,79 & 30,07 & 127 & 226,63 & 27,71 & 107 & 223,87 & 26,75 & 97 & 223,39 & 27,16 \\
\hline 14 & 95 & 234,72 & 31,28 & 92 & 231,08 & 31,36 & 72 & 230,61 & 31,51 & 66 & 228,94 & 29,57 \\
\hline 15 & 124 & 246,79 & 32,77 & 125 & 240,10 & 29,06 & 109 & 237,21 & 28,44 & 97 & 236,94 & 29,82 \\
\hline 16 & 99 & 249,77 & 27,33 & 94 & 245,02 & 26,12 & 71 & 245,13 & 27,34 & 66 & 243,61 & 25,35 \\
\hline 17 & 121 & 266,45 & 31,72 & 122 & 259,47 & 27,21 & 105 & 256,28 & 26,03 & 93 & 255,94 & 27,21 \\
\hline 18 & 102 & 275,90 & 28,14 & 97 & 271,23 & 26,74 & 75 & 271,31 & 27,88 & 71 & 270,48 & 26,90 \\
\hline 19 & 117 & 295,68 & 35,00 & 119 & 287,24 & 30,50 & 104 & 282,68 & 27,52 & 93 & 282,20 & 29,19 \\
\hline 20 & 105 & 305,54 & 30,68 & 100 & 302,54 & 30,80 & 76 & 301,72 & 31,52 & 71 & 301,51 & 30,83 \\
\hline 21 & 118 & 323,96 & 39,72 & 120 & 313,82 & 33,09 & 105 & 309,27 & 31,36 & 93 & 308,26 & 32,48 \\
\hline 22 & 105 & 327,83 & 34,25 & 98 & 325,16 & 35,71 & 76 & 324,92 & 34,79 & 70 & 324,33 & 34,56 \\
\hline 23 & 116 & 344,48 & 41,16 & 119 & 336,06 & 34,83 & 103 & 333,00 & 35,50 & 92 & 332,10 & 35,98 \\
\hline 24 & 106 & 341,46 & 35,32 & 100 & 339,40 & 36,59 & 78 & 340,53 & 36,38 & 72 & 340,49 & 36,26 \\
\hline 25 & 116 & 356,20 & 48,47 & 118 & 347,87 & 41,86 & 101 & 342,84 & 39,85 & 91 & 342,87 & 39,20 \\
\hline 26 & 110 & 354,92 & 39,08 & 102 & 350,47 & 40,45 & 80 & 352,24 & 38,70 & 73 & 352,64 & 41,58 \\
\hline 27 & 111 & 369,40 & 47,79 & 114 & 357,52 & 41,40 & 98 & 352,09 & 39,25 & 89 & 353,84 & 40,31 \\
\hline 28 & 120 & 366,00 & 51,54 & 113 & 363,11 & 47,71 & 84 & 366,96 & 44,73 & 77 & 367,91 & 48,06 \\
\hline 29 & 140 & 359,24 & 68,29 & 142 & 358,32 & 58,74 & 120 & 354,69 & 55,55 & 106 & 356,77 & 55,15 \\
\hline 30 & 125 & 382,10 & 58,19 & 118 & 382,03 & 54,91 & 89 & 383,52 & 53,51 & 79 & 385,52 & 55,69 \\
\hline 31 & 128 & 383,81 & 67,49 & 141 & 384,87 & 59,16 & 119 & 380,92 & 55,21 & 104 & 380,32 & 52,57 \\
\hline 32 & 127 & 410,02 & 65,67 & 120 & 406,03 & 59,28 & 94 & 405,10 & 54,97 & 83 & 407,78 & 54,99 \\
\hline 33 & 120 & 405,64 & 76,32 & 147 & 404,90 & 67,71 & 121 & 400,80 & 62,06 & 103 & 404,00 & 62,26 \\
\hline 34 & 119 & 417,51 & 77,24 & 129 & 414,42 & 71,27 & 99 & 418,71 & 63,75 & 90 & 418,39 & 65,36 \\
\hline 35 & 108 & 402,82 & 86,24 & 147 & 413,50 & 74,37 & 119 & 412,56 & 69,89 & 102 & 416,59 & 67,72 \\
\hline 36 & 87 & 398,22 & 90,01 & 106 & 412,33 & 83,73 & 85 & 411,45 & 80,91 & 70 & 424,00 & 84,45 \\
\hline 37 & 81 & 393,12 & 94,04 & 149 & 402,18 & 78,89 & 124 & 398,61 & 73,12 & 100 & 410,07 & 69,78 \\
\hline 38 & 52 & 349,02 & 74,80 & 91 & 383,04 & 68,41 & 77 & 381,75 & 66,38 & 65 & 383,99 & 67,38 \\
\hline 39 & 46 & 349,11 & 58,96 & 93 & 365,53 & 51,52 & 78 & 365,59 & 48,42 & 62 & 367,61 & 46,52 \\
\hline 40 & 45 & 362,13 & 66,13 & 94 & 367,92 & 54,33 & 76 & 359,59 & 60,27 & 62 & 363,60 & 56,40 \\
\hline
\end{tabular}


QUADRO IA: $\quad$ (Continuação) Número de pesos, pesos médios e desvio padrão por grupo de parto.

\begin{tabular}{|c|c|c|c|c|c|c|c|c|c|c|c|c|}
\hline \multirow[b]{2}{*}{$\begin{array}{l}\text { idade } \\
\text { em } \\
\text { meses }\end{array}$} & \multicolumn{3}{|c|}{$1^{\circ}$ parto } & \multicolumn{3}{|c|}{$2^{\circ}$ parto } & \multicolumn{3}{|c|}{$3^{\circ}$ parto } & \multicolumn{3}{|c|}{$4^{\circ}$ parto } \\
\hline & pesos & $\begin{array}{c}\text { peso } \\
\text { médio } \\
(\mathrm{kg})\end{array}$ & $\begin{array}{c}\text { desvio } \\
\text { padrão } \\
(\mathrm{kg})\end{array}$ & pesos & $\begin{array}{c}\text { peso } \\
\text { médio } \\
(\mathrm{kg})\end{array}$ & $\begin{array}{c}\text { desvio } \\
\text { padrão } \\
(\mathrm{kg})\end{array}$ & pesos & $\begin{array}{l}\text { peso } \\
\text { médio } \\
(\mathrm{kg})\end{array}$ & $\begin{array}{c}\text { desvio } \\
\text { padrão } \\
(\mathrm{kg})\end{array}$ & pesos & $\begin{array}{l}\text { peso } \\
\text { médio } \\
(\mathrm{kg})\end{array}$ & $\begin{array}{c}\text { desvio } \\
\text { padrão } \\
(\mathrm{kg})\end{array}$ \\
\hline 41 & 40 & 360,23 & 56,34 & 95 & 370,77 & 61,59 & 81 & 368,59 & 54,40 & 63 & 375,06 & 52,67 \\
\hline 42 & 39 & 361,10 & 58,02 & 83 & 379,59 & 57,50 & 72 & 379,63 & 56,52 & 59 & 379,49 & 57,90 \\
\hline 43 & 34 & 369,18 & 50,29 & 85 & 381,62 & 47,68 & 73 & 380,74 & 46,29 & 58 & 383,66 & 43,83 \\
\hline 44 & 35 & 383,60 & 68,72 & 97 & 386,39 & 56,17 & 77 & 382,09 & 62,04 & 65 & 391,95 & 62,23 \\
\hline 45 & 30 & 389,63 & 58,41 & 95 & 388,32 & 59,72 & 83 & 384,12 & 60,78 & 68 & 395,46 & 55,55 \\
\hline 46 & 29 & 387,79 & 47,24 & 76 & 398,45 & 57,06 & 65 & 400,29 & 55,04 & 57 & 5,49 & 52,62 \\
\hline 47 & 30 & 378,00 & 44,14 & 87 & 400,54 & 61,06 & 73 & 400,66 & 60,98 & 55 & 413,09 & 58,62 \\
\hline 48 & 23 & 399,48 & 62,77 & 98 & 402,55 & 61,70 & 79 & 405,35 & 65,95 & 66 & 14,44 & 62,16 \\
\hline 49 & 20 & 365,20 & 51,18 & 91 & 395,67 & 74,46 & 82 & 402,70 & 70,51 & 67 & 418,85 & 68,52 \\
\hline 50 & 13 & 388,62 & 78,26 & 70 & 384,86 & 70,26 & 72 & 388,06 & 69,31 & 60 & 393,63 & 66,01 \\
\hline 51 & 13 & 428,54 & 58,37 & 56 & 397,73 & 57,63 & 63 & 392,41 & 53,93 & 49 & 01,90 & 54,76 \\
\hline 52 & 11 & 415,36 & 64,58 & 69 & 399,61 & 53,62 & 72 & 395,35 & 58,41 & 61 & 3,74 & 53,65 \\
\hline 53 & 8 & 420,00 & 57,50 & 68 & 405,27 & 61,53 & 79 & 398,73 & 58,36 & 64 & 408,06 & 55,88 \\
\hline 54 & 7 & 431,86 & 74,87 & 64 & 408,03 & 71,04 & 76 & 407,42 & 61,77 & 65 & 413,08 & 65,75 \\
\hline 55 & 4 & 418,75 & 40,21 & 45 & 431,51 & 67,30 & 59 & 425,70 & 65,28 & 48 & 427,77 & 59,56 \\
\hline 56 & 5 & 478,20 & 67,47 & 60 & 425,60 & 67,99 & 74 & 425,70 & 66,87 & 59 & 431,00 & 65,69 \\
\hline 57 & 4 & 438,00 & 58,21 & 57 & 441,65 & 71,54 & 77 & 424,18 & 71,94 & 64 & ,69 & 63,34 \\
\hline 58 & 3 & 429,67 & 44,41 & 51 & 420,31 & 81,25 & 76 & 413,16 & 61,52 & & ,06 & 65,67 \\
\hline 59 & 1 & 400,00 & 0,00 & 39 & 470,05 & 75,17 & 60 & 457,15 & 75,93 & 50 & 463,96 & 71,58 \\
\hline 60 & 2 & 416,50 & 94,05 & 50 & 457,24 & 76,56 & 71 & 447,30 & 60,79 & 56 & 452,66 & 66,31 \\
\hline 61 & 2 & 397,00 & 55,15 & 36 & 442,83 & 98,48 & 71 & 431,09 & 75,33 & 63 & 441,70 & 70,56 \\
\hline 62 & 3 & 379,33 & 59,74 & 34 & 393,53 & 73,33 & 73 & 408,53 & 64,96 & 59 & 408,22 & 63,37 \\
\hline 63 & -- & -- & -- & 14 & 433,86 & 65,99 & 48 & 423,65 & 50,16 & 47 & 427,66 & 51,12 \\
\hline 64 & $\cdots$ & --. & $\cdots$ & 17 & 426,18 & 64,87 & 63 & 412,78 & 51,47 & 5 & 97,88 & 9,70 \\
\hline 65 & -- & -- & --- & 19 & 440,74 & 77,46 & 64 & 430,44 & 57,87 & 61 & 426,75 & 55,37 \\
\hline 66 & 2 & 482,50 & 19,09 & 28 & 418,96 & 62,64 & 65 & 425,06 & 55,11 & 58 & 425,95 & 52,53 \\
\hline 67 & -- & -- & -- & 8 & 404,63 & 47,51 & 43 & 447,86 & 61,90 & 48 & 433,17 & 58,62 \\
\hline 68 & $\cdots$ & -- & -- & 12 & 454,00 & 69,44 & 58 & 441,69 & 51,74 & 53 & 442,45 & 53,91 \\
\hline 69 & $\cdots$ & $\cdots$ & - & 14 & 462,57 & 62,75 & 63 & 453,03 & 60,33 & 64 & 458,98 & 51,20 \\
\hline 70 & -- & -- & -- & 22 & 441,32 & 64,27 & 56 & 447,21 & 66,78 & 62 & 446,07 & 65,34 \\
\hline 71 & -- & $\cdots$ & $\cdots$ & 5 & 472,60 & 59,70 & 35 & 478,71 & 61,30 & 45 & 468,36 & 52,67 \\
\hline 72 & - & -- & -- & 6 & 412,33 & 52,58 & 52 & 464,35 & 76,75 & 54 & 472,19 & 77,56 \\
\hline 73 & -- & -- & -- & 6 & 447,50 & 84,63 & 50 & 464,08 & 60,42 & 59 & 469,02 & 62,53 \\
\hline 74 & -- & -- & -- & 13 & 412,77 & 62,78 & 50 & 430,90 & 79,47 & 60 & 447,83 & 70,77 \\
\hline 75 & $\cdots$ & $\cdots$ & $\cdots$ & 2 & 456,00 & 96,17 & 19 & 450,90 & 61,54 & 39 & 440,92 & 54,31 \\
\hline 76 & - & - & --. & 4 & & 69,12 & 22 & 427,91 & 53,38 & 49 & 429,29 & 46,14 \\
\hline 77 & - & $\cdots$ & $\cdots$ & 4 & 519,50 & 61,84 & 28 & 459,36 & 76,46 & 51 & 460,04 & 68,02 \\
\hline 78 & -- & -- & -- & 6 & 411,67 & 28,10 & 42 & 451,67 & 54,38 & 64 & 450,44 & 59,65 \\
\hline 79 & - & --. & --- & 1 & 430,00 & 0,00 & 12 & 440,50 & 105,83 & 34 & 447,71 & 65,66 \\
\hline 80 & -- & -- & -- & 3 & 497,67 & 18,72 & 18 & 464,00 & 63,28 & 47 & 447,15 & 56,58 \\
\hline 81 & -- & -- & -- & 2 & 524,00 & 36,77 & 18 & 444,61 & 65,66 & 48 & 465,81 & 52,08 \\
\hline 82 & -- & -- & -- & 5 & 480,00 & 40,70 & 30 & 462,23 & 70,42 & 59 & 452,05 & 57,62 \\
\hline 83 & -- & -- & -- & 1 & & 0,00 & 8 & 494,88 & 96,65 & 31 & 478,23 & 66,36 \\
\hline 84 & - & --- & --- & 2 & 539,00 & 7,07 & 11 & 486,09 & 65,62 & 44 & 480,50 & 64,74 \\
\hline 85 & - & $\ldots$ & --. & $-\ldots$ & - & -- & 12 & 450,42 & 61,14 & 39 & 481,90 & 63,05 \\
\hline 86 & -- & -- & -- & 1 & 522,00 & 0,00 & 29 & 434,45 & 73,36 & 57 & 456,60 & 76,63 \\
\hline 87 & -- & --- & -- & --- & -- & -- & 6 & 468,50 & 80,49 & 24 & 455,29 & 56,07 \\
\hline
\end{tabular}


QUADRO IA: (Continuação) Número de pesos, pesos médios e desvio padrão por grupo de parto.

\begin{tabular}{|c|c|c|c|c|c|c|c|c|c|c|c|c|}
\hline \multirow[b]{2}{*}{$\begin{array}{l}\text { idade } \\
\text { em } \\
\text { meses }\end{array}$} & \multicolumn{3}{|c|}{$1^{\circ}$ parto } & \multicolumn{3}{|c|}{$2^{\circ}$ parto } & \multicolumn{3}{|c|}{$3^{\circ}$ parto } & \multicolumn{3}{|c|}{$4^{\circ}$ parto } \\
\hline & pesos & $\begin{array}{c}\text { peso } \\
\text { médio } \\
(\mathrm{kg})\end{array}$ & $\begin{array}{c}\text { desvio } \\
\text { padrão } \\
\text { (kg) }\end{array}$ & pesos & $\begin{array}{c}\text { peso } \\
\text { médio } \\
(\mathrm{kg})\end{array}$ & $\begin{array}{c}\text { desvio } \\
\text { padrão } \\
\text { (kg) }\end{array}$ & pesos & $\begin{array}{c}\text { peso } \\
\text { médio } \\
(\mathrm{kg})\end{array}$ & $\begin{array}{c}\text { desvio } \\
\text { padrão } \\
\text { (kg) }\end{array}$ & pesos & $\begin{array}{c}\text { peso } \\
\text { médio } \\
(\mathrm{kg})\end{array}$ & $\begin{array}{c}\text { desvio } \\
\text { padrão } \\
\text { (kg) }\end{array}$ \\
\hline 88 & -- & $\ldots$ & $\ldots$ & - & -- & $\ldots$ & 6 & 456,17 & 60,59 & 23 & 436,17 & 49,75 \\
\hline 89 & -- & -- & -- & $\ldots$ & - & $\ldots$ & 4 & 397,75 & 88,15 & 26 & 453,23 & 55,66 \\
\hline 90 & -- & -- & -- & --- & - & - & 16 & 491,44 & 63,81 & 37 & 471,08 & 69,26 \\
\hline 91 & --. & - & - & -- & -- & - & - & -- & -- & 17 & 444,94 & 74,05 \\
\hline 92 & -- & - & - & - & - & -- & 3 & 492,33 & 58,79 & 18 & 475,17 & 39,80 \\
\hline 93 & --. & -- & - & -- & --. & -- & 3 & 447,67 & 38,21 & 16 & 462,25 & 83,40 \\
\hline 94 & --- & -- & - & -- & --. & -.. & 8 & 486,75 & 73,99 & 27 & 463,00 & 78,38 \\
\hline 95 & $\ldots$ & -- & - & -. & $\ldots$ & $\cdots$ & - & - & - & 14 & 461,07 & 67,72 \\
\hline 96 & -- & $-\cdots$ & -- & --- & -- & - & 3 & 494,00 & 65,02 & 17 & 518,29 & 65,04 \\
\hline 97 & -- & --- & --- & -- & -- & $\ldots$ & 2 & 433,50 & 82,73 & 13 & 490,62 & 89,92 \\
\hline 98 & -- & -- & - & -- & -.. & --. & 4 & 420,75 & 85,70 & 20 & 452,55 & 98,09 \\
\hline 99 & $\ldots$ & $\ldots$ & $\ldots$ & $\ldots$ & - & -.. & 1 & 450,00 & 0,00 & 13 & 429,46 & 64,84 \\
\hline 100 & $\ldots$ & -- &.- & $-\ldots$ & - & -.. & $\ldots$ & -- & -- & 3 & 493,33 & 65,25 \\
\hline 101 & - & - & - & -- &.- & -- & 2 & 490,00 & 113,14 & 6 & 464,67 & 99,60 \\
\hline 102 & -- & $\cdots$ & $\cdots$ & -- & - & - & 1 & 415,00 & 0,00 & 14 & 462,36 & 61,53 \\
\hline 103 & -- & --. & $\cdots$ & -- & - & - & 1 & 556,00 & 0,00 & 13 & 467,31 & 81,40 \\
\hline 105 & $\cdots$ & --. & - & $\cdots$ & - & - & 2 & 510,00 & 28,28 & 3 & 467,33 & 62,01 \\
\hline 106 & -- & -. & - & -- & - & - & - & -- & - & 9 & 468,00 & 65,05 \\
\hline 107 & -.. & -.. & $-\ldots$ & -.- & $\ldots$ & - & -.. & $\ldots$ & $\ldots$ & 9 & 466,33 & 93,53 \\
\hline 109 & -- & - & -- & - & - & - & 1 & 575,00 & 0,00 & 3 & 434,00 & 29,46 \\
\hline 110 & $\cdots$ & $\cdots$ & -- & $\cdots$ & - & - & -- & - & -- & 4 & 488,75 & 126,06 \\
\hline 111 & - & -- & --- & --- & -- & -- & -- & -- & --. & 5 & 375,80 & 79,82 \\
\hline 113 & -- & -- & - & --- & -- & --- & -- & -.. & -- & 2 & 516,00 & 5,66 \\
\hline 114 & -- & -- & - & -- & -- & --. & -- & -- & --- & 1 & 430,00 & 0,00 \\
\hline 115 & $\ldots$ & -.. &.-- & -- & -- & --. & --. & -- & --. & 4 & 433,75 & 58,60 \\
\hline 117 & -- & -- & -- & -- & -- & --- & - & -- & --. & 2 & 550,50 & 6,36 \\
\hline 118 & $\cdots$ & $\cdots$ & -- & $\cdots$ & -- & --- & -- & --- & - & 1 & 454,00 & 0,00 \\
\hline 119 & - & -- & -- & -- & -- & - & -- & - & -- & 4 & 441,50 & 39,37 \\
\hline 122 & $\ldots$ & - & - & $\cdots$ & -- & -- & --- & -- & -- & 1 & 392,00 & 0,00 \\
\hline 123 & -- & -- & -- & - & -- & - & -- & -- & --- & 2 & 345,00 & 12,73 \\
\hline 127 & --. & $\cdots$ & $-\cdots$ & -- & -- & $\cdots$ & $\cdots$ & -- & --. & 1 & 410,00 & 0,00 \\
\hline 131 & $\ldots$ & $\cdots$ & - & -- & -- & - & - & - & - & 1 & 424,00 & 0,00 \\
\hline
\end{tabular}


QUADRO IIA: Análises de variância da idade do parto em meses sem intervalo entre partos como covariável no $2^{\circ}, 3^{\circ}$ e $4^{\circ}$ partos.

\begin{tabular}{|c|c|c|c|c|c|c|c|c|}
\hline \multirow{2}{*}{$\begin{array}{l}\text { fonte de } \\
\text { variação }\end{array}$} & \multicolumn{4}{|c|}{ graus de liberdade } & \multicolumn{4}{|c|}{ valor de F / valor de outras estatísitcas } \\
\hline & $1^{\circ}$ parto & $2^{\circ}$ parto & $3^{\circ}$ parto & $4^{\circ}$ parto & $1^{\circ}$ parto & $2^{\circ}$ parto & $3^{\circ}$ parto & $4^{\circ}$ parto \\
\hline ano de parto & 26 & 26 & 25 & 25 & $\begin{array}{l}5,41 \\
* * *\end{array}$ & $\begin{array}{l}3,24 \\
* * *\end{array}$ & $\begin{array}{l}2,93 \\
* * *\end{array}$ & $\begin{array}{l}3,42 \\
* * *\end{array}$ \\
\hline estação do ano de nasc/o & 3 & 3 & 3 & 3 & 1,64 & 0,41 & 0,79 & 1,70 \\
\hline estação de ano de parto & 3 & 3 & 3 & 3 & $\begin{array}{c}2,96 \\
*\end{array}$ & 1,12 & 1,08 & 0,25 \\
\hline touro & 35 & 38 & 38 & 34 & $\begin{array}{l}2,80 \\
* * *\end{array}$ & $\begin{array}{l}2,63 \\
* * *\end{array}$ & $\begin{array}{l}1,85 \\
* *\end{array}$ & $\begin{array}{l}2,01 \\
* * *\end{array}$ \\
\hline peso assintótico & 1 & 1 & 1 & 1 & 0,01 & $\begin{array}{l}21,76 \\
* * *\end{array}$ & $\begin{array}{l}17,00 \\
* * *\end{array}$ & $\begin{array}{c}6,94 \\
* *\end{array}$ \\
\hline taxa de maturação & 1 & 1 & 1 & 1 & $\begin{array}{c}50,50 \\
* * *\end{array}$ & $\begin{array}{c}19,81 \\
* * *\end{array}$ & $\begin{array}{c}28,45 \\
* * *\end{array}$ & $\begin{array}{c}28,45 \\
* * *\end{array}$ \\
\hline coeficiente de determinação & - & - & - & - & 0,80 & 0,69 & 0,65 & 0,67 \\
\hline $\begin{array}{l}\text { coeficiente de variação } \\
\text { quadrado médio do residuo }\end{array}$ & 307 & 300 & 243 & - & $\begin{array}{c}9,65 \% \\
15,36\end{array}$ & $\begin{array}{c}9,67 \% \\
32,48\end{array}$ & $\begin{array}{c}9,21 \\
48,76\end{array}$ & $\begin{array}{c}8,73 \% \\
64,02\end{array}$ \\
\hline
\end{tabular}

*,**, *** estatisticamente significativo ao nível de $\mathrm{P}<0,05 ; 0,01 \mathrm{e} 0,001$, respectivamente 